\title{
Programa de vapor de agua en columna del Centro de Investigación Atmosférica de Izaña: Análisis e intercomparación de diferentes técnicas de medida
}

Serie de notas técnicas digitales del

Centro de Investigación Atmosférica de Izaña (CIAl)

Nota técnica digital 1 del CIAI

\author{
Pedro Miguel Romero Campos (1) \\ Emilio Cuevas Agulló (1) \\ Ramón Ramos López ${ }^{(1)}$ \\ Marcelino Valdés Pérez de Vargas ${ }^{(2)}$ \\ Matthias Schneider (3)
}

(1) Centro de Investigación Atmosférica de Izaña (CIAI), AEMET

(2) Centro de Observaciones Geodésicas del Instituto Geográfico Nacional

(3) IMK-ASF, Forschungszentrum und Universität Karlsruhe 
(c) Ministerio de Medio Ambiente, y Medio Rural y Marino

Agencia Estatal de Meteorología

Madrid, 2009

Catálogo de Publicaciones de la Administración General del Estado:

https://cpage.mpr.gob.es/

NIPO: 784-09-009-9

https://doi.org/10.31978/784-09-009-9

Agencia Estatal de Meteorología (AEMET)

$\mathrm{C} /$ Leonardo Prieto Castro, 8

28040 Madrid

http://www.aemet.es/

@Aemet_Esp

f https://www.facebook.com/AgenciaEstataldeMeteorologia 


\section{Índice}

1. Introducción 1

1.1. Emplazamiento del Observatorio Atmosférico de Izaña .................... 1

1.2. El vapor de agua atmosférico como variable climática esencial .............. 1

1.3. Objetivos del Programa de Vapor de Agua en columna del CIAI .............. 3

2. Programa de vapor de agua en columna en Izaña 5

2.1. Instrumentación ....................................................... 5

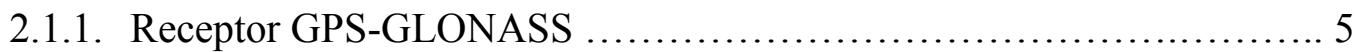

2.1.2. Radiómetro multicanal con banda de sombra rotante (MFRSR) ........6 6

2.1.3. Fotómetro solar CIMEL .......................................... 8

2.1.4. Sondeos aerológicos .......................................... 9

2.1.5. Espectrómetro de Infrarrojos por Transformada de Fourier (FTIR) .....10

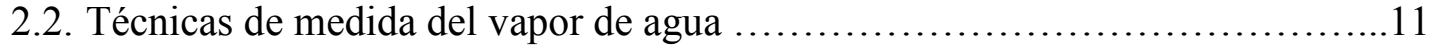

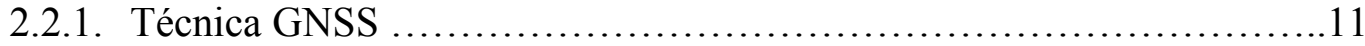

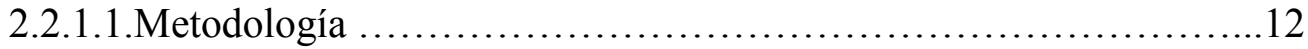

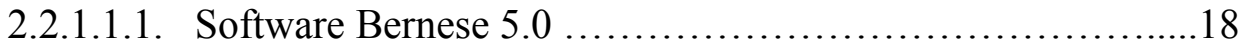

2.2.1.1.2. Algoritmos MATLAB ..................................20

2.2.1.1.3. Agua precipitable en tiempo real ..........................21

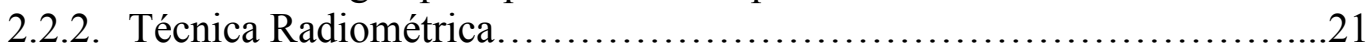

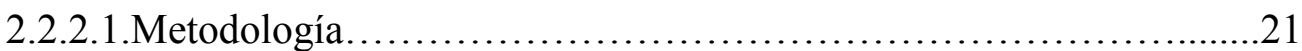

2.2.2.1.1. Caracterización del filtro del canal $941 \mathrm{~nm}$ del MFRSR .......22

2.2.2.1.2. Técnica Langley-Modificada...........................24

2.2.2.1.3. Calibración del vapor de agua...........................26

2.2.2.1.4. Filtros de nubes ....................................... 27

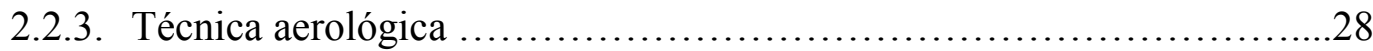

2.2.4. Técnica FTIR ..................................................... 31

3. Comparación entre las diferentes técnicas. Resultados 32

3.1. MFRSR frente a GNSS ................................................. 34

3.2. CIMEL frente a GNSS .................................................... 35

3.3. SONDEOS frente a GNSS .............................................. 36

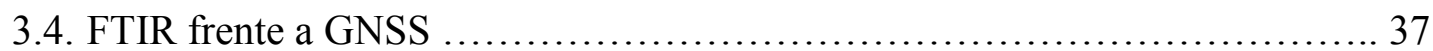

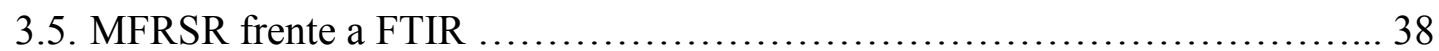

3.6. SONDEOS frente a FTIR .................................................... 39

3.7. CIMEL frente a FTIR .............................................. 40

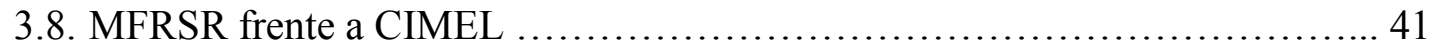

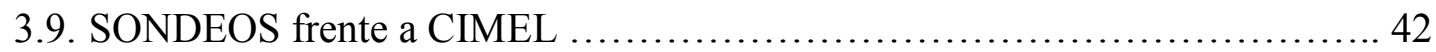

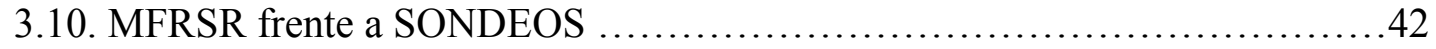

3.11. Resumen .........................................................43

4. Líneas futuras para reducir la incertidumbre en el agua precipitable GPS 45

5. Conclusiones 48

6. Agradecimientos $\quad 49$

7. Bibliografía $\quad 50$

8. Anexo 52 



\section{Introducción}

\subsection{Emplazamiento del Observatorio Atmosférico de Izaña}

El Observatorio Atmosférico de Izaña (OAI), situado a una latitud norte de $28^{\circ} 18^{\prime} 32.34^{\prime \prime}$ y a una longitud oeste de $16^{\circ} 29^{\prime} 57.78$ ', se encuentra emplazado sobre la montaña de Izaña, en la isla de Tenerife (España), a una altitud de 2373 metros sobre el nivel del mar. Forma parte del Centro de Investigación Atmosférica de Izaña (CIAI), perteneciente a la Agencia Estatal de Meteorología (AEMET), y está integrado dentro del programa de la red de Vigilancia Atmosférica Global (VAG) establecido por la Organización Meteorológica Mundial (OMM) en 1989.

El OAI se encuentra situado en la troposfera libre, por encima de una capa estable y casi permanente de inversión de temperatura debida a la subsidencia asociada con el anticiclón de las Azores, y debajo de la rama descendente de la célula de Hadley, justamente en la zona de transición entre la atmósfera de latitudes medias y la atmósfera tropical que están separadas por el chorro subtropical. Esta situación le permite estar libre de influencias antropogénicas locales y disfrutar de condiciones de cielos limpios y despejados durante la mayor parte del año. Estas circunstancias hacen del OAI un lugar idóneo para la investigación del fondo ("background”) atmosférico así como del transporte a gran escala de masas de aire desde los trópicos a latitudes más altas en la alta troposfera y baja estratosfera. Por otro lado, y dada su proximidad al continente africano, es también un lugar ideal para el estudio particular de los fenómenos de transporte de polvo desde África hacia el Atlántico Norte (Prospero et al, 1995; Alastuey et al., 2005; Alonso-Pérez, et al., 2007). El vapor de agua es un gas que se encuentra casi en su totalidad (99\%) confinado en la troposfera (por debajo de los 11-12 km., aproximadamente). Izaña, por su situación en la troposfera libre, es un lugar estratégico para el estudio de esta importante variable climática en la baja, media y alta troposfera.
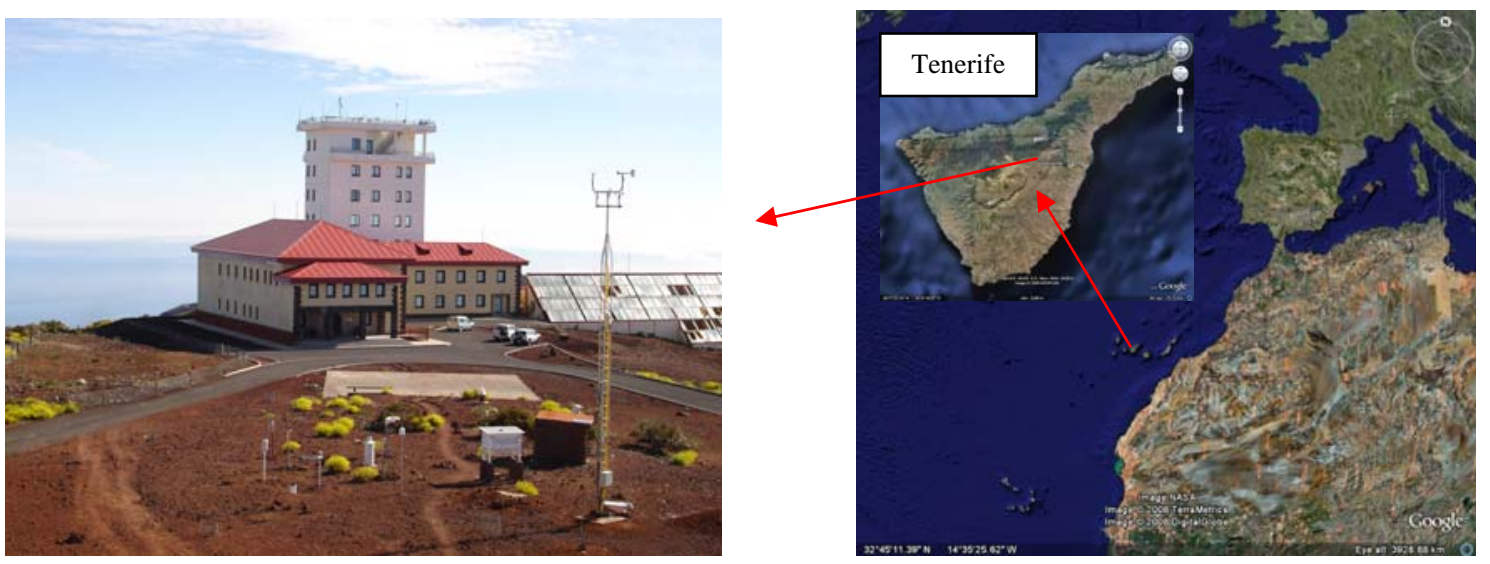

Figura 1.1.1. Vista general y situación geográfica del Observatorio Atmosférico de Izaña.

\subsection{El vapor de agua atmosférico como variable climática esencial}

El vapor de agua atmosférico es una de las 44 variables climáticas esenciales que, actualmente, han sido definidas como tales por el Sistema de Observación del Clima Mundial (GCOS). Estas son variables de observación sistemática cuyos valores actuales e históricos se intercambian internacionalmente con objeto de dar soporte al 
trabajo realizado por el Panel Intergubernamental para el Cambio Climático (IPCC) y por la Convención de Naciones Unidas para el Cambio Climático (UNFCCC).

El conocimiento de la cantidad de vapor de agua contenida en el aire atmosférico, es de vital importancia por el papel que esta variable desempeña en el clima, actuando como vehículo energético que almacena energía en forma de calor latente, para luego liberarla en los procesos de condensación. Su estudio es fundamental, no sólo para la predicción meteorológica a corto o muy corto plazo, sino también, al ser el principal gas de efecto invernadero, para la comprensión de los fenómenos involucrados en el proceso del cambio climático.

La mayor parte del agua en la atmósfera se encuentra en forma de vapor de agua. Éste juega un papel crítico en procesos clave en los ciclos hidrológico y energético. Como se ha dicho, el vapor de agua es el gas de efecto invernadero más importante porque es un elemento esencial del clima actual y porque introduce procesos de retroalimentación positivos y negativos en el calentamiento global. La abundancia y la distribución vertical de vapor de agua en la atmósfera, interactúa fuertemente con los procesos convectivos y la nubosidad, influyendo de forma decisiva sobre el albedo del planeta así como sobre la "opacidad infrarroja” de la atmósfera. Reducir las incertidumbres en las predicciones del clima futuro es uno de los retos de la ciencia hoy día. Las proyecciones de calentamiento de hasta $5{ }^{\circ} \mathrm{C}$ en los próximos 100 años, se basan de una manera importante en la retroalimentación positiva del vapor de agua en la atmósfera (Cubasch et al., 2001). En la mayor parte de los modelos climáticos, un calentamiento inicial causado por una cantidad adicional de $\mathrm{CO} 2 \mathrm{y}$ otros gases de efecto invernadero (GEI), conlleva un aumento de la evaporación en la superficie y un aumento de la humedad en la atmósfera. Dado que el vapor de agua es un potentísimo absorbente en el rango infrarrojo, el aumento de humedad causa un aumento añadido de temperatura en la atmósfera. El efecto de amplificación puede ser muy importante, incrementando el calentamiento global promedio en un 70\%-90\% comparado con cálculos que mantienen fijo el vapor de agua (Cess et al., 1990). Sin embargo, para realizar estos cálculos, no es suficiente conocer la distribución y evolución del vapor de agua en la superficie de la Tierra, sino en toda la columna atmosférica. Es por ello que el vapor de agua en columna y su distribución vertical son variables esenciales para la realización de estudios de cambio climático. El agua precipitable $u$ en un perfil atmosférico, o contenido de vapor de agua en una columna vertical de base unitaria extendida desde la altura $z$ hasta una altura dada $h$, es calculada como:

$$
u=\int_{z}^{h} \rho\left(z^{\prime}\right) \times d z^{\prime}
$$

donde $\rho\left(z^{\prime}\right)$ es la densidad del vapor de agua a una altura $z^{\prime}$. El vapor de agua integrado en la columna atmosférica, o agua precipitable, se expresa como altura (mm.) o masa $\left(1 \mathrm{~mm} . \sim 0.1 \mathrm{gcm}^{-2}\right)$ que se obtendría si todo el vapor de agua contenido en una columna específica de la atmósfera, de sección transversal horizontal unitaria, se condensase y precipitase. En esta Nota Técnica utilizaremos indistintamente los términos "vapor de agua en columna" y "agua precipitable". En todo caso, cualquier referencia a "vapor de agua” siempre se entenderá integrado en la columna atmosférica.

En el contexto actual de calentamiento atmosférico se han realizado algunos intentos de estimar las tendencias a nivel global y regional de agua precipitable. Para ello, se han utilizado medidas desde satélites específicos y reanálisis de modelos (ERA40 y NCEP). La mayor parte de los estudios indican un aumento del agua precipitable sobre los océanos a nivel global que oscila entre $+0.40 \pm 0.09 \mathrm{~mm}$./década (Trenberth et 
al.; 2005) a $+0.90 \pm 0.06 \mathrm{~mm}$./década (Brown et al., 2007). Son tendencias muy pequeñas y cuestionadas por la corta extensión de las series y por el tipo de datos utilizados: satélites y reanálisis, en muchas ocasiones afectados por "artefacts". En algunas regiones se detectan tendencias ligeramente negativas. Concretamente, en la región subtropical donde se encuentra el Observatorio de Izaña, la expansión de la circulación asociada a la célula de Hadley implica una expansión de la banda de subsidencia subtropical hacia el norte, y por tanto, un calentamiento de latitudes medias y desplazamiento hacia el polo de la zona seca subtropical (Hu and Fu, 2007). La pequeña magnitud de las tendencias observadas, y las grandes incertidumbres sobre la evolución de procesos atmosféricos a gran escala que modulan la concentración de vapor de agua en la atmósfera, exigen la creación de un sistema de observación del vapor de agua en columna de muy alta calidad que pueda ser utilizado en estudios científicos.

Hasta hace algunos años, la única técnica sistemática de medida de vapor de agua en columna de que se dispone, es el tradicional sondeo PTU aerológico. Sin embargo, esta técnica tiene algunas limitaciones muy importantes: en primer lugar, su poca resolución temporal, ya que, normalmente, se realizan sólo dos al día (a las 00:00h y 12:00h TMG). En segundo lugar, el tiempo que dura un sondeo (más de una hora y media), y el hecho de que durante este tiempo la sonda se haya desplazado una distancia significativa de la vertical del lanzamiento, introducen incertidumbres importantes en el vapor de agua integrado en columna dada la enorme variabilidad espacio-temporal de este componente. Y por último, y hasta la aparición de la nueva sonda RS-92 en 2004, sus antecesoras no eran muy precisas en la medida de vapor de agua, descartándose, por poco fiable, las medidas tomadas por encima de $7 \mathrm{~km}$. Este hecho hace que las series de perfiles verticales de humedad de mínima calidad disponibles con esta técnica sean realmente muy cortas. Desde el punto de vista de investigación atmosférica, es necesario disponer de medidas de vapor de agua en columna de muy alta calidad. En estos momentos, y desde hace muy pocos años, disponemos de técnicas radiométricas, Sistema Global de Navegación por Satélite (GNSS) y radiosondeos de gran fiabilidad para la medida de vapor de agua en columna. La descripción, análisis y comparación de estas técnicas es el objeto de esta Nota Técnica.

\subsection{Objetivos del Programa de Vapor de Agua del CIAI}

La instrumentación avanzada y de alta precisión que se utiliza en el Observatorio Atmosférico de Izaña para la medida de vapor de agua en columna, como el Espectrómetro Infrarrojo por Transformada de Fourier (FTIR), el fotómetro solar CIMEL, el radiómetro con banda de sombra rotante (MFRSR), y la radiosonda RS-92, se ha visto complementada desde julio de 2008, con la instalación de un receptor GPSGLONASS gestionado conjuntamente con el Instituto Geográfico Nacional (IGN). La técnica GNSS para la obtención de agua precipitable y la validación de estas medidas con las obtenidas con las otras técnicas suponen uno de los mejores programas actuales a nivel internacional para el análisis de la evolución del vapor de agua en la columna atmosférica.

Los objetivos del Programa de vapor de agua en columna son los siguientes:

1. Vigilar e investigar la evolución a largo plazo del vapor de agua y su caracterización para diferentes situaciones meteorológicas, tanto a nivel sinóptico como local.

2. Validar los productos satelitales de vapor de agua suministrados por diferentes plataformas. 
3. Probar y validar nuevos instrumentos y metodologías para obtención de vapor de agua en columna que puedan ser utilizados tanto en programas operacionales meteorológicos como en sistemas de investigación atmosférica.

4. Contribuir al programa EGVAP de medida de vapor de agua con GNSS de la Red de Servicios Meteorológicos Europeos (EUMETNET).

5. Proponer al Observatorio Atmosférico de Izaña (OAI) como lugar de referencia mundial para la comparación y medida del vapor de agua en columna utilizando diferentes técnicas, e integrarlo en breve plazo en la red GRUAN (The GCOS Reference Upper-Air Network). El Observatorio Atmosférico de Izaña figura ya como candidato en esta red GCOS que es el Sistema de Observación del Clima Mundial (Global Climate Observing System).

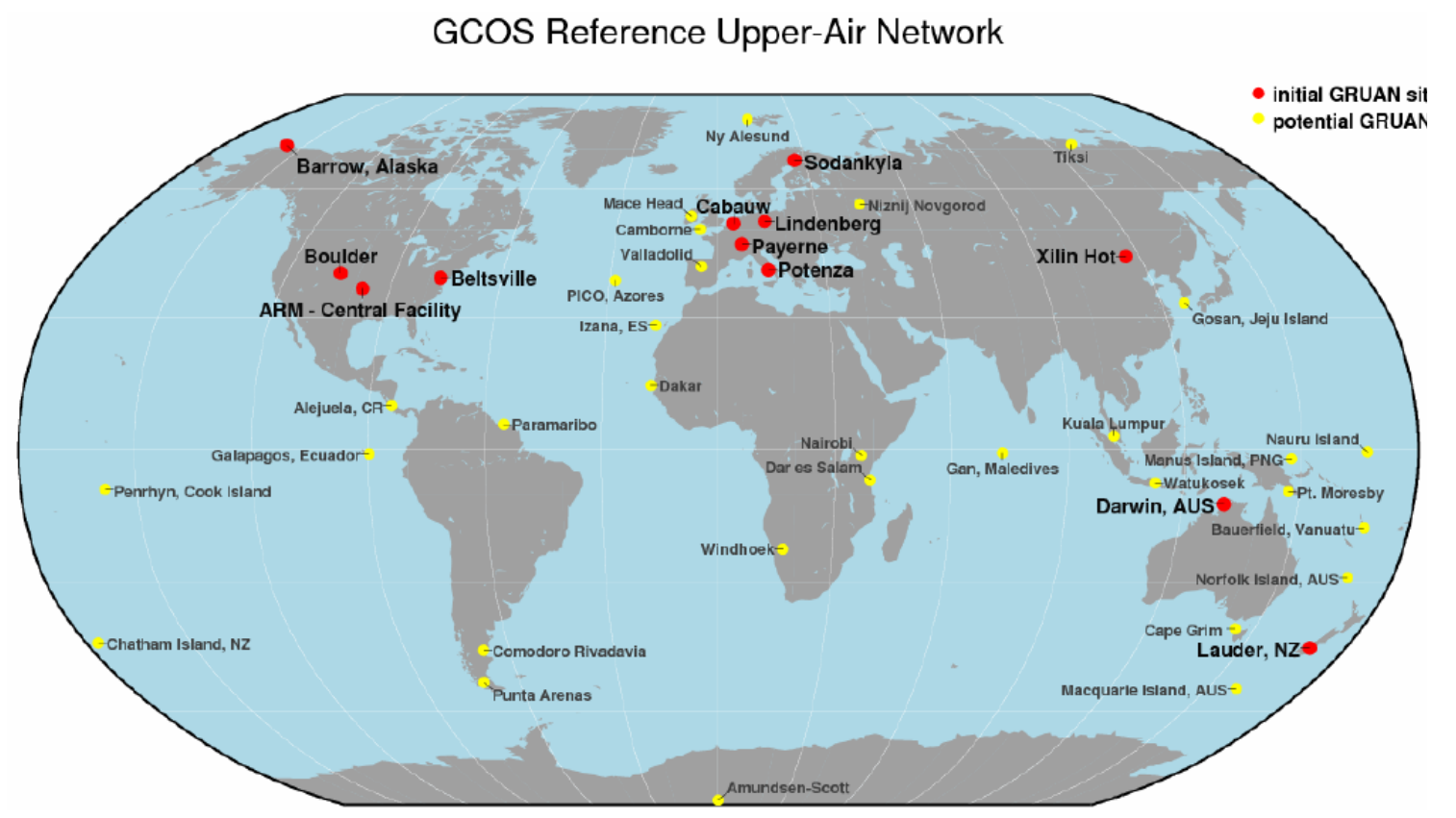

Report of the GRUAN Implementation Plan (GCOS 121- WMO/TD No. 1435)

Figura 1.3.1. Red de Referencia Atmosférica del GCOS (GRUAN).

Esperamos que esta Nota Técnica resulte interesante y útil para todos aquellos que se introduzcan o trabajen ya con técnicas de medidas de vapor de agua en columna. 


\section{Programa de vapor de agua en columna en Izaña}

\subsection{Instrumentación}

\subsubsection{Receptor GPS-GLONASS}

Los Sistemas Globales de Navegación por Satélite (GNSS) consisten en constelaciones de satélites orbitando alrededor de la Tierra que emiten señales electromagnéticas que pueden ser recibidas por antenas receptoras. A partir de estas señales recibidas, y mediante los apropiados algoritmos de cálculo, podemos deducir la posición de la antena en un Sistema de Referencia Terrestre con una alta precisión.

Actualmente, la Unión Europea, está desarrollando su propio GNSS, denominado sistema Galileo, pero aún no es operativo. Hasta la fecha, los sistemas globales, plenamente establecidos y operativos, para la navegación por satélite, son dos: el sistema GPS (Sistema de Posicionamiento Global) gestionado por el Departamento de Defensa de los Estados Unidos y el sistema GLONASS, contrapartida al anterior, y gestionado por el Ministerio de Defensa de Rusia.

La investigación y tratamiento de estos sistemas de navegación por satélite, ha llevado en la actualidad a que sean usados para otros fines científicos que los relacionados únicamente con la Geodesia, la Topografía, la información geográfica o la Cartografía. Hoy en día, destaca la aplicación GNSS al estudio de la atmósfera terrestre $\mathrm{y}$ de los distintos fenómenos que ocurren en ella y de sus capas, especialmente el estudio de la ionosfera, desconocida en muchos de sus aspectos. Una de las aplicaciones que está tomando vigor es la obtención de agua precipitable en la columna atmosférica que existe encima de la antena del receptor, en la que nos centraremos en esta Nota Técnica.

El 16 de mayo de 2008 finalizó la instalación en el Observatorio Atmosférico de Izaña de un equipo GPS-GLONASS de la casa Leica con receptor modelo GRX1200GGPro y antena LEIAT504GG cuyo radomo o protector de antena es de tipo LEIS con $0.4 \mathrm{~m}$ de diámetro. Este equipo pertenece al Sistema de Vigilancia Volcánica del Instituto Geográfico Nacional (IGN) y es explotado conjuntamente por el IGN y el CIAI. Con el fin de minimizar posibles vibraciones y desplazamientos del terreno, la instalación ha requerido la construcción de una base de hormigón de 4.5 toneladas con un pilar enterrado de $2.4 \mathrm{~m}$ de profundidad y $1.4 \mathrm{~m}$ de diámetro. La altura del pilar sobre la superficie es de $1.20 \mathrm{~m}$.
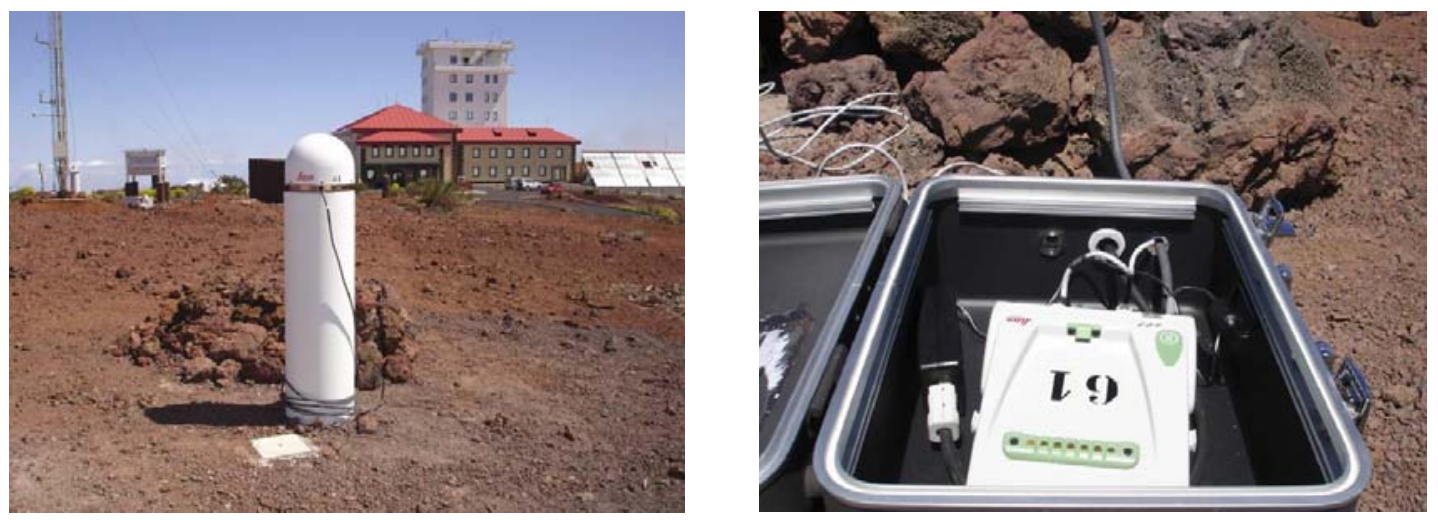

Figura 2.1.1.1. A la izquierda, parte superficial del pilar (cilindro blanco vertical) y antena (parte superior); a la derecha, el receptor GPS-GLONASS en el OAI. 
En la instalación, se ha buscado la máxima recepción posible de satélites a partir de la ubicación y altura más apropiadas y de un control previo de posibles interferencias. Con este objetivo, la antena instalada es de las llamadas de tipo geodésico, las cuales optimizan la recepción.

El equipo instalado en Izaña tiene capacidad para recibir las señales que emiten los satélites GPS y GLONASS, los cuales, constan de osciladores de precisión que generan una determinada frecuencia fundamental, a partir de la cual, se obtienen dos portadoras en la banda L de radiofrecuencia, denominadas L1 y L2. En el caso del GPS, las frecuencias de la L1 y L2 son iguales para toda la constelación y, además, en breve, se emitirá una tercera portadora que se llamará L5. En el caso de GLONASS, las frecuencias L1 y L2 dependen de cada satélite, y en breve también, emitirán una nueva portadora L3. El receptor usa, pues, dos frecuencias distintas, lo cual permite, discriminar la influencia de la ionosfera en el retraso de la señal. El equipo trabaja de manera continua grabando datos con un muestreo de un segundo. La puesta en operación y gestión de datos de nuestra estación permanente GNSS no se completó hasta julio de 2008. El 18 de enero de 2009 se incluyó de manera oficial en la EPN (http://www.epncb.oma.be) que es la Red Permanente de la Sub-Comisión de la Asamblea Internacional de Geodesia (IAG) para Europa (EUREF) que se dedica a la definición, realización y mantenimiento de la infraestructura geodésica europea en proyectos que requieren una precisa referenciación terrestre (http://www.euref-iag.net).

El receptor GRX1200GGPro tiene varios puertos de conexión. Posee un puerto Ethernet con conexión LAN/WAN. Además, dispone de un puerto de entrada de frecuencia externa, un puerto de salida de un pulso/seg. y un puerto IP con restricción específica de acceso para Internet. Posee FTP y correo, y puede ser totalmente configurado desde una interface web. Es un equipo especialmente diseñado para ser usado como referencia de manera remota y desatendida, proporcionando, de forma continua, datos de alta calidad. Los datos observados se recopilan en ficheros horarios y son inmediatamente publicados para su procesamiento.

\subsubsection{Radiómetro multicanal con banda de sombra rotante (MFRSR)}

Este radiómetro, fabricado por YES (Yankee Environmental Systems), mide simultáneamente, con un único detector de silicio y para el rango visible e infrarrojo cercano, la radiación solar directa, normal a la dirección de incidencia y la radiación solar difusa y global horizontales (ángulo sólido $2 \pi$ ). Dispone de siete filtros para sus 7 canales de medida, 6 de banda estrecha con longitudes de onda centradas en 413-495613-671-868-941nm y con anchos de banda (FWMH) comprendidos entre 10 y $12 \mathrm{~nm}$, según el canal, más un canal de banda ancha ("broadband") con un ancho de banda similar al de los piranómetros convencionales (0.3-3.0) micras.

El radiómetro dispone de una banda semicircular que proyecta sombra sobre un difusor situado encima del cuerpo cilíndrico principal, bajo el cual, se encuentra el detector. Cuando la banda se sitúa por debajo del cuerpo cilíndrico (posición NADIR o posición HOME), el equipo realiza una medida de la radiación, que será por tanto radiación global; seguidamente, mueve la banda de forma automática a tres posiciones consecutivas, dos laterales, $9^{\circ}$ a la izquierda y derecha del difusor, respectivamente, $\mathrm{y}$ una central cubriendo completamente al mismo.

En cada una de estas posiciones realiza una medida. La que corresponde a la posición central sobre el difusor representa una primera aproximación a la radiación difusa, ya que la única luz que le llega al detector será la que procede del cielo en un ángulo de $2 \pi$, exceptuando la proveniente directamente del haz solar, ya que este es 
bloqueado por la posición de la banda. Esta medida de radiación difusa debe corregirse debido al exceso de cielo cubierto por la anchura de la banda sobre el difusor. Para corregirla, se usan las dos medidas laterales que se tomaron a cada lado de éste. Finalmente, la radiación directa horizontal se obtiene como diferencia de la global horizontal y la difusa horizontal corregida. La radiación directa normal a la dirección de incidencia se obtiene dividiendo la anterior por el coseno del ángulo cenital o ángulo que forma la posición del sol con la vertical medido desde el cénit.

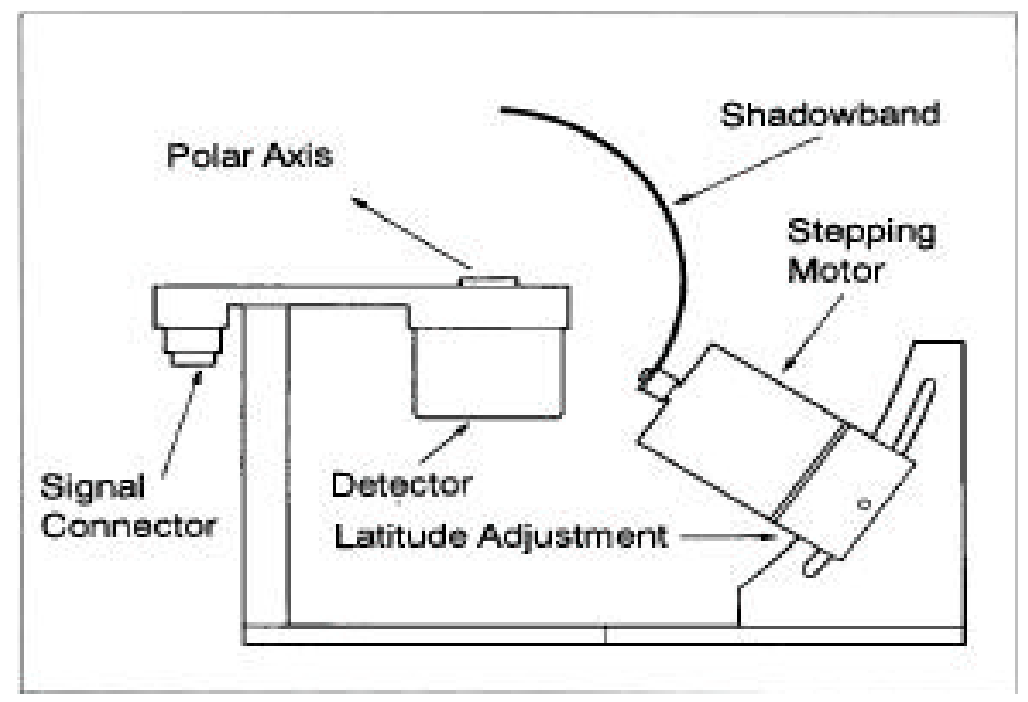

Figura 2.1.2.1. Componentes principales del radiómetro MFRSR

Todo este proceso de medidas, cálculo y correcciones se realiza de forma automática por el software del equipo. Entre los canales de banda estrecha hay uno que está centrado en los $941 \mathrm{~nm}$. Esta es una banda característica de absorción del vapor de agua, y por esta razón, es precisamente este canal el que usaremos para obtener nuestras estimaciones de dicha variable. La razón de muestreo es de cuatro medidas al minuto (una cada $15 \mathrm{~s}$ ) y se realiza un promedio minutal de las mismas.

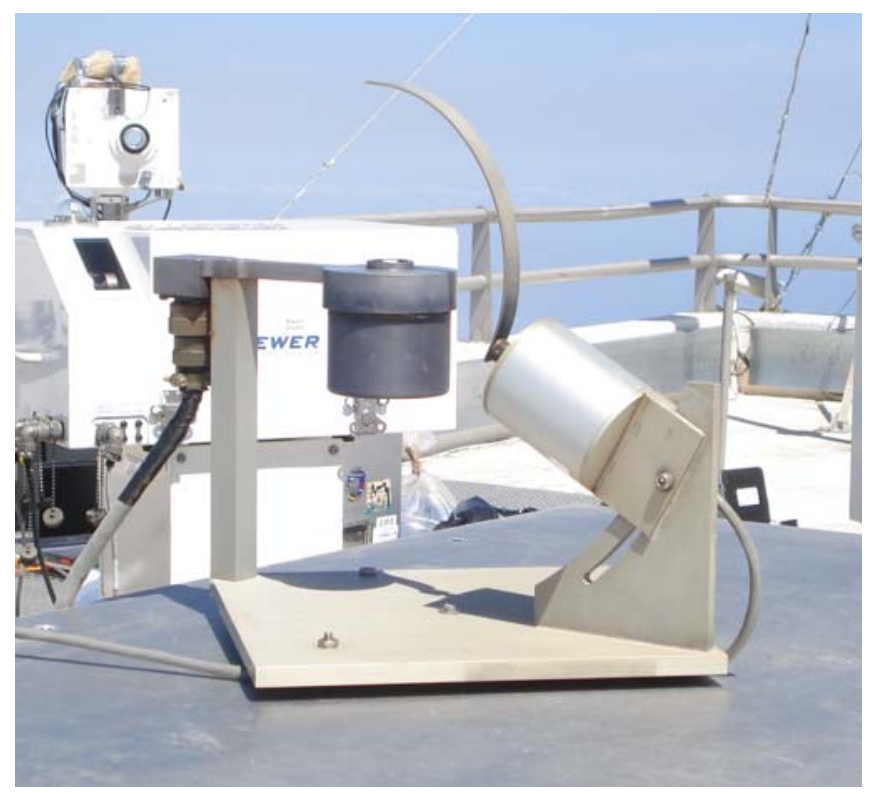

Figura 2.1.2.2. Multifilter Rotating Shadowband Radiometer (MFRSR) en el OAI 


\subsubsection{Fotómetro solar CIMEL}

Este fotómetro, integrado en la red AERONET (Red de Robots de Aerosoles: http://aeronet.gsfc.nasa.gov), es un radiómetro espectral de 8 canales con longitudes de onda centradas en 1020-870-675-440-936-500-340-380nm. El fotómetro trabaja con dos detectores de silicio pero han sido mejorados en una versión posterior sustituyendo el segundo detector de silicio por uno de Indio-Galio-Arsenio y mejorando la óptica del cabezal del sensor. Dispone de un canal centrado en los $936 \mathrm{~nm}$ donde el vapor de agua absorbe de manera significativa y es el que se usa para la obtención de agua precipitable. El equipo apunta de manera automática al sol usando un software preprogramado y se alimenta mediante un panel solar. Los datos los manda vía satélite para que sean recopilados y procesados en AERONET (AErosol RObotic NETwork de la NASA; http://aeronet.gsfc.nasa.gov).

El radiómetro efectúa dos medidas básicas: una directa al sol (SUN) y la otra hacia el cielo (Sky). Las medidas directas al sol se realizan con un campo de visión de 1.2 grados en los 8 canales espectrales y se tarda aproximadamente unos 10 segundos en total. Los 8 filtros interferenciales están colocados en una rueda de filtros activada y movida por un motor de pasos. Las medidas se toman desde una masa óptica relativa de 7 por la mañana hasta una masa óptica relativa de 7 por la tarde. El espesor óptico del aerosol se determina de la extinción espectral en el haz de radiación directa a cada longitud de onda usando la ley de Bouguer-Lambert-Beer y eliminando la dispersión Rayleigh, la absorción del ozono y la de otros gases contaminantes. Se aplica también una técnica de filtrado de nubes consistente en el análisis de tripletes de datos tomados 30 segundos aparte a las medidas simultáneas para cada longitud de onda. Este análisis se basa en que las variaciones en el tiempo de las nubes son mayores que las causadas por la presencia de aerosoles. Para más detalles del algoritmo, consultar: http://aeronet.gsfc.nasa.gov/new_web/Documents/Cloud_scr.pdf

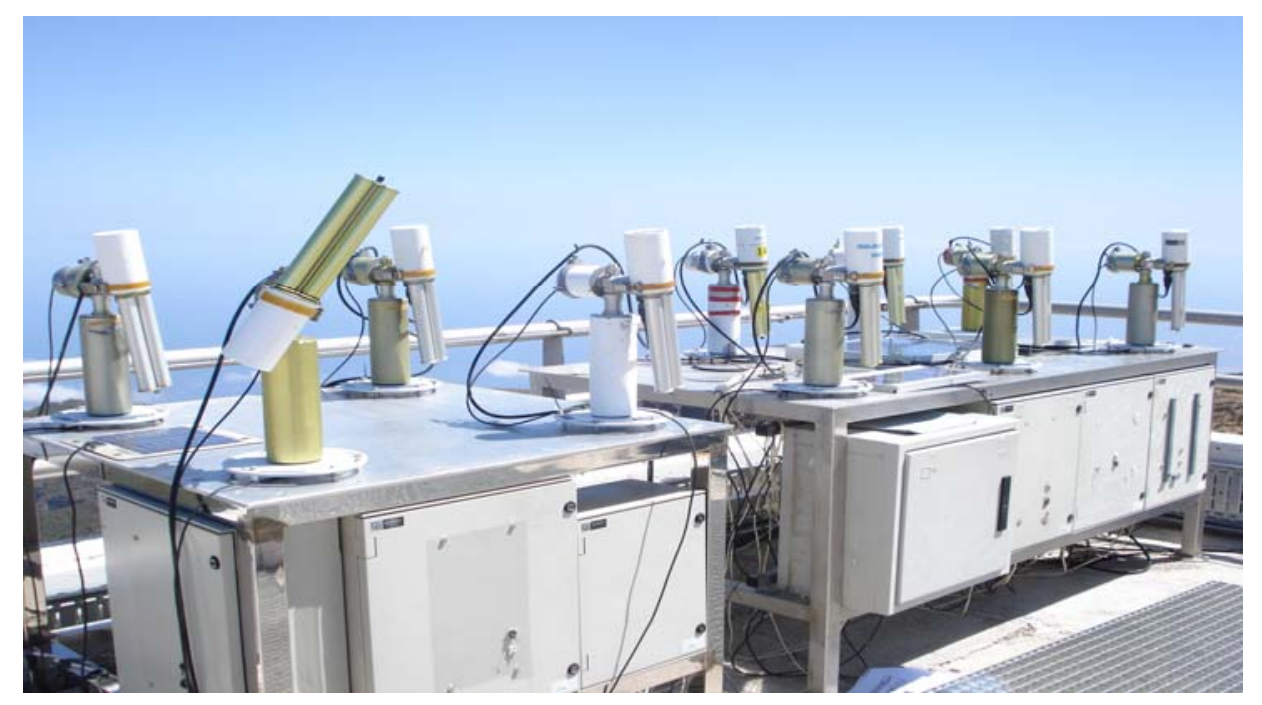

Figura 2.1.3.1. Fotómetros CIMEL masters de las redes PHOTONS/RIMA/AERONET en el $O A I$

El segundo tipo de medidas son las radiancias de cielo en cuatro bandas espectrales (440-670-870-1020nm), hechas hasta 9 veces al día en el plano principal solar (acimut fijo, ángulo de dispersión variable) y hasta 6 veces al día en el plano del almucántar solar (acimut variable, ángulo de elevación solar fijo). A partir de estas 
medidas, y mediante técnicas de inversión, se calculan distribuciones por tamaños de aerosoles, funciones de fase, así como espesores ópticos de aerosoles y agua precipitable en columna.

En el Observatorio Atmosférico de Izaña las medidas de los CIMEL son especialmente buenas ya que provienen, no de un único instrumento, sino de una serie de instrumentos masters de las redes PHOTONS y RIMA de AERONET que van siendo calibrados en Izaña. Se trata, pues, de instrumentos especialmente estables elegidos para ser mantenidos como patrones.

\subsubsection{Sondeos aerológicos}

El programa de sondeos diarios consiste en el lanzamiento de una sonda PTU dos veces al día: a las 00:00h GMT y a las 12:00h GMT. Hasta el año 2005 la sonda usada fue la sonda Vaisala RS-80 y el lanzamiento se hacía de forma manual desde Santa Cruz de Tenerife (28.46N, 16.26W, 36 m.s.n.m.). A partir de junio de 2005, la sonda se substituye por la RS-92 y el sondeo se realiza automáticamente desde Güímar (28.32N, 16.38W, 105 m.s.n.m., Estación OMM n ${ }^{\circ}$ 60018). El paso de la sonda RS80 a la RS92 ha implicado, por un lado, una mejora en los sensores $\mathbf{P}$ (sensor de silicio BAROCAP con resolución $0.1 \mathrm{hPa}$ y error de $1.5 \mathrm{hPa}$ ), $\mathbf{T}$ (sensor F-THERMOCAP con resolución de $0.1^{\circ} \mathrm{C}$ y error de $0.5^{\circ} \mathrm{C}$ ) y $\mathbf{U}$ (sensores H-HUMICAP con resolución de $1 \%$ de HR y error de $5 \%$ de HR) y en su calibración, y por otro, una mejora de hasta un 3\% en la medida de la humedad relativa. Esta se infravaloraba con la RS-80 debido al problema de la contaminación de hielo y agua condensada en la superficie del sensor de humedad, hecho que ya no se produce con la RS-92. Esta dispone de dos sensores de humedad H-HUMICAP que son precalentados antes del lanzamiento del sondeo a fin de eliminar cualquier contaminación previa. Durante el sondeo, uno de los sensores limpios comienza a medir mientras el otro sigue calentándose; el que mide se va contaminando y enfriando durante la medida. Entonces deja de medir y entra en juego el otro, mientras que el primero pasa ahora a la fase de calentamiento, y así sucesivamente, de forma que siempre hay un sensor limpio que mide correctamente.

El sistema de sondeo actual es el MW31 de Vaisala Digicora III que dispone de antena y tecnología GPS para proporcionar datos de viento con alta resolución. En la figura 2.1.4.1 se muestra una sonda RS-92, y en la figura 2.1.4.2, se representa un esquema de los componentes involucrados en el radiosondeo. En general, un sondeo dura unas 2 horas y se suelen alcanzar los $30 \mathrm{~km}$. Para más información, consultar en:

http://www.hobeco.net/pdf/vaisalars92brochure.pdf

http://www.upperair.cn/uploadfile/20064323290416.pdf

$>$ http://www.wmo.int/pages/prog/www/IMOP/meetings/Upper-Air/SystemsIntercomp/Doc5(1)Vaisala.pdf

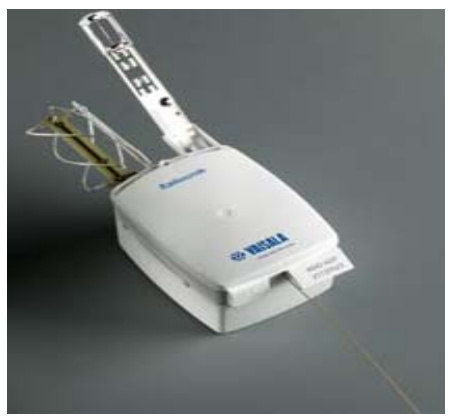

Figura 2.1.4.1. Radiosonda Vaisala RS-92 


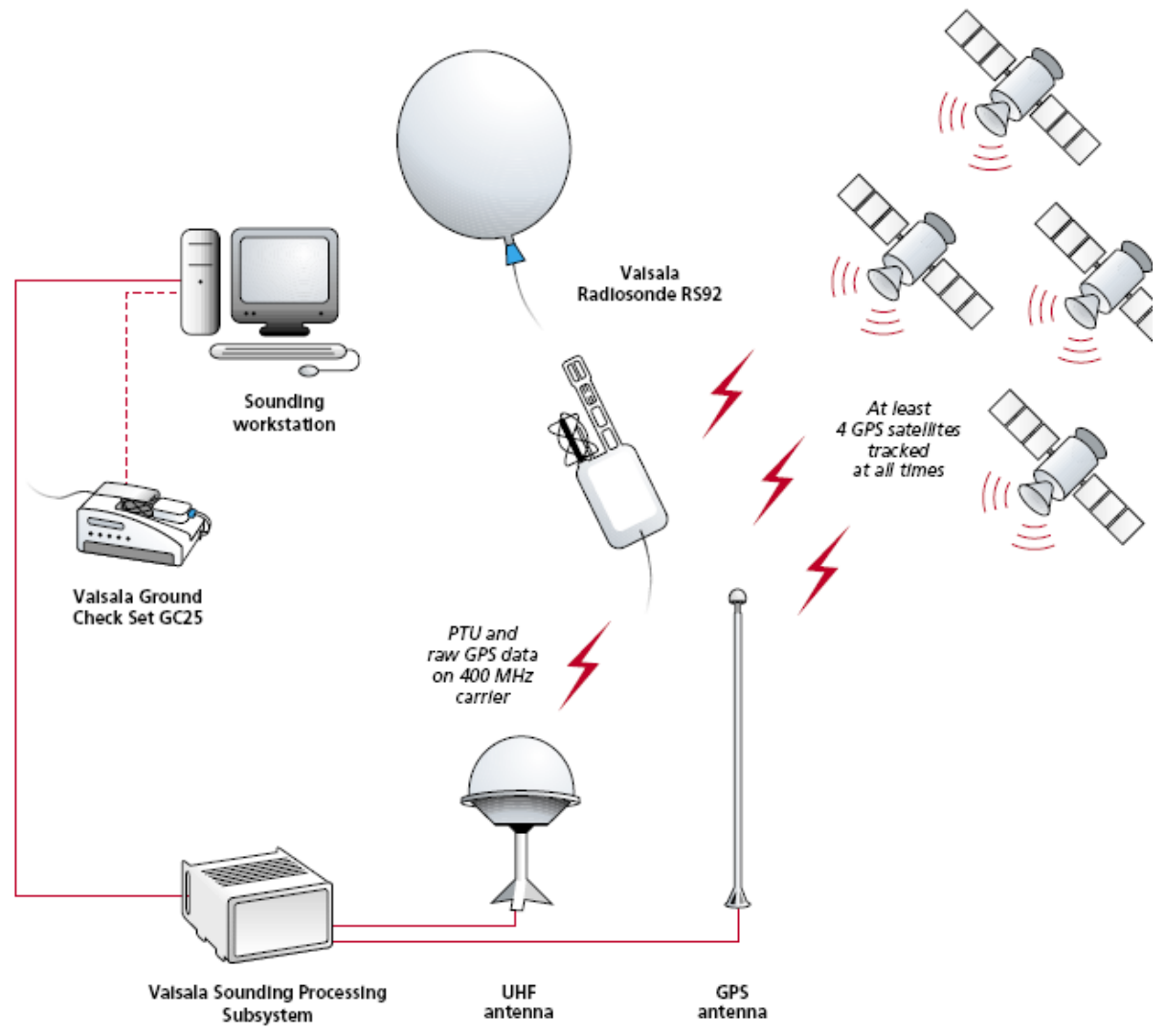

Figura 2.1.4.2. Sistema Digicora III

\subsubsection{Espectrómetro de Infrarrojos por Transformada de Fourier (FTIR)}

Las actividades con la técnica FTIR comienzan en el Observatorio Atmosférico de Izaña en 1999 con la participación activa del IMK (Karlsruhe, Forschungszentrum) de Alemania. Actualmente se encuentra instalado en el OAI un FTIR IFS 125/HR. Es un instrumento de última generación en espectroscopia de alta resolución integrado en el programa NDACC (Network for Detection of Atmospheric Composition Change) y en el TCCON (Total Carbon Column Observing Network).

La técnica FTIR, básicamente, emplea un sistema de entrada de luz montado sobre un seguidor solar, muy preciso, que recoge el haz de radiación solar directa y lo envía al interferómetro. Esta técnica constituye una herramienta muy potente para la investigación atmosférica: con ella se miden, de forma rutinaria, concentraciones en columna y perfiles verticales de gases traza como el $\mathrm{O}_{3}, \mathrm{H}_{2} \mathrm{O}$ y $\mathrm{CH}_{4}$, entre otros. $\mathrm{Su}$ principio de funcionamiento es el del interferómetro de Michelson. Para más detalles sobre dicha técnica, consultar en Davis et al, 2001.

En la figura 2.1.5.1, podemos ver una imagen del equipo en el OAI. La parte izquierda, es el seguidor situado en el techo del laboratorio, y la de la derecha, es propiamente, el espectrómetro FTIR. El espectrómetro FTIR de Izaña posee 3 detectores y es capaz de reconocer líneas espectrales con un poder de resolución espectral $\frac{\lambda}{\Delta \lambda} \cong 10^{6}$. El rango espectral que cubre es bastante amplio, abarcando desde $1.1 \mu$, hasta $14.3 \mu$. 
Teóricamente, es el equipo con más precisión para la medida de constituyentes atmosféricos que absorben en el infrarrojo y es el que usaremos, como referencia, para validar las medidas del agua precipitable de los restantes equipos.

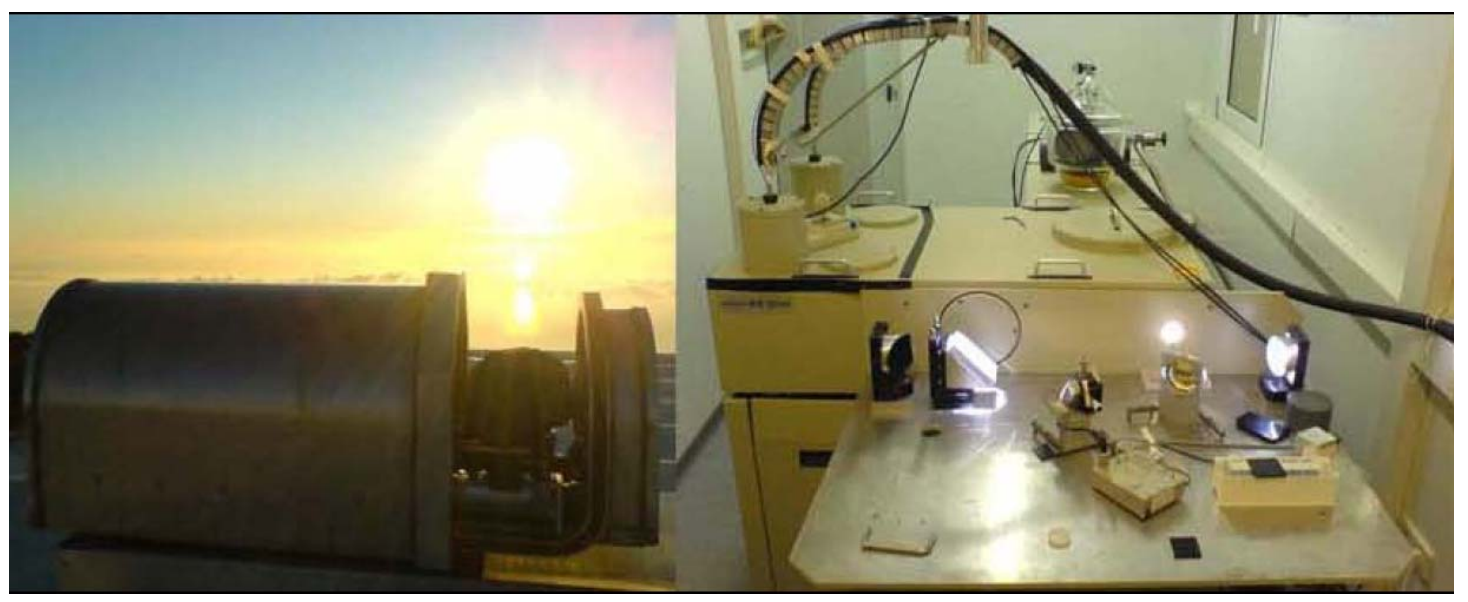

Figura 2.1.5.1. FTIR en el OAI. A la izquierda el seguidor; a la derecha el IFS.

\subsection{Técnicas de medida del vapor de agua}

\subsubsection{Técnica GNSS}

Todas las señales que se propagan desde los satélites (GPS o GLONASS) hasta las antenas de los receptores sufren un retraso a su paso a través de la atmósfera debido a la refracción atmosférica. Esta hace que se desvíe la onda desde su camino inicial y recorra una distancia mayor que la que hubiera recorrido de no existir la atmósfera. Debido a esto, la llegada de la señal al receptor se produce con un cierto retraso que puede ponerse en función del exceso de distancia recorrida como consecuencia de la refracción. Por esta razón, dicho retraso de señal suele venir expresado en unidades de distancia (mm.). Ahora bien, la refracción de la onda electromagnética emitida por el satélite, y por tanto, el retraso en la señal de llegada a la antena del receptor en tierra, depende, entre otras cosas, de la capa atmosférica que atraviesa, y también, de que haya o no vapor de agua en ella. Así, en la ionosfera, que se extiende entre los $70 \mathrm{~km}$. y los $1000 \mathrm{~km}$., aproximadamente, no hay vapor de agua y la propagación de la señal está principalmente afectada por partículas libres cargadas siendo un medio dispersivo para señales GNSS. Esto significa que la propagación va a depender de la frecuencia. Sin embargo, el efecto ionosférico o dispersivo en el retraso de la señal puede ser eliminado usando una combinación lineal de datos a dos frecuencias distintas. Una vez que este efecto dispersivo de la ionosfera ha sido eliminado, el retraso restante que queda en la señal se debe exclusivamente a la porción de atmósfera que es eléctricamente neutra y que por eso se le conoce como atmósfera neutral. La atmósfera neutral abarca la troposfera y una parte de la estratosfera que, en conjunto, suman unos $20 \mathrm{~km}$ de espesor. Como la mayor parte de la atmósfera neutral es troposfera muchas veces se le nombra únicamente como troposfera. Al ser eléctricamente neutra es un medio no dispersivo para ondas de radio hasta unos $15 \mathrm{GHz}$ y por tanto para las frecuentas típicas GPSGLONASS.

A su vez, el retraso troposférico tiene dos componentes: la denominada componente "seca" o retraso hidrostático, que se debe a la mezcla de gases que componen el aire atmosférico seco, es decir, exceptuando el vapor de agua, y la 
componente "húmeda" que depende del contenido en vapor de agua de la atmósfera. El primero es el responsable aproximadamente del $90 \%$ del retraso neutral de la señal, mientras que el segundo es el responsable del 10\% restante. Sin embargo, aunque la componente seca tenga un efecto mayor en el retraso que la húmeda, los errores en los modelos, en el caso de esta segunda, son mayores que los de la seca, ya que, la distribución del vapor de agua en la atmósfera presenta una gran variación espacial y temporal.

La corrección debida a la componente seca no es del todo seca en el sentido de que depende de la presión total de la atmósfera. Esta incluye tanto la presión parcial de los gases secos como la presión parcial del vapor de agua. Sin embargo, si asumimos que hay equilibrio estático y que el aire atmosférico se comporta como un gas ideal, el retraso hidrostático resulta ser una función lineal de la presión barométrica superficial total que puede ser modelada con un nivel de precisión de $1 \mathrm{~mm}$. Para más información, se puede consultar:

http://www.csr.utexas.edu/texas_pwv/midterm/gabor/gabor.html y

http://www.danotario.com/manuales/gpsglonass.pdf

\subsubsection{1. $\quad$ Metodología}

A partir de los ficheros horarios de observación de las estaciones GNSS involucradas en el cálculo, y de los resultados de hasta 12 horas anteriores, se evalúa el ZTD (Zenith Total Delay) en cada punto de una red de, aproximadamente, 200 estaciones repartidas por el Suroeste de Europa y Noroeste de África. Los cálculos se realizan en tiempo casi-real, no tardando más de una hora después de la última observación. Para ello, se usa un software científico de cálculo de precisión de señales GNSS, denominado Bernese. El algoritmo básico para el cálculo es el llamado de Dobles-Diferencias. Se utilizan productos ultra-rápidos del Servicio Internacional GNSS (IGS) de partida. El cálculo de las señales GNSS suministra cada 15 minutos una medida del retraso cenital total ZTD de la señal expresado en $\mathrm{mm}$. De esta medida puede extraerse qué parte del retraso es debida a la presencia de vapor de agua en la atmósfera y deducir de ahí su cantidad. Para ello procedemos de la siguiente forma. Sabemos que el retraso cenital total es la suma del retraso hidrostático cenital ZHD, que es la componente seca del retraso, o sea, la debida al aire exceptuando el vapor de agua, más el retraso húmedo cenital $Z W D$, que es el debido a la presencia de vapor de agua:

$$
Z T D=Z H D+Z W D \quad(2.2 .1 \cdot 1.1)
$$

El retraso hidrostático cenital se encuentra bien documentado en la literatura y se puede calcular fácilmente a través de la siguiente relación:

$$
Z H D=10^{-6} \times k_{1} \times \frac{R}{g} \times P
$$

donde, $R=8.31 \times 10^{7} \frac{\text { dinas } \times \mathrm{cm}}{\mathrm{K} \times \mathrm{mol}}$ es la constante universal de los gases, $g=978.67 \frac{\mathrm{cm}}{\mathrm{sg}^{2}}$ es la aceleración de la gravedad, y $k_{1}=77.6 \frac{\mathrm{K}}{\mathrm{hPa}}$ y $P(h P a)$ es la presión en superficie 
en el lugar de la antena del GPS. Si queremos expresar ZHD en mm., tendremos en cuenta que la densidad del aire seco es de $28.9 \frac{\mathrm{gr}}{\mathrm{mol}}$ con lo que:

$$
\begin{aligned}
& =10^{-6} \times 77.6 \frac{\mathrm{K}}{\mathrm{hPa}} \times \frac{8.31 \times 10^{7} \times \frac{\mathrm{dinas} \times \mathrm{cm}}{\mathrm{K} \times \mathrm{mol} \times 28.9 \frac{\mathrm{gr}}{\mathrm{mol}}}}{978.67 \frac{\mathrm{cm}}{\mathrm{sg}^{2}}} \times P(\mathrm{hPa}) \\
& \mathrm{ZHD}(\mathrm{mm})=7760 \times \frac{8.31}{978.67 \times 28.9} \times P(\mathrm{hPa})
\end{aligned}
$$

De (2.2.1.1.1), obtenemos el retraso húmedo cenital como:

$$
Z W D=Z T D-Z H D \quad(2.2 .1 .1 .4)
$$

El vapor de agua precipitable $P W V$, puede obtenerse del retraso húmedo cenital mediante la siguiente expresión:

$$
P W V=\prod \times Z W D \quad(2.2 .1 .1 .5)
$$

donde, П, es la llamada función de mapeo (Li, P.W. et al., 2005) y puede obtenerse como sigue:

$$
\Pi=\frac{10^{6}}{\rho \times R_{v}\left[\frac{k_{3}}{T_{m}}+k_{2}-w \times k_{1}\right]}
$$

donde, $\rho=1 \frac{\mathrm{gr}}{\mathrm{cm}^{3}}$ es la densidad del agua líquida, $R_{v}=4.61 \times 10^{6} \frac{\text { dinas } \times \mathrm{cm}}{\mathrm{K} \times \mathrm{gr}}$ es la constante de los gases referida al vapor de agua, $T_{m}(K)$ es la temperatura media en la columna atmosférica, $w=0.622$ es la relación entre el peso molecular del agua y el del aire seco, y finalmente, $k_{1}=77.6 \frac{\mathrm{K}}{\mathrm{hPa}}, k_{2}=70.4 \frac{\mathrm{K}}{\mathrm{hPa}}$ y $k_{3}=3.739 \times 10^{5} \frac{\mathrm{K}^{2}}{\mathrm{hPa}}$ son constantes derivadas por Bevis et al. (1994). Teniendo en cuenta que $1 \frac{\text { dina }}{\mathrm{cm}^{2}}=10^{-3} \mathrm{hPa}$ y sustituyendo todos los valores de las constantes anteriores en la fórmula (2.2.1.1.6), el valor de la función de mapeo para valores típicos de la temperatura media es de, aproximadamente, 0.15 . Este valor puede elegirse como primera aproximación o como valor por defecto.

A partir de los sondeos diarios podemos evaluar la temperatura media ponderada en la columna atmosférica sobre Izaña. Esta ponderación se refiere a que cuanto más fría sea la capa y cuanto mayor sea la tensión de vapor de agua de la misma, más peso tendrá en la temperatura media. Esta temperatura media en la columna atmosférica se define de la siguiente manera: 


$$
T_{m}=\frac{\int \frac{e_{v}}{T} d z}{\int \frac{e_{v}}{T^{2}} d z}
$$

donde $e_{v}$ es la tensión $(h P a)$ del vapor de agua a la temperatura $T(K)$ en la capa y $z(m)$ es la altitud de la capa.

La temperatura media ponderada en la columna atmosférica la determinamos a partir de los datos de los sondeos. Esto lo hacemos con el programa MATLAB "Temeatm.m" (listado en el anexo). Pero este valor lo necesitamos a priori como entrada para poder evaluar el vapor de agua precipitable mediante el receptor GNSS. Por tanto, es necesario que, o bien supongamos un determinado valor o valores para esta variable realizando algunas hipótesis, o bien dispongamos de alguna relación por la que podamos obtener la $T_{m}$ a partir de algún dato fácilmente medible en superficie. A este respecto, el programa "Temeatm.m", no sólo calcula las temperaturas medias en la columna atmosférica a partir de los sondeos sino que también, en el formato del fichero de salida, introduce una columna para la variable "Temperatura del sensor en superficie" $\left(T_{s}\right)$ medida por un barómetro situado cerca de la antena del equipo GNSS y a su misma altura. Esto nos permitirá relacionar mediante una regresión lineal ambas temperaturas: la de la superficie, con la media en columna. Este es el procedimiento comúnmente seguido por otros autores (Li, P.W. et al., 2005) el cual proporcionaría, sin necesidad de sondeos, el valor de $T_{m}$ a partir del valor medido de la temperatura en superficie. En las siguientes dos figuras podemos ver la relación entre la temperatura media y la medida en superficie usando sondeos con, al menos, 2000 valores.

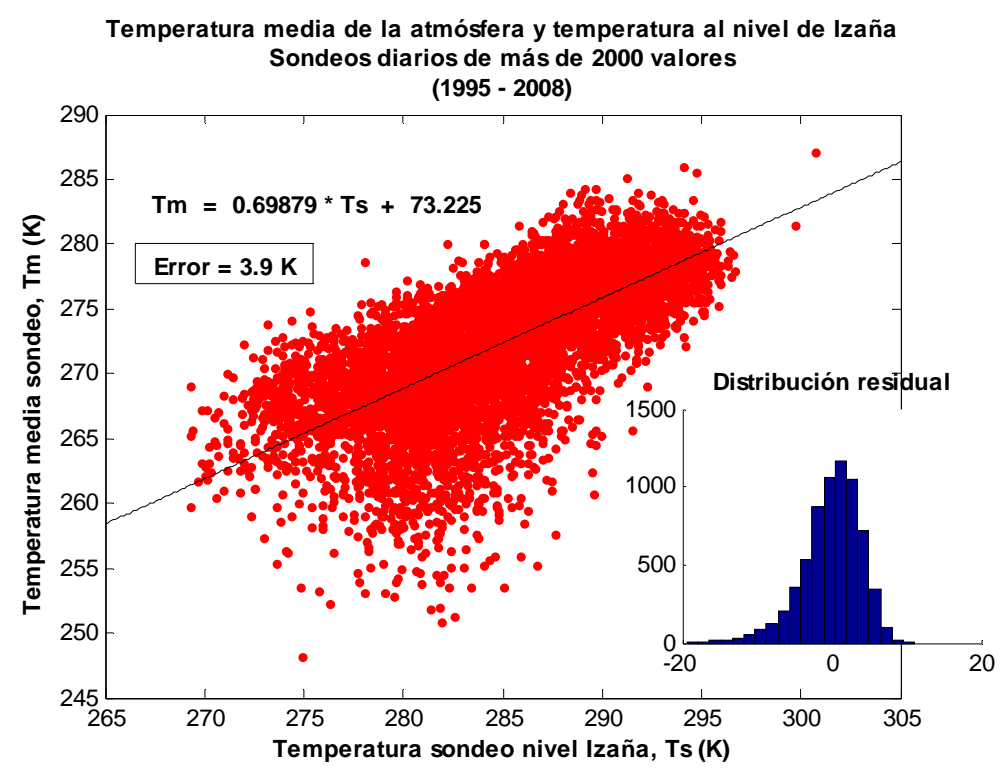

Figura 2.2.1.1.1. Temperatura media en la columna atmosférica y temperatura superficial medida al nivel de Izaña por el propio sondeo. 


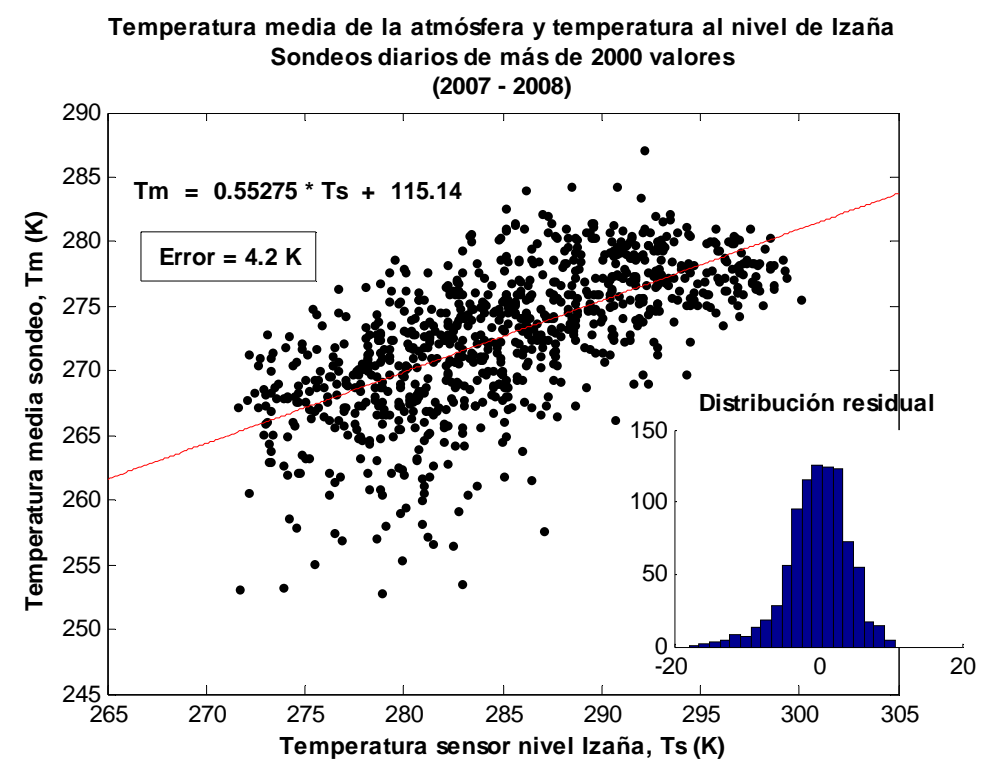

Figura 2.2.1.1.2. Temperatura media en la columna atmosférica y temperatura superficial medida al nivel de Izaña por un sensor en superficie.

Nosotros, además, hemos asumido otras alternativas posibles como valor para las $T_{m}$ y así poder comparar con cuál de ellas obtenemos los mejores resultados de agua precipitable. Para ello, hemos comparado el agua precipitable obtenida a través del receptor GNSS usando diferentes familias de $T_{m}$ y las obtenidas a partir de los sondeos en el período comprendido entre el 13 de julio y el 12 de noviembre de 2008. Los resultados, han sido los siguientes:

Caso 1 Suponemos sobre Izaña una atmósfera estándar. Esta atmósfera es una atmósfera teórica basada en medidas climatológicas medias mundiales y que viene caracterizada por un gradiente térmico negativo de: $-6.5^{\circ} \mathrm{C}$ por cada 1000 metros de elevación hasta la altura de la troposfera, que en Izaña está sobre los $12 \mathrm{~km}$., aproximadamente; la presión desciende con la altura como una función potencial y la humedad también desciende pero como función exponencial decreciente. Las ecuaciones las tomamos del manual del software Bernese (Hugentobler et al., 2007), que es el que se usa para el procesamiento de las señales GNSS. Estas ecuaciones se encuentran listadas en el programa MATLAB "atmoestandar.m" del anexo, utilizado para evaluar, mediante la expresión (2.2.1.1.7), la temperatura media en la columna atmosférica de la atmósfera estándar, dando como resultado $T_{m}=269.9 \mathrm{~K}$.

Mediante el programa "VAPGPSSOND.m" calculamos el agua precipitable GNSS usando los datos cruzados de este con los sondeos y los de temperatura y presión en superficie medidos cerca de la antena GNSS. El resultado, presenta un error medio entre GNSS y sondeos de $-0.69 \mathrm{~mm}$ y una desviación estándar de $\pm 1.19 \mathrm{~mm}$, lo cual mejora lo obtenido en otros lugares por otros autores (Boccolari et al., 2002). Esto significa que el GNSS tiende a medir menos agua precipitable que la obtenida con la RS-92. La correlación obtenida es muy buena y el error medio en el ajuste es del orden de $1 \mathrm{~mm}$.

Veremos cómo estos resultados aún admiten ciertas mejoras. 


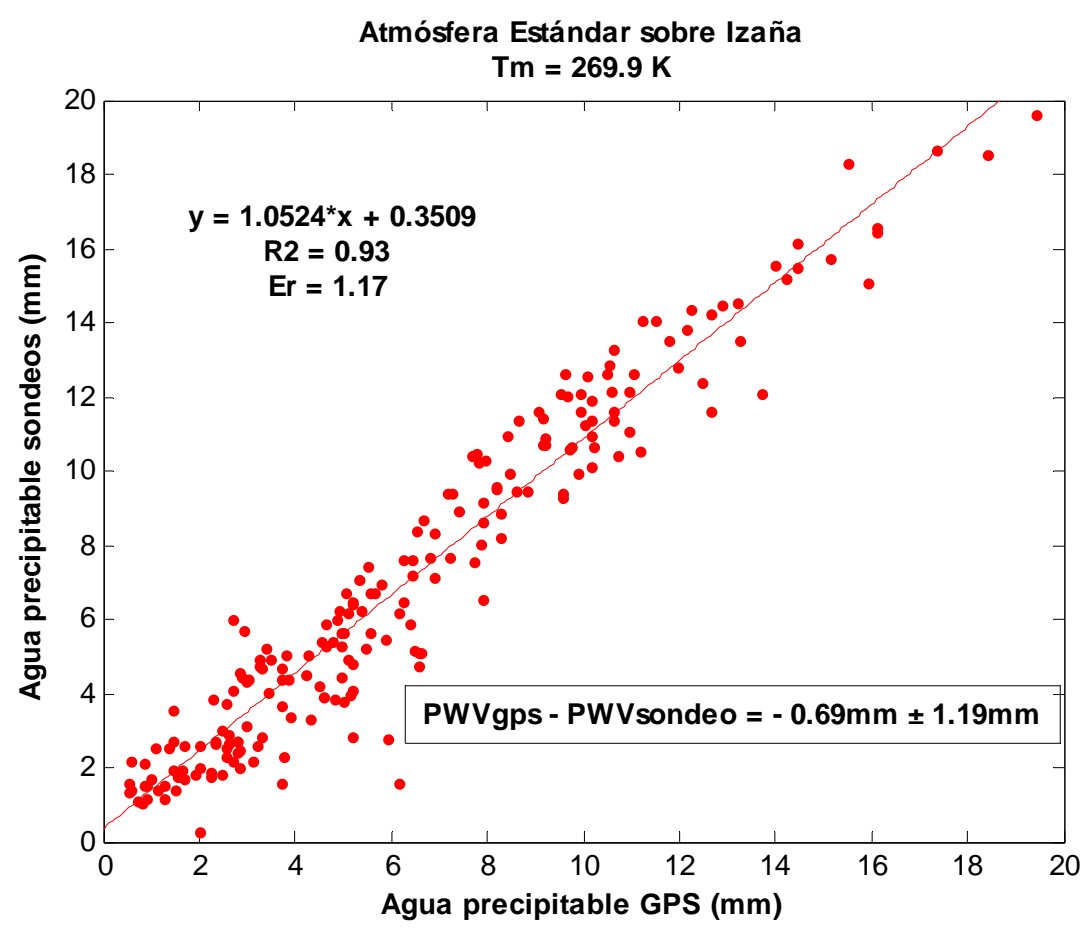

Figura 2.2.1.1.3. Correlación GPS-sondeos en atmósfera estándar sobre Izaña.

Caso 2 Consideramos la atmósfera real sobre Izaña. En este caso, nuestra relación empírica entre temperatura media $T_{m}$ y temperatura en superficie $T_{s}$ está basada, por un lado, en los datos de presión, temperatura y humedad que proporcionan los sondeos cuando rebasan el nivel de Izaña y, por otro, del sensor de temperatura situado al nivel de la antena GNSS o bien del propio sensor de temperatura del globosonda justo en el momento en que rebasa el nivel de Izaña. En el primer caso, disponemos de muchos más datos para el cálculo de la regresión lineal entre ambas magnitudes, ya que, podemos usar datos de sondeos desde 1995. En el caso de usar la temperatura del sensor en tierra al lado de la antena GNSS disponemos de menos datos pero estos serán más idóneos ya que no dependen del sondeo y además están medidos en tierra, cerca de dicha antena. En este último caso, el programa para cruzar ambas temperaturas es "cruza.m". Eligiendo la segunda de estas relaciones entre temperatura media y superficial, por las razones antes apuntadas, obtenemos para el agua precipitable en la atmósfera real la correlación que aparece en la figura 2.2.1.1.4. Vemos que aumenta algo el grado de correlación y que todos los errores han disminuido comparados con los resultados del caso 1.

Caso 3 Ahora, en vez de usar una relación lineal para obtener $T_{m}$, aplicaremos una climatología de esta variable sobre Izaña basada en un año estándar de 366 días. Para cada día natural del año, se tendrá un valor climatológico de $T_{m}$ en Izaña obtenido como media móvil cíclica a 11 días de los valores de las medianas diarias de $T_{m}$ asociadas a cada día en cuestión. Para ello se ha hecho uso de sondeos desde 1995 hasta noviembre de 2008 y de la fórmula (2.2.1.1.7). Esta climatología es la que se representa en la figura 2.2.1.1.5. Es útil y se usará como valores por defecto para la temperatura media en la columna atmosférica sobre Izaña cuando falte el dato del sondeo y, sobre todo, cuando necesitemos calcular en tiempo real el valor del agua precipitable de las medidas del receptor GNSS. 


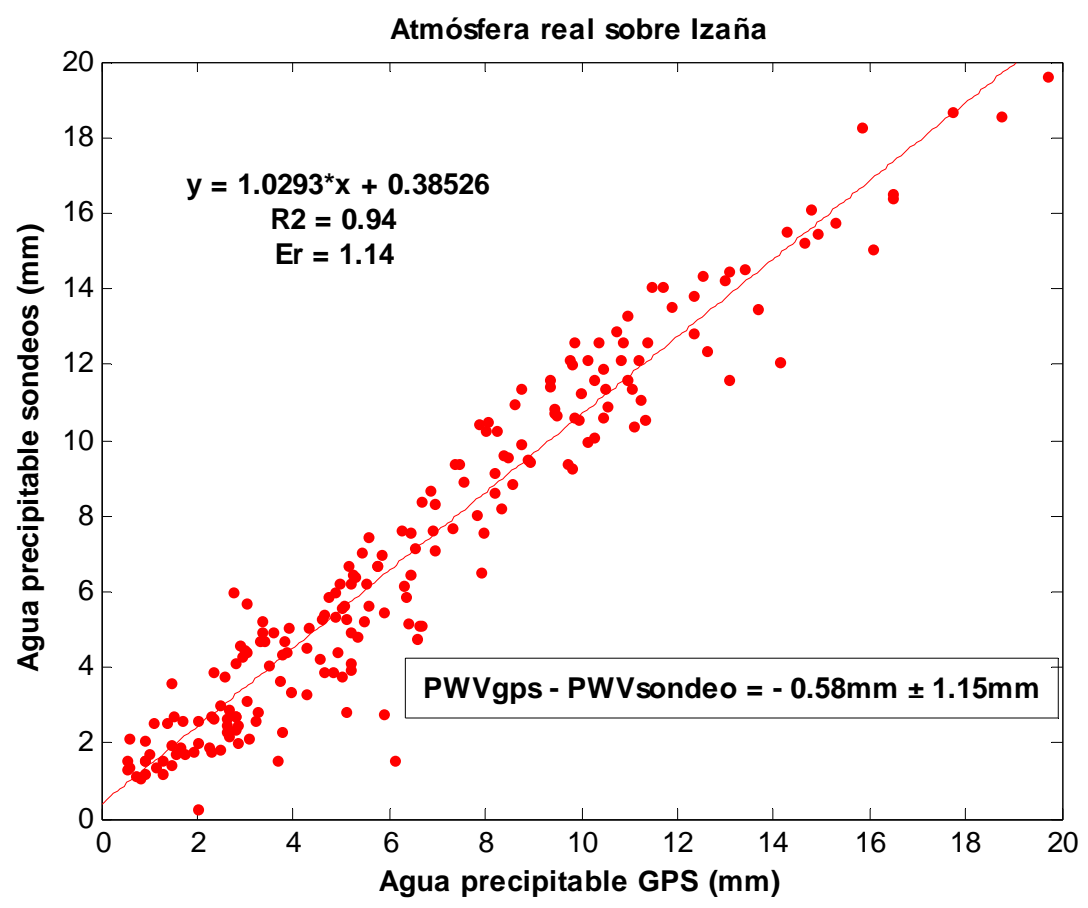

Figura 2.2.1.1.4. Correlación GPS-sondeos en atmósfera real sobre Izaña.

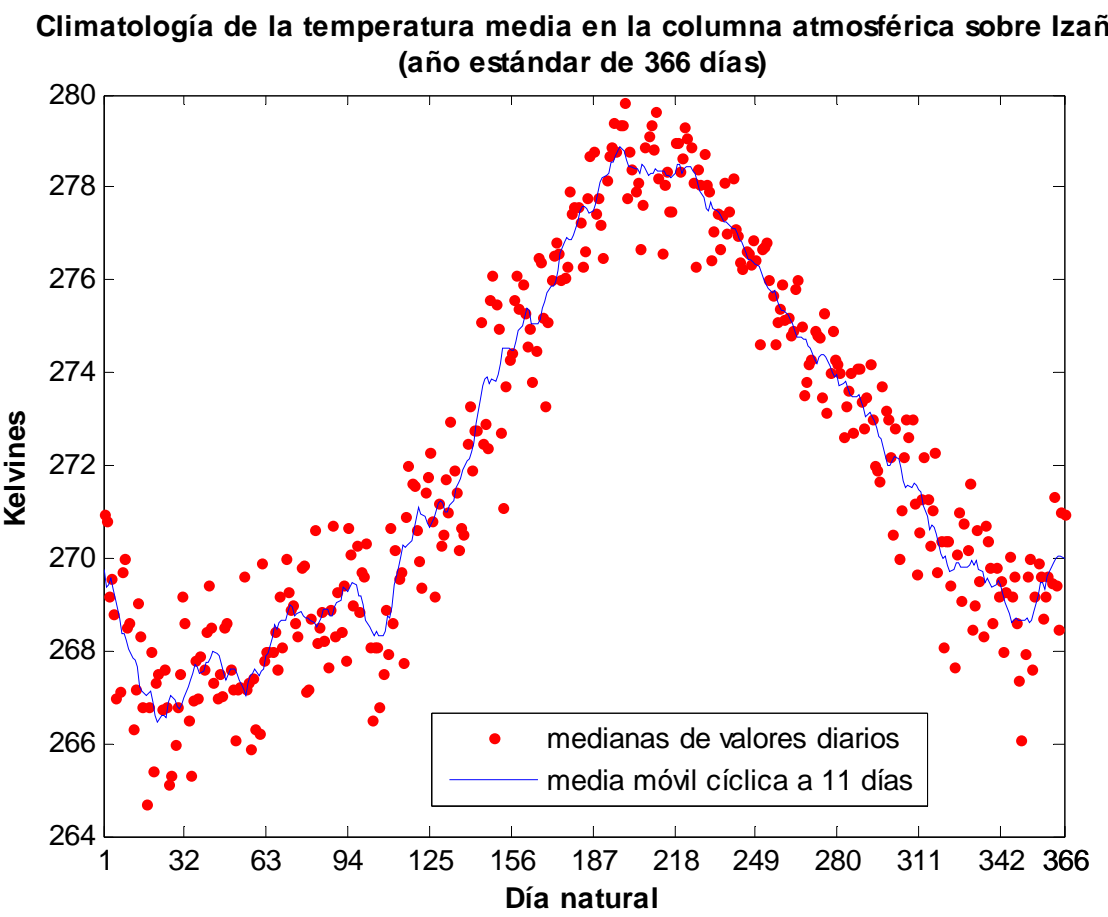

Figura 2.2.1.1.5. Climatología para la temperatura media en la columna atmosférica sobre Izaña. Año estándar de 366 días.

Los resultados de aplicarla al cálculo del agua precipitable se muestran en la siguiente gráfica donde podemos ver que, el error medio entre GNSS y sondeo, se ha mejorado algo, mientras que la desviación estándar respecto del error medio y el error en el ajuste son ligeramente más altos. 


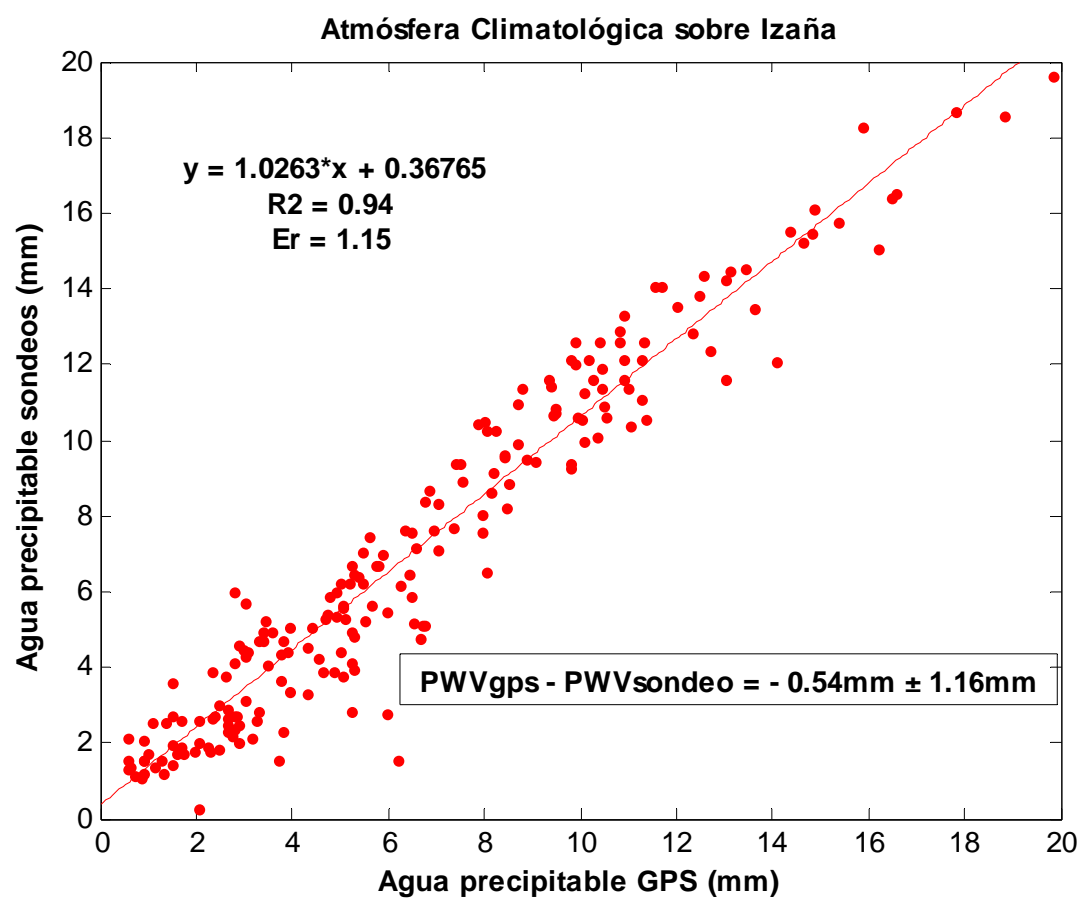

Figura 2.2.1.1.6. Correlación GPS-sondeos en atmósfera climatológica sobre Izaña.

Para el estudio en tiempo real del vapor de agua escogeremos por defecto, como relación base entre temperaturas, la de la climatología sobre Izaña, ya que da un resultado excelente y no es necesario disponer de los datos de temperatura y presión en tiempo real.

\subsection{Software Bernese 5.0}

El software Bernese (Hugentobler et al., 2007) es una potente herramienta para aplicaciones geodésicas que utilizan los Sistemas de Navegación Global por Satélite (GNSS). Este software puede trabajar tanto con el sistema GPS estadounidense como con el GLONASS ruso. Es el que se usa para la obtención del retraso cenital total de la señal del satélite (ZTD). Entre las características más importantes del software cabría destacar las siguientes:

- Procesa y combina con rigor datos de un gran número de receptores GPS, GLONASS y GPS/GLONASS.

- Permite el control de parámetros tanto en la ionosfera como en la troposfera.

- Permite la determinación de las órbitas de los satélites y de los parámetros de orientación de la Tierra.

Es un software tremendamente complejo que posee 300.000 líneas de código fuente y unos 1200 módulos. Dispone de un sistema de menús que actúa como interface de usuarios para más de 100 programas. En la figura siguiente, se ilustra esquemáticamente cómo funciona la lógica de este software. 


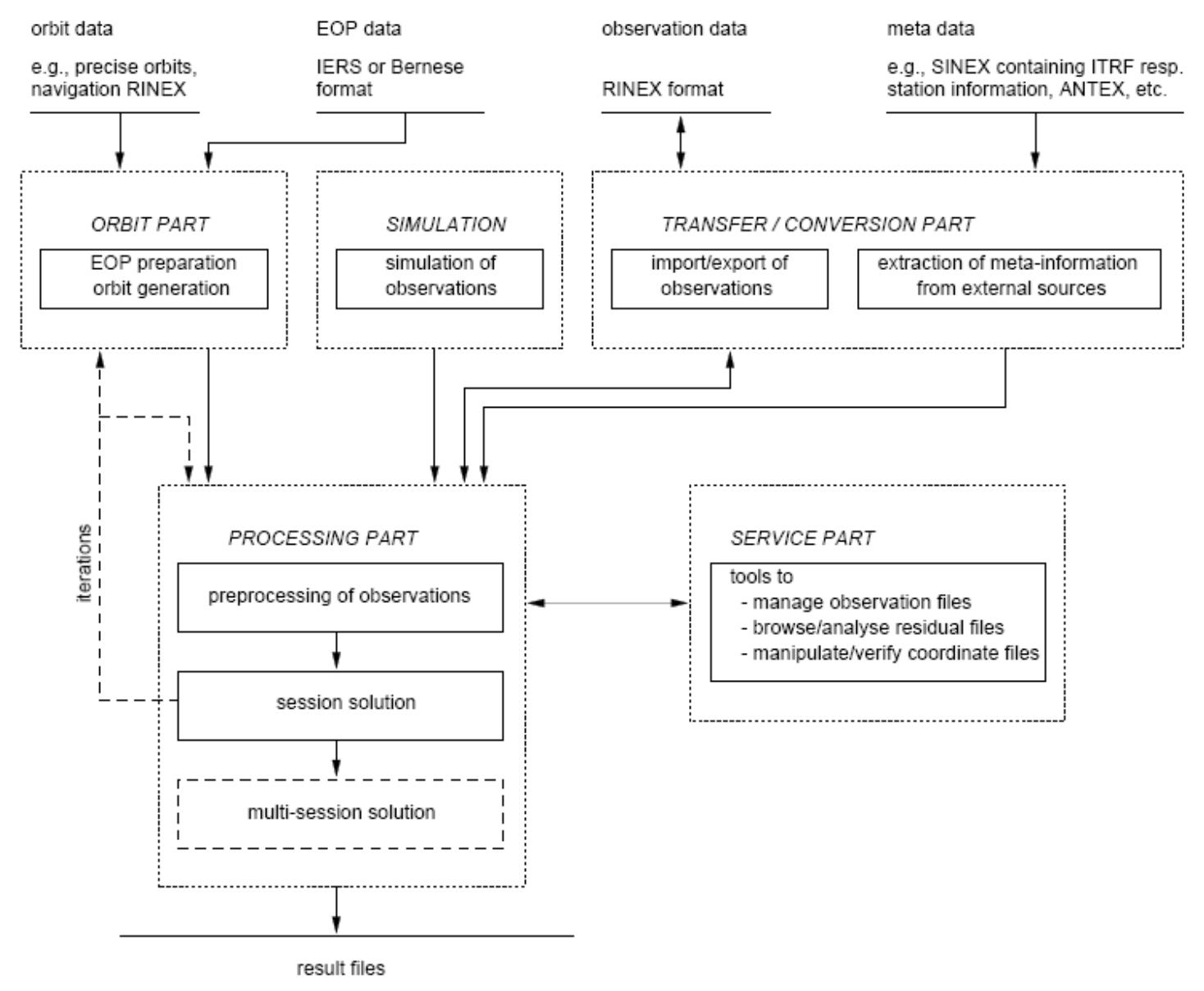

Figura 2.2.1.1.1.1. Diagrama de flujo funcional del proceso estándar en software Bernese 5.0.

En la denominada parte de transferencia (TRANSFER PART) se generan a partir del formato RINEX (Formato de Intercambio Independiente del Receptor) ficheros en formato Bernese y viceversa. También esta parte contiene herramientas para la manipulación en general de los ficheros de intercambio entre receptores RINEX.

En el módulo de conversión (CONVERSION PART) se extrae la información externa necesaria para el procesado (coordenadas y velocidades).

En el módulo orbital (ORBIT PART) tenemos todas las herramientas para la manipulación y cálculo de los parámetros asociados con la orientación de la Tierra y con la generación y comparación de órbitas estándares.

El procesado de las observaciones GPS-GLONASS se realiza mediante el programa GPSEST y la superposición de los sistemas de ecuaciones normales se realiza mediante el programa ADDNEQ2. Todo ello dentro del módulo de procesado (PROCESSING PART).

El módulo de simulación (SIMULATION), como su propio nombre indica es donde se generan observaciones simuladas GPS-GLONASS basadas en información estadística y que sirven para comparaciones.

Por último, el módulo de servicio (SERVICE PART) es una colección de programas y herramientas útiles para editar y manipular ficheros de datos binarios, comparar conjuntos de coordenadas, representar residuos, y programas de conversión de ficheros binarios a ASCII y viceversa.

Usando el software Bernese 5.0, el Instituto Geográfico Nacional nos proporciona el retraso cenital total (ZTD) expresado en $\mathrm{mm}$. de la señal que envían los 
satélites a nuestro receptor a su paso a través de la atmósfera. Este es el punto de partida desde el cual nosotros obtenemos el agua precipitable en columna a partir de los programas MATLAB que se describen en la siguiente sección.

\subsection{Algoritmos MATLAB}

MATLAB es una potente herramienta de cálculo que nos permite automatizar, mediante programas, la evaluación analítica, numérica y estadística de datos e imágenes de todo tipo, así como las representaciones gráficas correspondientes.

Son varios los algoritmos MATLAB de confección propia que se han aplicado para distintas utilidades en esta Nota Técnica. Se listan en el apéndice final los códigos fuente correspondientes, tanto al programa base usado en la obtención de agua precipitable a partir de las señales GNSS, como otros igualmente útiles, los cuales ya aparecen debidamente comentados en sus propios scripts. Como estos programas están particularizados para la estación de Izaña, en esta sección, daremos algunas directrices generales sobre cómo usarlos o particularizarlos para las necesidades concretas de cualquier otro usuario.

El primer paso que hay que dar es desarrollar una climatología para las temperaturas medias en la columna atmosférica sobre el lugar de que se trate a partir de los datos de los sondeos PTU de dicho lugar usando la fórmula (2.2.1.1.7). Para ello, habrá que calcular las tensiones de vapor en los diferentes estratos de los sondeos e integrar posteriormente. El fichero climatológico final, una vez obtenida la climatología correspondiente a esta temperatura media, debería producir una curva parecida a la que se muestra en la figura 2.2.1.1.5. Estos datos nos servirán de entrada al programa "precgps.m" para evaluar el agua precipitable. En nuestro caso, el fichero que tiene la climatología se denomina "temedatm.txt" y tiene cuatro columnas de las cuales la primera es el día natural del año y la cuarta es la que contiene el valor climatológico de la variable. Como la climatología está hecha para un año estándar de 366 días el registro correspondiente al día 60 siempre se referirá al 29 de febrero.

También es necesario disponer del fichero diario de presión en la estación para el día que se está evaluando. En nuestro caso, dicho fichero no se encuentra en el mismo PC donde se ejecuta el programa "precgps.m" sino que se encuentra en un equipo remoto al que se accede vía red. Para ello, el programa lo descarga desde allí usando una unidad de asignación de red definida como $\mathrm{Z}$ en el PC en el que se ejecuta y que contiene la información sobre la ubicación remota (path) del fichero de presión. Por tanto, para el caso en que el usuario se encuentre en una situación similar y quiera usar este bloque del programa para obtener el fichero diario de presión, deberá preasignar una unidad de red en el PC donde ejecute el programa con esta información y cambiar, en su caso, el nombre $\mathrm{Z}$ por el correspondiente tras la asignación.

Por último, decir que, en el bloque de lectura de los ficheros originales de los resultados del procesamiento GNSS, en formato COST, figuran no sólo los datos del retraso cenital total (ZTD) de nuestra estación, sino de otras muchas. Por tanto, es necesario seleccionar y extraer la correspondiente a la nuestra. En el caso de Izaña, dicha información viene dentro de un bloque identificado por la palabra "IZAN". El usuario deberá pues tener esto en cuenta a la hora de aplicarlo para su propia estación y sustituir dicha palabra por la que corresponda en su caso.

El programa "precgps.m" construye a partir de los ficheros originales COST un fichero intermedio de tres columnas, denominado "todgps.txt", con la información de la fecha-hora, el valor medio del retraso cenital total correspondiente a dicho momento expresado en milímetros y la desviación estándar respecto de dicho valor medio. Luego, 
tomando como entrada este fichero intermedio, calcula el agua precipitable escribiendo a un fichero final estos valores y los de todas las variables y parámetros intermedios y finales implicados en el proceso.

\subsection{Agua precipitable en tiempo real}

El procesamiento GNSS, actualmente, nos proporciona una medida del retraso cenital total cada 15 minutos. Es fácil, a partir del programa base anterior, construir uno que obtenga, en tiempo cuasi-real, el valor del agua precipitable accediendo a los datos originales GNSS en formato COST a través de la ftp y representando posteriormente dichos valores en una gráfica. Esta gráfica se envía al servidor web y se actualiza cada hora con los datos quince minutales provenientes del procesamiento GNSS; así podemos ver la evolución del agua precipitable durante todo el día. La técnica GNSS, convenientemente validada con los resultados del agua precipitable obtenidos con otras técnicas, nos va a permitir disponer de una evolución diaria detallada del vapor de agua en columna con precisión igual o superior a la que podría obtenerse con un sondeo tradicional. Por tanto, esto sería equivalente a disponer de un sondeo de vapor de agua integrado en columna cada 15 minutos.

El programa que hace esto, en el caso de Izaña, también aparece listado en el anexo final y se llama "gpstiemreal.m". Básicamente es igual al anterior solo que incorpora un primer bloque inicial de instrucciones para permitir acceder vía ftp a los datos, resultado del procesamiento GNSS, y volcarlos a nuestro ordenador. Al final, hay otro bloque de instrucciones que nos permiten trazar los gráficos correspondientes en tiempo real y guardarlos como imagen en formato ".jpg" en el servidor web. También se han ido añadiendo convenientemente instrucciones para borrar variables intermedias y así liberar memoria una vez que estas ya no se iban a usar.

Una característica importante de este programa es que se ha añadido una primera línea que permite tratar al script como una función MATLAB y así puede ser compilado con el compilador de MATLAB a un fichero ".exe" para que pueda ser ejecutado desde cualquier ordenador aunque no tenga instalado MATLAB. No obstante, previamente habría que instalar en dicho ordenador el módulo denominado MCR correspondiente a la versión de MATLAB con el que ha sido compilado dicho script.

\subsubsection{Técnica Radiométrica}

\subsubsection{1. $\quad$ Metodología}

Consiste básicamente en aplicar la denominada técnica Langley-Modificada (Yankee Environmental Systems, Inc. Installation and User Guide. Version 2.0) a los datos de radiación directa solar de algún canal radiométrico de banda estrecha que esté centrado alrededor de los $935 \mathrm{~nm}$ ó $940 \mathrm{~nm}$, aproximadamente. Esta banda presenta una absorción significativa de radiación por el vapor de agua y nos permite determinar su cantidad como vamos a demostrar. Previamente, es necesario caracterizar el filtro del canal a analizar y determinar las denominadas constantes del filtro.

Se han usado dos radiómetros: un fotómetro solar CIMEL y un radiómetro multifiltros con banda de sombra rotante (MFRSR). En esta sección se describirá únicamente cómo se aplica la técnica al MFRSR (Prata et al., 2000). Los datos de vapor de agua del fotómetro CIMEL han sido obtenidos por la red AERONET (Red Robótica de Aerosoles) usando una técnica similar y pueden descargarse directamente de su enlace de red. 


\subsection{Caracterización del filtro del canal 941nm del MFRSR}

La respuesta espectral del filtro del canal $941 \mathrm{~nm}$ del MFRSR a la radiación incidente viene dada por su transmisividad. La transmisividad es el cociente entre la radiación directa que pasa y sale a través del filtro respecto de la radiación directa que entra en él.

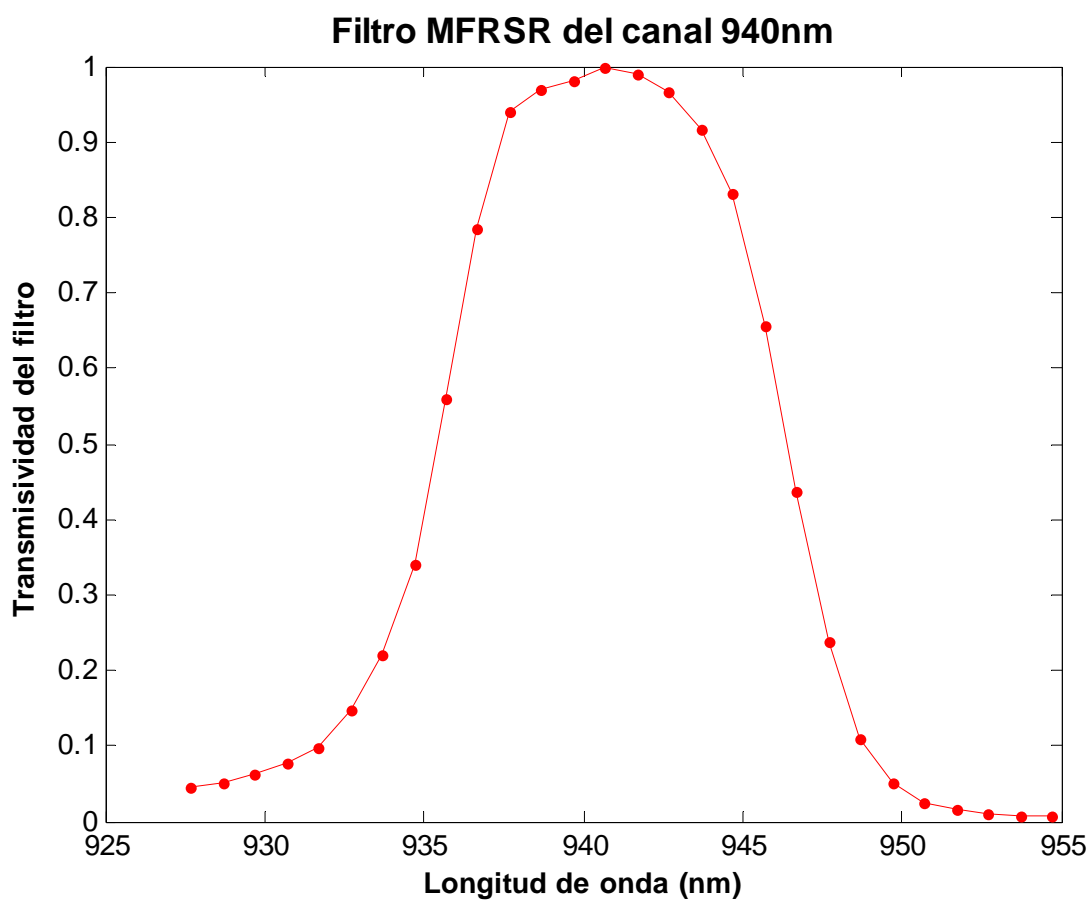

Figura 2.2.2.1.1.1. Transmisividad del filtro MFRSR de 941nm.

Es fácil comprender, por tanto, que la transmisividad del filtro variará entre $0 \mathrm{y}$ 1. La respuesta espectral del filtro se obtiene en laboratorio; su determinación es experimental y caracteriza a un filtro concreto. Se entrega con la documentación del equipo y, en nuestro caso, es la que se representa en la figura anterior. En caso de no disponer de esta información, la respuesta espectral del filtro podría aproximarse por una gausiana.

Está claro que, a mayor cantidad de vapor de agua presente en la atmósfera, menor será la transmisividad atmosférica en la banda de absorción de $941 \mathrm{~nm}$. También la transmisividad será menor a través del propio filtro del instrumento, con lo cual, la transmisividad total que se mide a la salida del canal de $941 \mathrm{~nm}$ será la combinación de ambas transmisividades: la de la atmósfera y la del filtro. Esto, matemáticamente, significa que la transmisividad total puede obtenerse como el producto de las otras dos:

$$
T_{\text {tot }}=T_{\text {atm }} \times T_{\text {fil }}
$$

La fórmula anterior ha de entenderse como un producto componente a componente entre los dos vectores transmisividad correspondientes a la atmósfera y al filtro. Esta transmisividad total hay que integrarla en todo el rango de longitudes de onda del filtro y luego normalizarla con la integral de la transmisividad del filtro en dicho rango. Ahora bien, para estudiar la transmisividad atmosférica del vapor de agua lo que hacemos es usar un modelo. Aquí se ha usado el denominado "random model" o modelo aleatorio (Iqbal, 1983). Según este modelo, la transmisividad del vapor de agua 
a través de la atmósfera puede expresarse en función de la masa óptica mediante la siguiente expresión:

$$
T_{a t m}=\exp \left(\frac{-0.2385 \times C(\lambda) \times u \times m}{(1+20.07 \times C(\lambda) \times u \times m)^{0.45}}\right)
$$

donde $m$ es la masa óptica relativa cuya obtención, en función de la elevación solar $\alpha$, puede deducirse de la fórmula de Kasten:

$$
m=\frac{1}{\operatorname{sen}(\alpha)+0.15 \times(3.885+\alpha)^{-1.253}}
$$

$u$ es la cantidad de vapor de agua en columna y $C(\lambda)$ es el coeficiente de absorción del vapor de agua para la longitud de onda $\lambda$. Estos se encuentran tabulados en la literatura y su valor para longitudes de onda intermedias entre dos valores tabulados se puede extrapolar desde dichos valores mediante interpolación lineal. Los valores de la elevación solar en el momento de la medida se pueden obtener de los parámetros de fecha y hora en dicho momento y los del vapor de agua en la columna atmosférica pueden obtenerse de los sondeos diarios cuando estos rebasan el nivel de Izaña, según el procedimiento que se explicará en la sección 2.2.3 de técnica aerológica. La transmisividad total normalizada a través del filtro la calculamos integrando la transmisividad filtrada en el ancho de banda del filtro y, posteriormente, dividiendo entre la integral del filtro. Es decir,

$$
T_{\text {totnorm }}=\frac{\int\left(T_{a t m} \times T_{\text {fil }}\right) \times d \lambda}{\int T_{f i l} \times d \lambda}
$$

Representando esta última frente al camino óptico del agua precipitable en la atmósfera podemos ver cómo se comporta nuestro filtro particular frente a la transmisividad del vapor de agua. La figura 2.2.2.1.1.2 muestra estos resultados. El camino óptico del agua precipitable se calcula como el producto de la masa óptica por la cantidad de agua precipitable en la columna atmosférica. Para evaluarlo, tuvimos que usar los sondeos aerológicos diarios desde 1995 hasta finales de 2007 y extraer el agua precipitable en columna tal y como se explicará en la siguiente sección. La curva resultante se puede aproximar por una exponencial decreciente y deducir de ahí las constantes $\mathrm{k} \mathrm{y} \mathrm{b}$, propias de nuestro filtro. Las constantes obtenidas para el filtro son similares a las obtenidas por otros autores (Prata et al., 2000).

En la siguiente figura se representa el ajuste del filtro y los parámetros asociados. Podemos ver que la transmisividad a través del filtro mediante una función exponencial decreciente se ajusta perfectamente y correlaciona bastante bien con los datos experimentales de los sondeos, lo cual, nos permite caracterizar nuestro filtro particular del radiómetro MFRSR para la atmósfera de Izaña. 


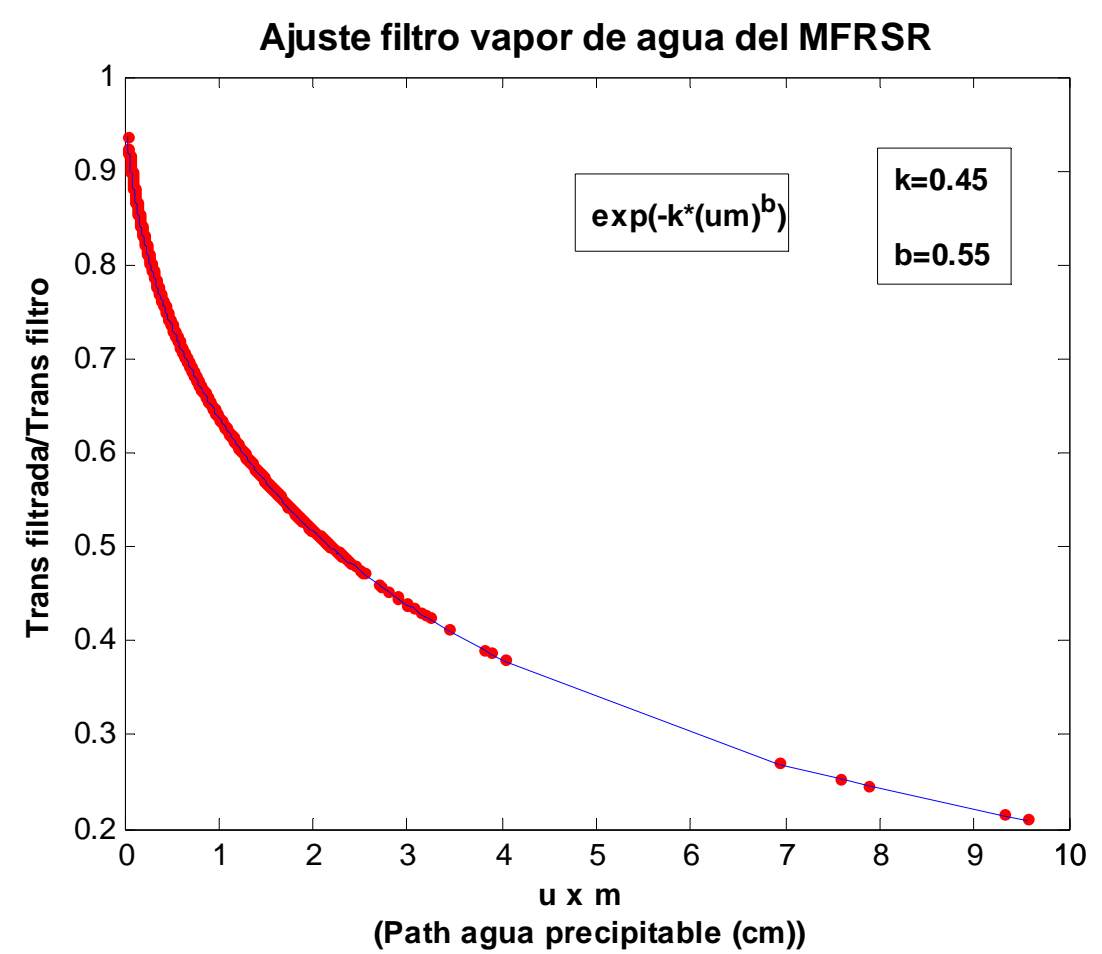

Figura 2.2.2.1.1.2. Transmisividad del filtro de vapor de agua del MFRSR.

\subsection{Técnica Langley-Modificada}

La ley de Bouguer-Lambert-Beer nos dice cuál es la radiación directa solar monocromática que llega al sensor de nuestro equipo procedente de la parte superior de la atmósfera cuando atraviesa un determinado camino óptico en ella.

Matemáticamente, se expresa así:

$$
I(\lambda)=I_{0}(\lambda) \times \exp (-\tau(\lambda) \times m) \quad(2.2 .2 .1 .2 .1)
$$

donde $I_{0}(\lambda)$ es la radiación solar directa en la parte superior de la atmósfera a la longitud de onda $\lambda$ y $\tau(\lambda)$ es la extinción óptica por unidad de masa óptica relativa $m$ a la longitud de onda $\lambda$. tendremos:

Si tomamos logaritmos neperianos en ambos miembros de la ecuación anterior

$$
\ln I(\lambda)=\ln I_{0}(\lambda)-\tau(\lambda) \times m \quad(2.2 .2 .1 .2 .2)
$$

Esto no es más que la ecuación de una recta considerando como variable independiente la masa óptica y, como variable dependiente, el logaritmo neperiano de la intensidad en el primer miembro. Como la masa óptica se puede calcular de los datos de fecha y hora del día, y nuestro instrumento nos proporciona los valores de la intensidad que le llega, podemos representarla y calcular la recta de mejor ajuste a los datos por el procedimiento de mínimos cuadrados. La pendiente de la recta nos dará la extinción óptica total sufrida por el haz de radiación solar directa a su paso por la atmósfera, mientras que la ordenada en el origen, nos dará el valor de la constante extraterrestre o radiación solar que incide en la parte superior de la atmósfera (masa óptica 0) para una cierta longitud de onda. La extinción total depende de todos los constituyentes que hay 
en la atmósfera, desde la dispersión Rayleigh a la absorción de gases uniformemente mezclados, absorción del ozono, absorción y dispersión de aerosoles, absorción del vapor de agua, etc.

Ahora bien, separando la contribución a la extinción de cada uno de los componentes que intervienen en la misma, podría intentarse calcular la cantidad de estos componentes que hay en la columna atmosférica. Para el caso del vapor de agua, existe una técnica descrita en (Yankee Environmental Systems, Inc. Installation and User Guide. Version 2.0) y usada por otros autores (Alexandrov et al., 2009) mediante la cual se puede deducir la cantidad de agua precipitable en la columna atmosférica modificando la ecuación 2.2.2.1.2.2 y poniéndola de la siguiente manera:

$$
\ln I(\lambda)+\tau_{\text {scat }}(\lambda) \times m=\ln I_{0}(\lambda)-k \times(u \times m)^{b}
$$

donde $u$ es la cantidad de agua precipitable en la columna atmosférica (dirección cenital), $\tau_{\text {scat }}(\lambda)$ es el espesor óptico del aerosol más el de dispersión Rayleigh a $941 \mathrm{~nm}$ $\left(\tau_{\text {scat }}(\lambda)=E O A(\lambda)+\delta_{R}(\lambda)\right)$, y $k$ y $b$, son constantes propias del filtro de $941 \mathrm{~nm}$ y que se determinan como se explicó en la sección precedente. La expresión 2.2.2.1.2.3 es lo que se conoce como técnica Langley-Modificada.

La componente de dispersión Rayleigh de $\tau_{\text {scat }}(\lambda)$ se puede determinar fácilmente aplicando la siguiente expresión:

$$
\delta_{R}(\lambda)=0.00864 \times \lambda^{-\left(3.916+0.074 \lambda+\frac{0.050}{\lambda}\right)} \times \frac{p}{1013.5}
$$

donde $\lambda$ es la longitud de onda en micras y p es la presión atmosférica en $\mathrm{hPa}$.

La componente de aerosol de $\tau_{\text {scat }}(\lambda)$ se puede obtener en función del espesor óptico del aerosol en las otras longitudes de onda del equipo aplicando la ley de Angstrom. Esta ley establece que, para una misma distribución por tamaños de partículas aerosoles y una misma cantidad de ellos en la columna atmosférica, el espesor óptico del aerosol (EOA) o grado de extinción de luz directa, debido exclusivamente a la presencia de estas partículas, se puede poner en función de la longitud de onda mediante una ley potencial:

$$
\operatorname{EOA}(\lambda)=\beta \times \lambda^{-\alpha} \quad(2.2 .2 .1 .2 .5)
$$

donde $\alpha$ y $\beta$ son los denominados parámetros de Angstrom. El exponente de Angstrom $\alpha$ es un parámetro asociado a la distribución por tamaños de las partículas y está relacionado con el cociente entre partículas finas y gruesas. El parámetro $\beta$, en cambio, es un parámetro asociado con la cantidad de aerosoles presentes en la columna atmosférica. Por tanto, la contribución del aerosol a la extinción en $941 \mathrm{~nm}$ puede obtenerse a partir de la contribución del aerosol a la extinción en el resto de longitudes de onda de banda estrecha del radiómetro. Con sólo usar dos espesores ópticos, correspondientes a dos longitudes de onda distintas, ya nos permitiría obtener los parámetros $\beta$ y $\alpha$, y a partir de aquí, deducir cualquiera de los otros espesores. En nuestro caso, disponemos hasta de cinco canales de banda estrecha además del de vapor de agua. La mejor forma de obtener el espesor óptico del aerosol en $941 \mathrm{~nm}$ en estos casos es no emplear sólo dos de ellos sino usar los cinco espesores ópticos de las cinco 
longitudes de onda restantes. Si tomamos logaritmos neperianos en los dos miembros de la expresión anterior, tenemos:

$$
\ln \operatorname{EOA}(\lambda)=\ln \beta-\alpha \ln \lambda \quad(2.2 .2 .1 .2 .6)
$$

Tomando como variable independiente el $\ln \lambda$ y como variable dependiente el $\ln E O A(\lambda)$, la expresión de arriba representa una recta. Podemos obtener la recta de mejor ajuste a los puntos anteriores por el procedimiento de mínimos cuadrados y deducir lo que valen los coeficientes $\alpha$ y $\beta$. A partir de aquí, deducimos el EOA correspondiente a cualquier longitud de onda, en nuestro caso, la de $941 \mathrm{~nm}$.

Volviendo a la expresión 2.2.2.1.2.3, nuevamente, aplicando la técnica de regresión lineal por mínimos cuadrados a ambos miembros de la ecuación, y considerando como variable independiente $\mathrm{m}^{b}$, podemos obtener tanto la constante $\ln I_{0}$ para el vapor de agua como la pendiente $k u^{b}$. Una vez obtenida la pendiente, la deducción de la cantidad de agua precipitable es inmediata ya que conocemos cuáles son las constantes $k$ y $b$ propias de nuestro filtro.

\subsection{Calibración del vapor de agua}

Es importante señalar que, dada la gran variabilidad espacial y temporal del vapor de agua, este es mucho menos estable que el aerosol. Para conseguir una constante extraterrestre estable para el vapor de agua es necesario construir una serie en el tiempo con valores diarios del $\ln I_{0}$ y extraer de ella la mediana o ajustar dicha serie a una tendencia lineal para tener en cuenta la posible degeneración o decaimiento del filtro. El valor obtenido para el $\ln I_{0}$ de esta serie es el que se usará en la expresión

2.2.2.1.2.3 para despejar la pendiente $k u^{b}$ y deducir de ella el valor del agua precipitable. En la figura 2.2.2.1.3.1, se representa la calibración final de la serie de constantes extraterrestres para el vapor de agua. Para ello, se usaron sondeos desde septiembre de 2004 hasta enero de 2009. El ajuste a la calibración final se hizo usando la técnica Least Absolute Residuals (LAR) de MATLAB basada en la minimización de los residuos absolutos asignando poco peso a los puntos más alejados del ajuste. Como puede verse, hay una pequeña degradación del filtro del canal $941 \mathrm{~nm}$ del equipo que se manifiesta por una ligerísima pendiente positiva en la recta de regresión. El ajuste es bastante bueno proporcionando un coeficiente de correlación al cuadrado mayor de 0.9. Teniendo en cuenta el papel crítico que juega la constante extraterrestre en la determinación del agua precipitable en la técnica radiométrica y la variabilidad propia del vapor de agua, es importante hacer notar que el ajuste también podría haberse realizado por tramos. Es decir, no considerar una única función lineal para todo el período considerado sino dividir este en intervalos más pequeños de manera que, para cada uno de ellos, tuviéramos una constante que serviría solamente en dicho intervalo. Este procedimiento suele seguirse cuando, a pesar de disponer de valores de calidad, ya filtrados para la constante extraterrestre, vemos que hay una variación significativa en la misma entre intervalos contiguos de la serie general. Este hecho puede deberse a contaminación local de la superficie del difusor del equipo, pequeños cambios en el offset de la señal, etc.

Nosotros, no obstante, y a la vista de la figura 2.2.2.1.3.1 hemos preferido, por sencillez, ajustar todo el período conjunto a una única función lineal dada la buena correlación obtenida y el método robusto de ajuste utilizado. 


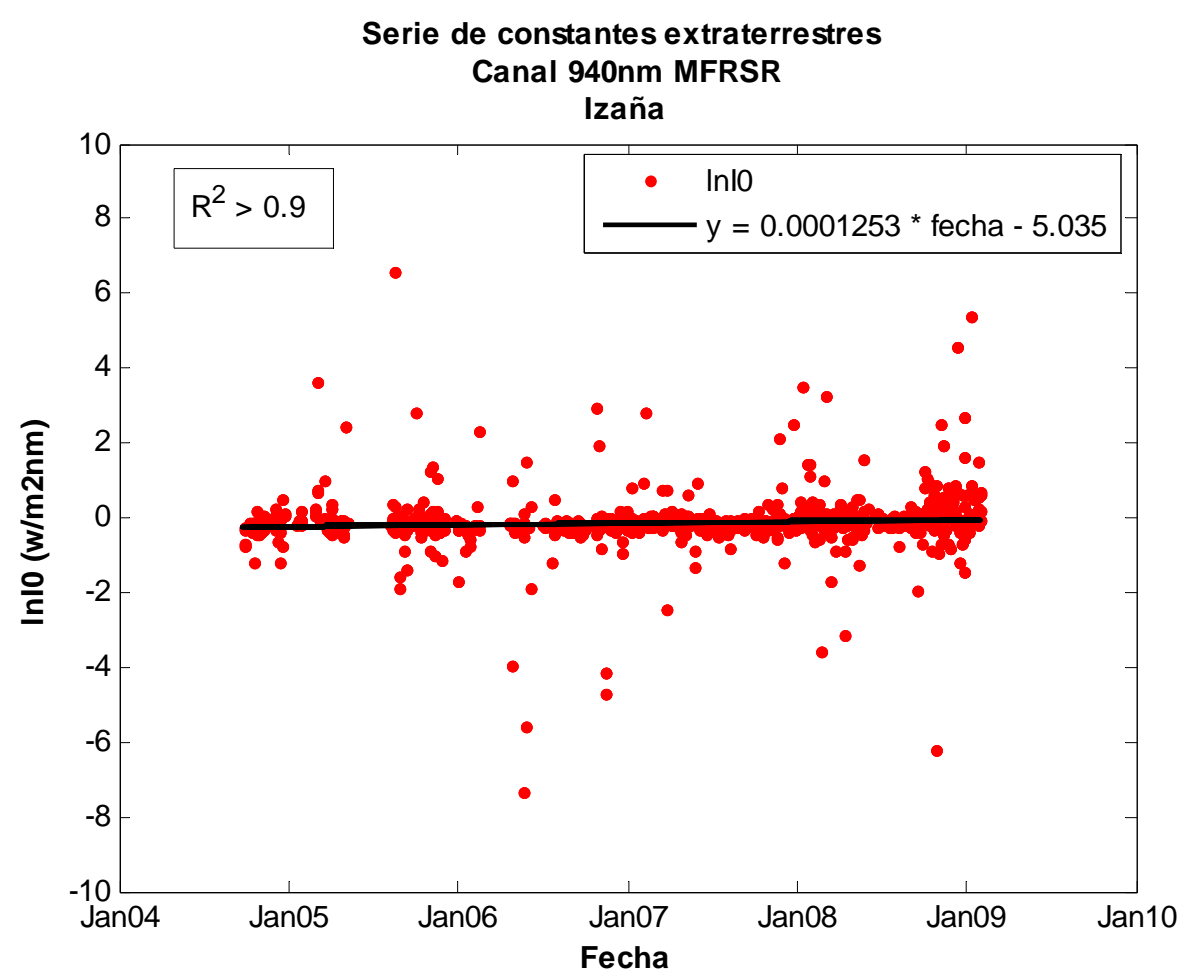

Figura 2.2.2.1.3.1. Ajuste mediante tendencia lineal de la serie de constantes extraterrestres para el vapor de agua. Canal 941nm MFRSR Izaña.

\subsection{Filtros de nubes}

Para que los resultados obtenidos empleando la técnica anterior sean buenos es necesario asegurar que los espesores ópticos del aerosol no están contaminados por ninguna otra fuente. Como sabemos, la nubosidad interfiere e influye en la extinción de radiación directa solar por lo que es imprescindible realizar un filtrado previo de datos afectados por nubosidad en el haz de radiación directa a fin de eliminar esta influencia. En la literatura científica hay varios procedimientos implementados de forma más o menos automatizada para realizar este filtrado.

Aquí se han usado dos procedimientos diferentes. Uno es el que usa AERONET para la evaluación de datos de los CIMEL y que viene esquematizado y explicado en su enlace de red, y el otro, es un criterio propio aplicado a la evaluación de datos MFRSR. Este último es el que describiremos aquí.

Nuestro criterio de filtrado de nubes se basa en calcular, para la mañana y la tarde, la máxima diferencia entre los neperianos de la radiación real medida y el ajuste langley-plot resultante tras una serie de iteraciones que han ido eliminando los puntos más alejados del mismo y que nos han permitido llegar a un coeficiente final de correlación al cuadrado superior o igual a 0.995 con un mínimo de 10 puntos. Para cada canal individual, consideramos como dato no afectado por nubes aquel cuya distancia al ajuste final correspondiente de la mañana o de la tarde es menor o igual que tres veces la distancia máxima a dicho ajuste de los puntos finales seleccionados. Puede darse el caso de que una medida simultánea para longitudes de onda distintas del MFRSR produzca resultados diferentes en cuanto al carácter nuboso o despejado del dato. Por esta razón, a cada dato medido en cada canal, le asociamos inicialmente una etiqueta individual donde se refleja el carácter provisional nuboso o despejado del mismo. Finalmente, el dato se tomará como despejado, si para ese instante, hay al menos tres 
canales en los que el dato correspondiente tiene etiqueta individual de dato despejado. En este caso, se redefine la etiqueta nubosa individual del dato correspondiente.

\subsubsection{Técnica Aerológica}

El agua precipitable se define como la masa total de vapor de agua por unidad de área en la columna atmosférica.

El sondeo PTU tradicional nos da, para cada nivel, el valor de la presión (P), la temperatura (T) y la humedad relativa (HR). Vamos a describir en esta sección cómo a partir de este perfil de datos podemos deducir la cantidad de agua precipitable en la columna total atmosférica.

Procederemos calculando el agua precipitable en cada estrato o capa del sondeo, y finalmente, integraremos o sumaremos para todos los niveles o capas.

La humedad relativa es una de las diversas formas que tenemos de expresar el contenido de vapor de agua que hay en la atmósfera. Pero, para ver mejor la relación entre agua precipitable y vapor de agua, partiremos del concepto de humedad específica. La humedad específica $q$ se define como la masa de vapor de agua contenida en la unidad de masa de aire húmedo. Matemáticamente, esto puede expresarse de la siguiente manera:

$$
q=\frac{m_{v a}}{m_{a h}}=\frac{m_{v a}}{m_{a s}+m_{v a}}=\frac{\frac{m_{v a}}{v}}{\frac{m_{a s}+m_{v a}}{v}}=\frac{\rho_{v a}}{\rho_{a s}+\rho_{v a}}=\frac{\rho_{v a}}{\rho_{a h}}
$$

donde $m_{v a}, m_{a s}$ y $m_{a h}$ son la masa del vapor de agua, la masa del aire seco y la masa del aire húmedo, respectivamente; $v$ es el volumen y $\rho_{v a}, \rho_{a s} \mathrm{y} \rho_{a h}$ son las densidades del vapor de agua, la densidad del aire seco y la densidad del aire húmedo, respectivamente.

Por la ecuación hidrostática sabemos que la presión $p$ varía con la altura de la siguiente manera:

$$
\Delta p=-\rho_{a h} g \Delta h \quad(2.2 .3 .2)
$$

donde $\Delta p=p_{0}-p_{s}$ y $\Delta h=h_{0}-h_{s}$ son los incrementos de presión y de altura relacionados con cada estrato. A la presión $p_{0}$ le corresponde la altura $h_{0} \mathrm{y}$ a la presión $p_{s}$ le corresponde la altura $h_{s}$. Como la presión y la altura varían de forma inversa, es decir, conforme aumenta la altura disminuye la presión, es claro que si $h_{s}$ es menor que $h_{0}$, entonces $p_{s}$ es mayor que $p_{0}$.

De (2.2.3.2) se deduce que:

$$
\rho_{a h}=-\frac{\Delta p}{g \Delta h}=\frac{p_{s}-p_{0}}{g \times\left(h_{0}-h_{s}\right)}
$$

sustituyendo (2.2.3.3) en (2.2.3.1), tenemos: 


$$
q=\frac{\rho_{v a} \times\left(h_{0}-h_{s}\right) \times g}{p_{s}-p_{0}}
$$

Si nos fijamos bien, la expresión $\rho_{v a} \times\left(h_{0}-h_{s}\right)$ no es otra cosa que la masa de vapor de agua por unidad de superficie en el estrato que estamos considerando, ya que, $\rho_{v a}$ es una densidad, es decir una masa por unidad de volumen, que al ser multiplicada por la altura del estrato, se transforma en una masa por unidad de superficie en la columna. Esto coincide con la definición dada al principio de esta sección para el agua precipitable. De manera que:

$$
u=\rho_{v a} \times\left(h_{0}-h_{s}\right)
$$

Entonces, ya estamos en condiciones de expresar la humedad específica $q$ en función de la cantidad de agua precipitable en la columna atmosférica.

$$
q=\frac{u \times g}{p_{s}-p_{0}}
$$

de donde:

$$
u=\frac{1}{g} \times q \times\left(p_{s}-p_{0}\right)
$$

o bien, en forma integral, sería:

$$
u=\frac{1}{g} \int_{p_{0}}^{p_{s}} q \times d p
$$

El siguiente paso sería obtener, de los datos del sondeo, la humedad específica y aplicar (2.2.3.7), o simplemente, la densidad del vapor de agua en cada estrato y aplicar (2.2.3.5). Finalmente, habría que sumar para todos los estratos o niveles del sondeo a fin de tener el agua precipitable en toda la columna atmosférica.

Como el sondeo nos proporciona el valor de la humedad relativa $H R$ y sabemos que esta se puede poner en función de la tensión del vapor de agua $e_{v a} \mathrm{y}$ la tensión saturante $E_{v a}(T)$ del vapor de agua a la temperatura $\mathrm{T}$ del estrato mediante la siguiente expresión:

$$
H R=100 \times \frac{e_{v a}}{E_{v a}(T)}
$$

de aquí, podemos despejar la tensión de vapor, quedando:

$$
e_{v a}=\frac{H R}{100} \times E_{v a}(T)
$$

y, aplicando la ley de experimental de Magnus para la tensión saturante tenemos que: 


$$
E_{v a}(T)=6.10 \times 10^{\frac{7.4475 \times t}{234.07+t}}
$$

En esta expresión, la temperatura $t$ se da en grados centígrados y la tensión saturante viene expresada en hPa. Sustituyendo (2.2.3.11) en (2.2.3.10), tendremos la tensión del vapor de agua en $\mathrm{hPa}$. Una vez conocida la tensión del vapor en el estrato, podemos calcular su densidad sin más que aplicar la ecuación de los gases ideales para el vapor de agua:

$$
\begin{gathered}
e_{v a} \times v=n \times R \times T=\frac{g r}{P m_{v a}} \times R \times T \\
e_{v a}=\frac{g r}{v} \times \frac{R}{P m_{v a}} \times T=\rho_{v a} \times R_{v a} \times T \\
\rho_{v a}=\frac{e_{v a}}{R_{v a} \times T}(2.2 .3 .14)
\end{gathered}
$$

aquí, $P m_{v a}$ es el peso molecular del vapor de agua y $R_{v a}$ es la constante universal de los gases referida al vapor de agua. Análogamente para el aire seco tendríamos que:

$$
\rho_{a s}=\frac{p-e_{v a}}{R_{a s} \times T}
$$

donde $p$ es la presión total o presión del aire húmedo y $R_{a s}$ es la constante universal de los gases para el aire seco (o sea, sin el vapor de agua). Esta última constante se determina a partir de la constante universal de los gases sin más que dividirla por el peso molecular del aire seco:

$$
R_{a s}=\frac{R}{P m_{a s}}
$$

Hay que tener presente que la aplicación de la fórmula (2.2.3.5) ó (2.2.3.7) requiere, respectivamente, un valor de densidad del vapor de agua o de humedad específica que sea constante en el estrato considerado, y es este valor, el que ha de multiplicarse por la diferencia de presiones en la parte inferior y superior del mismo. Para ello, lo que hacemos es tomar como valor característico o constante del estrato el valor medio entre los límites superior e inferior del mismo para la variable que estemos usando, ya sea el vapor de agua en la fórmula (2.2.3.5) o la humedad específica en la fórmula (2.2.3.7).

Para finalizar, habrá que sumar el agua precipitable que se ha calculado para cada intervalo o capa del sondeo y así obtener el valor deseado representativo de toda la columna atmosférica sobre el lugar. 


\subsubsection{Técnica FTIR}

La ecuación básica para el análisis FTIR del espectro de absorción solar no es otra que la ley de Lambert-Beer:

$$
I(\lambda)=I_{\text {sun }}(\lambda) \times \exp \left(-\int \sigma_{x}(\lambda, s(T, p)) x(s) d s\right)
$$

Aquí $I(\lambda)$ es la intensidad medida a la longitud de onda $\lambda, I_{\text {sun }}(\lambda)$ es la intensidad solar, $\sigma_{x}(\lambda, s)$ es la sección transversal de absorción y $x(s)$ es la concentración del absorbente $x$ en la posición $s$. La integración se realiza a lo largo de todo el camino que el haz solar directo recorre en la atmósfera. La técnica FTIR consiste en simular un espectro teórico análogo al de la expresión (2.2.4.1) usando modelos de transferencia radiativa línea a línea muy precisos. Asume un perfil atmosférico compuesto por diferentes capas situadas a distintos niveles o altitudes y va realizando la integral del segundo miembro de la ecuación (2.2.4.1) en cada capa y para cada absorbente. De esta manera, se obtiene una relación simple entre el espectro de absorción solar $\vec{y}$ y la distribución vertical del absorbente $\vec{x}(z)$ que podemos expresar de la siguiente forma:

$$
\vec{y}=\vec{F}(\vec{x}) \quad(2.2 .4 .2)
$$

$\vec{F}$ es una función vectorial que simula la transferencia radiativa atmosférica y las características del sistema de medida (resolución espectral, forma de la línea instrumental, etc.). Los cambios producidos en los flujos espectrales $\vec{y}$, como consecuencia de los cambios en la distribución vertical del absorbente $\vec{x}$, vienen dados por las derivadas parciales de $\vec{y}$ con respecto a $\vec{x}$, es decir, por la matriz Jacobiana:

$$
\partial \vec{y}=K \partial \vec{x}
$$

Invirtiendo $K$ en la ecuación (2.2.4.3) podemos obtener $\vec{x}$. Por razones de no linealidad hay que hacerlo iterativamente para aproximarnos a la solución real. Pero la solución no está unívocamente determinada porque las columnas del Jacobiano no son linealmente independientes y puede haber muchas soluciones en buen acuerdo con las medidas y aparentemente aceptables. Sin embargo, se tomará como estimación óptima o solución, la distribución más probable de los absorbentes para una cierta medida, y vendrá dada, por el valor máximo de la función densidad de probabilidad condicional que se obtiene como producto de dos: una primera que describe la estadística de la diferencias entre los espectros simulado y medido o real (es lo que se conoce como matriz de las covariancias del ruido de la medida) y, una segunda, que describe las probabilidades conocidas a priori de la distribución de absorbentes tomada del modelo. Este método se llama “optical estimation". Para más detalles, consultar Rodgers, 2000, y para su aplicación específica, en el caso del vapor de agua, consultar Schneider and Hase, 2009. 


\section{Comparación entre las diferentes técnicas. Resultados}

La comparación entre los valores de agua precipitable de los distintos equipos se ha hecho para los diferentes períodos comunes resultantes del cruce de los datos de cada pareja de instrumentos. De los cinco equipos usados, el SONDEO es el más antiguo de todos disponiendo de una serie de medidas desde el año 1995. Pero fue desde junio de 2005 cuando se cambió la sonda Vaisala RS-80 por la RS-92. Dadas las ventajas y mejoras que aporta esta última, el período de comparación con el SONDEO se elegirá, pues, a partir de esta fecha. Del radiómetro MFRSR, tenemos medidas desde 1996 pero el equipo sufrió un cambio de sensor y filtros en septiembre de 2004, de manera que, el período para la comparación con él, se tomará a partir de aquí. El espectrómetro FTIR, mide en Izaña desde 1999, pero en 2005 se renueva totalmente, cambiándose por otro más estable y con otro sensor, así que tomaremos esta fecha como inicio de la comparación. Por otro lado, usaremos para el fotómetro CIMEL los datos de agua precipitable obtenidos por AERONET en los ficheros de nivel 2. Estos ficheros contienen datos de espesores ópticos a diferentes longitudes de onda y también otras variables de interés como el agua precipitable. En ellos, los datos han sido inspeccionados visualmente y convenientemente depurados, aplicándoles la calibración correspondiente, según el canal. Además, los datos que figuran en ellos, no están afectados por nubes, es decir, están filtrados de nubes mediante un algoritmo automático que es descrito dentro de la página de información de AERONET. La red AERONET asegura la calidad de dichos datos y pueden bajarse libremente desde su página web. Para Izaña, disponemos de datos de nivel 2 del CIMEL desde finales de 2003 hasta finales de 2007. No obstante, y dado que el equipo GNSS es la última adquisición de todos los equipos evaluados aquí, y su puesta en operación data de julio de 2008, la comparación entre GNSS y CIMEL tendremos que hacerla con los datos CIMEL de nivel 1.5. Estos datos están filtrados por nubes pero pueden no tener una calibración aplicada y AERONET no garantiza la calidad de los mismos. Aún así, mostraremos que la diferencia entre el agua precipitable obtenida a partir de datos de nivel 1.5 y 2.0, para el período común entre ambos niveles, produce prácticamente idénticos resultados.

El criterio seguido a la hora de cruzar los datos de los distintos instrumentos ha sido el de comparar medias horarias en períodos comunes. Se ha hecho por dos razones básicas; la primera, porque cada técnica emplea un tiempo diferente en tomar una medida, y cada equipo tiene una referencia de tiempo que puede no coincidir exactamente con la de los demás, por lo que podrían producirse pequeños desfases en las medidas simultáneas entre los diferentes equipos. La segunda razón es porque, con medias horarias, se estabiliza mucho más la señal que con medidas instantáneas y se minimiza el ruido. El período escogido de una hora es una buena solución de compromiso para la gran variabilidad espacio-temporal del vapor de agua. En el caso del sondeo, se calcula la hora en la que éste rebasa el nivel de Izaña y el agua precipitable medida entonces es la que se usa como valor de comparación con otras técnicas.

El análisis se hará representando el agua obtenida de un equipo frente a la obtenida con el otro. Usando MATLAB, ajustaremos la representación a una regresión lineal simple que pase por el origen mediante el método de mínimos cuadrados. Previamente al ajuste, aplicaremos un filtro a los datos de ambos equipos descartando aquellos valores no creíbles porque sean excesivamente altos o por no tener sentido físico (valores negativos). Con objeto de delimitar qué rango de variación real tiene el agua precipitable en la columna sobre Izaña y descartar así los valores que caigan fuera de dicho rango, hemos representado las series en el tiempo de agua precipitable en 
columna obtenidas con cuatro de las cinco técnicas. De la figura 3.1 se desprende que podemos elegir de forma bastante razonable como rango de variación real del agua precipitable en columna sobre Izaña el intervalo comprendido entre $(0,25] \mathrm{mm}$.
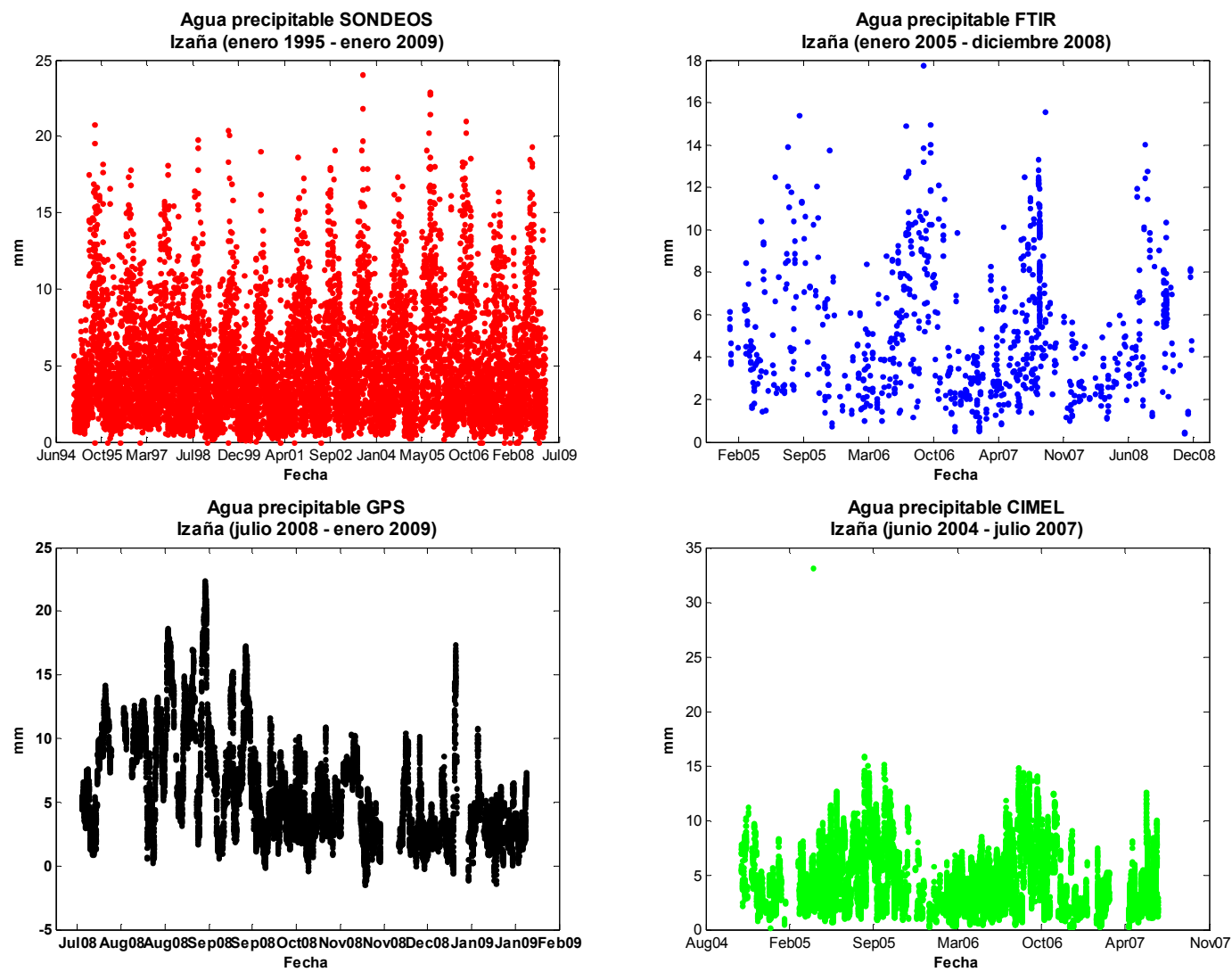

Figura 3.1. Agua precipitable en columna sobre el OAI medida por diferentes técnicas

Una vez filtrados los datos y realizados los ajustes correspondientes entre cada par de técnicas, calcularemos, como estimación del error en cada ajuste, la desviación media respecto del mismo mediante la siguiente expresión:

$$
\text { Eajuste }=\sqrt{\frac{\sum\left(H 2 O_{\text {equipoY }}-A \times H 2 O_{\text {equipoX }}\right)^{2}}{N-2}}
$$

donde $H 2 O_{\text {equipoX }}$ es el agua precipitable medida por el equipo que se representa en el eje de abscisas, $H 2 O_{\text {equipoY }}$ es el agua precipitable medida por el equipo que se representa en el eje de ordenadas, $A$ es la pendiente de la recta de ajuste y $N$ es el número de datos que se han comparado entre ambos instrumentos. Por otro lado, también nos ha parecido conveniente calcular el error o diferencia relativa porcentual entre las medidas en cada pareja de equipos. El valor de la media o de la mediana de este error, podrá servir, dependiendo de cada caso, como índice para valorar en qué proporción se separan las medidas de agua obtenidas por ambos instrumentos. La fórmula empleada para el cálculo del error relativo porcentual es la tradicional:

$$
\text { Erelativo }=100 \times \frac{H 2 O_{\text {equipo }}-H 2 O_{\text {equipo } X}}{H 2 O_{\text {equipoX }}}
$$


Los resultados son los que se muestran en las siguientes figuras que comentaremos seguidamente.

\subsection{MFRSR frente a GNSS}

MFRSR versus GNSS

Izaña (julio 2008 - enero 2009)

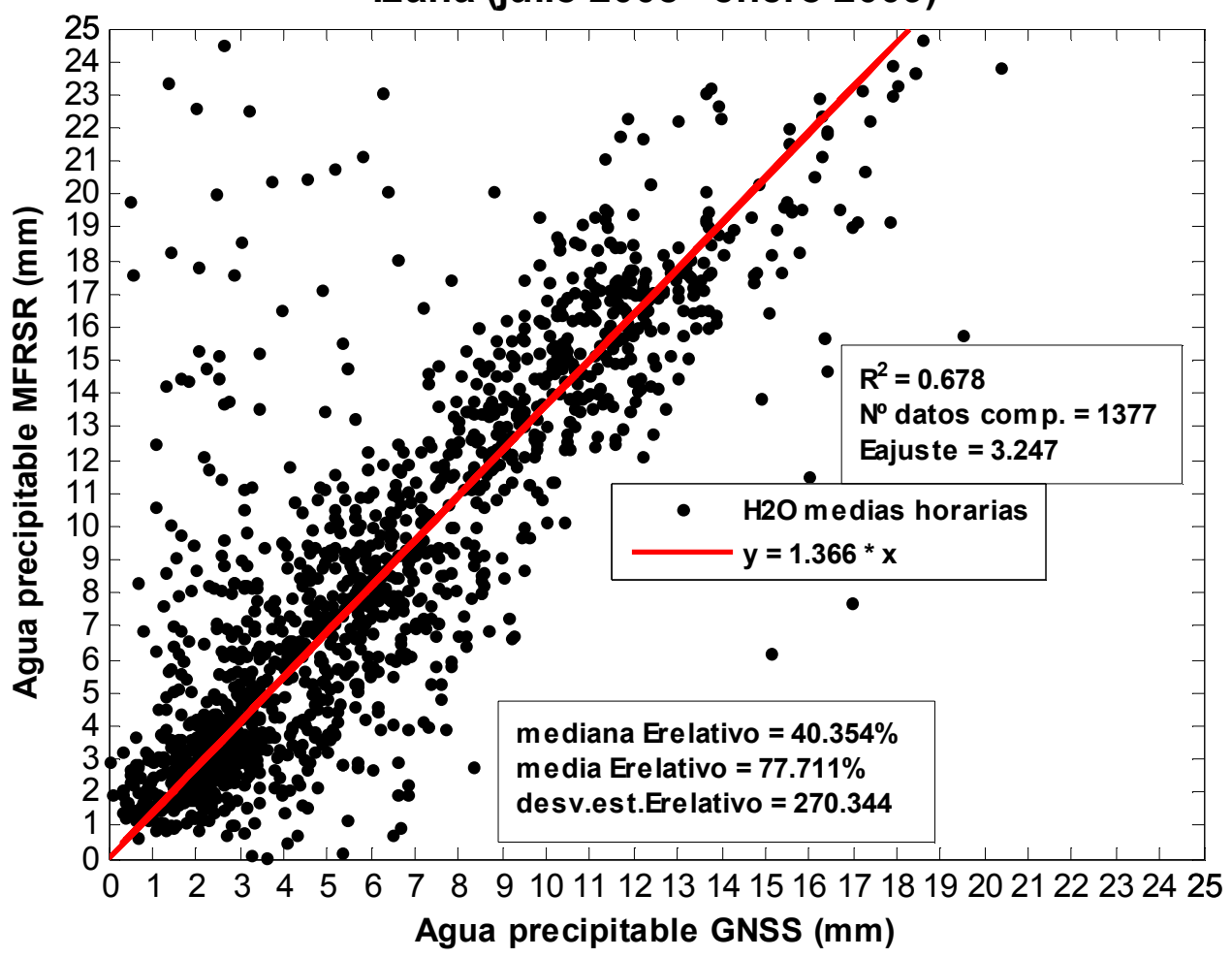

Figura 3.1.1. Comparación MFRSR-GNSS

En esta primera comparación, resulta que, del total de los 1997 valores cruzados existentes entre ambos equipos, hay que prescindir, por estar fuera de rango, de 17 obtenidos mediante la técnica GNSS y de 75 obtenidos mediante la técnica MFRSR. A estos hay que añadirles 528 datos más que el filtro de depuración de nubes del MFRSR rechaza por considerarlos afectados por estas. En total, nos quedan 1377 datos comparables. Como podemos ver, la correlación no es muy buena y los valores medidos por una y otra técnica difieren considerablemente. La mediana del error relativo se estima en un $40 \%$, aproximadamente, lo que significa que el radiómetro MFRSR mide, por lo general, casi la mitad más de agua que lo que mide la técnica GNSS. Hay valores que se alejan bastante del ajuste. Estos resultados creemos que son debidos, en parte, a que el filtro usado para la catalogación del dato radiométrico como dato despejado o afectado por nubes, no ha funcionado correctamente en todos los casos. Se ha podido dar por buenos datos que no corresponden a medidas hechas sin nubes, o bien, son medidas que teniendo un error excesivo, escapan a los criterios del filtro. Este error excesivo puede ser también debido a la recta de calibración elegida para el canal de vapor de agua del MFRSR. El valor del agua precipitable es muy sensible al valor de calibración y pequeñas variaciones de este podrían dar lugar a grandes variaciones en el valor del agua precipitable obtenida. Es posible que pudieran mejorarse estos resultados 
eligiendo, en vez de una única recta de calibración para todo el período, varias rectas de calibración para cortos períodos consecutivos de tiempo.

\subsection{CIMEL frente a GNSS}

CIMEL versus GNSS

Izaña (octubre 2008 - enero 2009)

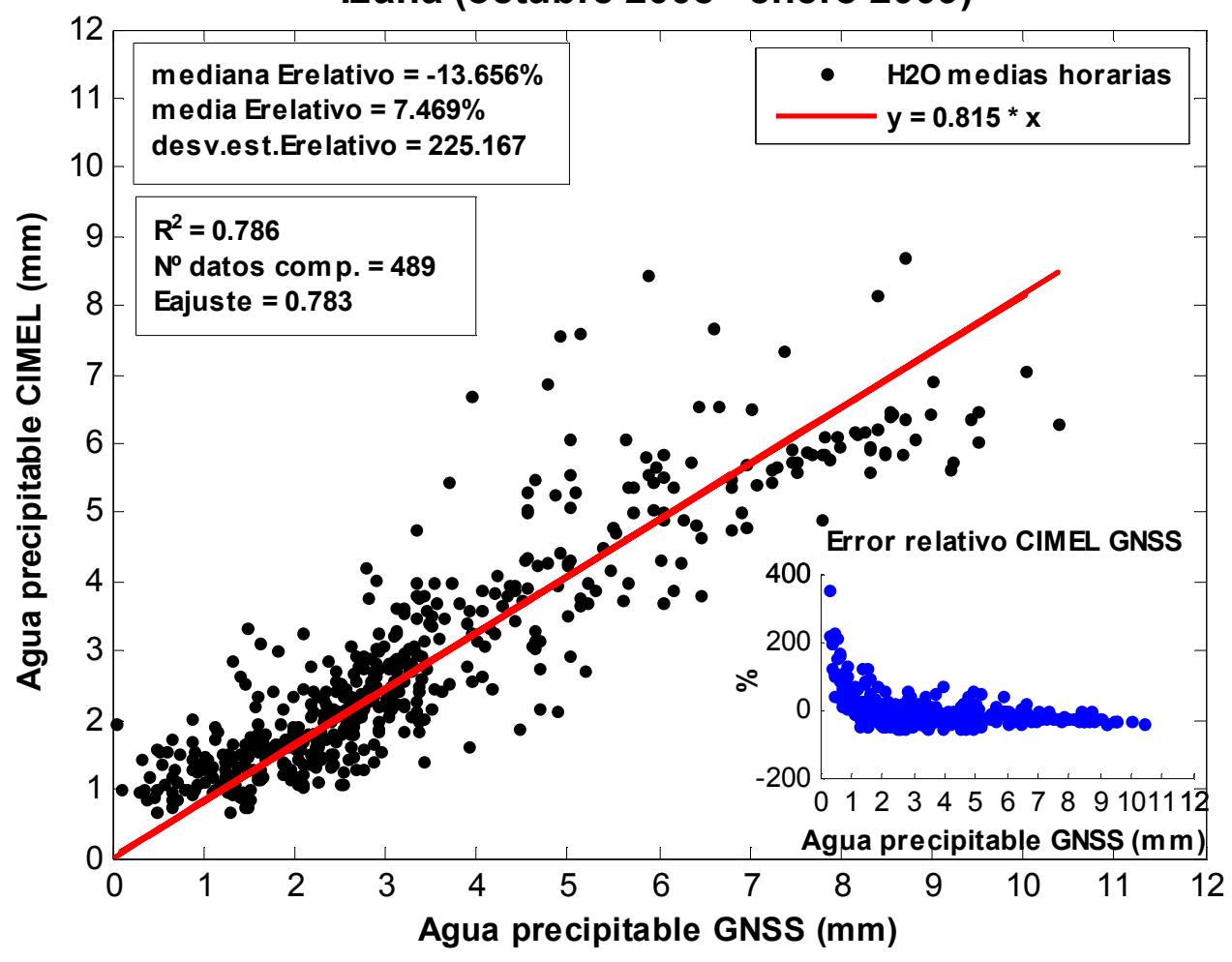

Figura 3.2.1. Comparación CIMEL-GNSS

Las medidas entre una y otra técnica correlacionan algo mejor que en el caso anterior aunque también se observa bastante dispersión en las mismas; la ventaja es, que ahora, la magnitud de la mediana del error relativo entre ambas se reduce al $-14 \%$, aproximadamente. Si observamos el gráfico del error relativo frente a la cantidad de agua precipitable (gráfica de puntos azules), vemos que la dispersión parece acentuarse positivamente en valores por debajo de los 2-3mm. Por otro lado, de los 501 datos cruzados entre ambos equipos hemos de descartar 12 de la técnica GNSS por ser negativos. Dichos valores negativos se corresponden con valores de agua CIMEL por debajo de $1.2 \mathrm{~mm}$. Todo esto nos indica que, en atmósferas secas, la técnica GNSS tiende a infravalorar la medida, y en las que son extremadamente secas, esta técnica es incapaz de detectar la escasa medida de agua en columna dando valores negativos. Por esta razón, se dispara positivamente el error entre ambos equipos al ser el valor del agua GNSS más baja de lo que debiera. Este hecho es importante tenerlo en cuenta al valorar los resultados y como sugerencia en investigaciones futuras para mejorar la calidad de los mismos.

Como se comentó anteriormente, los datos que figuran en esta comparación son los de nivel 1.5 del CIMEL. Para ver cuál es la diferencia con los datos de nivel 2.0, lo que hacemos, es una representación gráfica simple de uno frente al otro. Esta representación es la de la figura 3.2.2. 
Exceptuando cuatro valores de agua precipitable, el resto coinciden totalmente en ambos niveles. Como en esta comparación se han usado 412 valores, la discordancia representa tan sólo un $0.97 \%$ del total. Para visualizar mejor de qué valores se trata, se han hecho zooms en las zonas de la regresión lineal donde se localizan. La diferencia entre los datos discordantes es inferior al $8 \%$.

\section{Comparación datos CIMEL nivel 1.5 y CIMEL nivel 2.0} Izaña (enero 2005 - julio 2007)

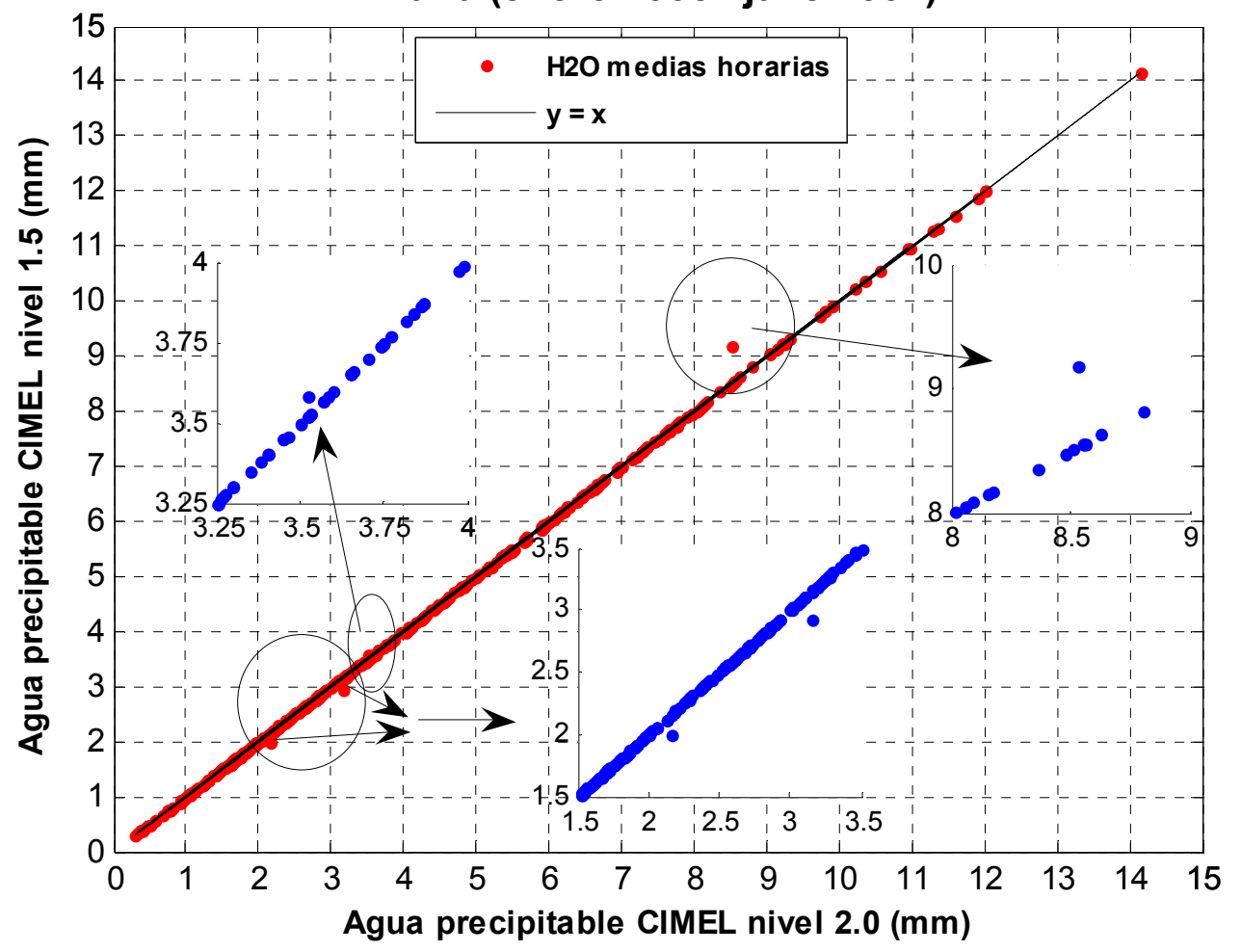

Figura 3.2.2. Comparación datos CIMEL

Por lo tanto, concluimos que la diferencia entre valores de agua precipitable correspondientes a los niveles 1.5 y 2.0 del CIMEL, es completamente despreciable y es indiferente usar uno u otro nivel a efectos de estas comparaciones.

\subsection{SONDEOS frente a GNSS}

Dado que sólo se lanzan dos sondeos diarios (a las 00:00 GMT y a las 12:00 GMT), únicamente podremos comparar como máximo dos datos diarios de agua precipitable mediante esta técnica. Esto, unido al corto período de operación del equipo GNSS, hace que el cruce de datos entre ambos equipos sólo produzca 321 parejas de datos. De estos, tenemos que descartar 2 del GNSS por ser negativos y 1 de los sondeos por ser 0. Por tanto, son 318 los datos comparables. Los sondeos se han venido lanzando tradicionalmente desde Santa Cruz de Tenerife, pero a partir del 2005, se lanzan desde Güímar. En cualquier caso, la medida de agua precipitable se obtiene del sondeo a partir de cuando este rebasa el nivel de Izaña. Es importante señalar que la duración estimada de un sondeo suele ser de una hora, aproximadamente, desde que se rebasa el nivel de Izaña hasta que llega a la tropopausa, y que el perfil que se va obteniendo de las variables de interés ( $\mathrm{P}, \mathrm{T}, \mathrm{HR})$ se considera que se mantiene constante mientras dure el mismo. Esto rigurosamente no es cierto ya que el sondeo, a diferencia 
del equipo GNSS o de los radiómetros, no es una medida instantánea. Sin embargo, y a pesar de estos inconvenientes, los resultados de la comparación de la técnica del sondeo con la técnica GNSS son excelentes, como puede apreciarse en la figura 3.3.1. La correlación es muy buena y el error en el ajuste es del orden del 1\%. Entre las medidas de ambos equipos existe una mediana del error relativo porcentual de $-3 \%$. Esto, en un principio, nos indica que, en general, el sondeo mide un $3 \%$ menos agua precipitable que el equipo GNSS. Sin embargo, hay que tener en cuenta, observando la gráfica del error relativo SONDEOS GNSS (gráfica de puntos azules), que cuando la cantidad de agua en columna es muy pequeña, el error relativo se dispara positivamente. Esto, unido a que la técnica GNSS ofrece algunos valores negativos, nos hace pensar, como dijimos en la comparación anterior, que esta última tiende a infravalorar la medida del agua en atmósferas secas. En general, por debajo de 2-3mm, aumenta de forma considerable el error cometido entre ambas técnicas haciéndose muy grande en condiciones de extrema sequedad.

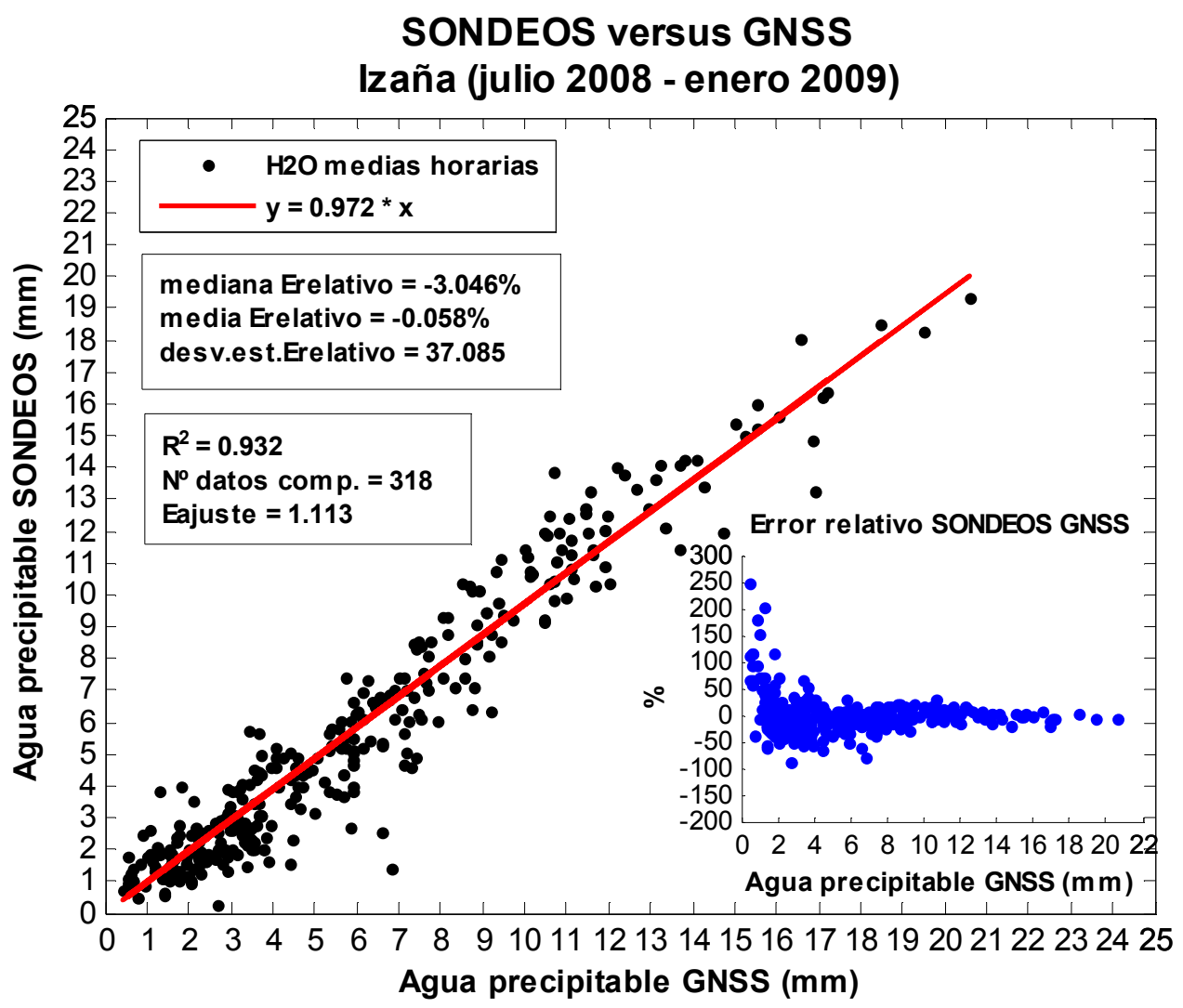

Figura 3.3.1. Comparación SONDEOS-GNSS

Para interpretar correctamente estos resultados, es necesario ver primero cómo son las medidas GNSS cuando se compara con el espectro-radiómetro de infrarrojos por transformadas de Fourier (FTIR) y valorar, conjuntamente, todas las comparaciones.

\subsection{FTIR frente a GNSS}

Disponemos de 59 medidas cruzadas, ya que el FTIR, es un equipo que mide manualmente, sólo en días despejados y cuando las condiciones de operatividad del personal del observatorio lo permiten. De estos 59 datos, hubo que descartar 2 del GNSS porque eran valores negativos. Esto ocurría para valores de agua FTIR de 
$0.41 \mathrm{~mm}$ y $0.45 \mathrm{~mm}$. De nuevo volvemos a constatar que, en atmósferas muy secas (por debajo de $1 \mathrm{~mm}$ de agua precipitable, aproximadamente) la técnica GNSS no es capaz de detectar tan poca agua. En cambio, el FTIR no presenta valores negativos del agua precipitable aún en condiciones de extrema sequedad.

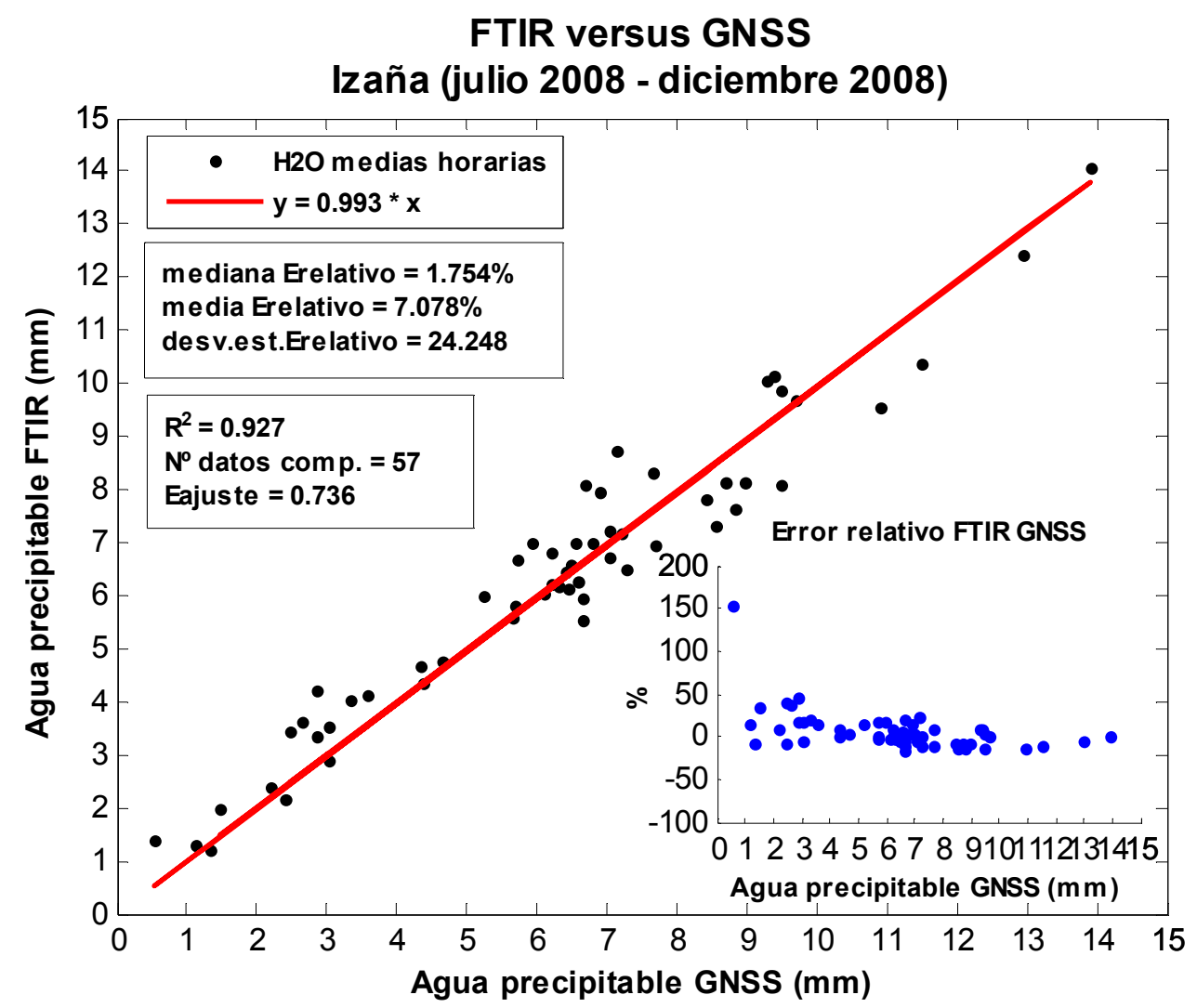

Figura 3.4.1. Comparación FTIR-GNSS

Como vemos en la gráfica azul, el error relativo se acrecienta significativamente y se dispersa cuando hay menos de $3 \mathrm{~mm}$ de agua precipitable en la columna atmosférica sobre Izaña, de manera que este valor $(3 \mathrm{~mm})$ podría marcar el umbral por debajo del cual ya la medida GNSS empieza a infravalorarse. Por otro lado, y como se observa en la parte principal de la figura 3.4.1, el ajuste, en general, es muy bueno y la mediana del error relativo porcentual entre ambas medidas está por debajo del $2 \%$; es decir, FTIR y GNSS miden de forma comparable.

Finalmente, decir que, entre 7 y $8 \mathrm{~mm}$, parece verse una especie de zona de transición a partir de la cual se invierte la situación, y es el FTIR, el que mide menos agua que la técnica GNSS.

\subsection{MFRSR frente a FTIR}

De los 705 datos cruzados entre el radiómetro y el FTIR tuvimos que rechazar 26 datos del MFRSR por estar fuera de rango y otros 55 más por ser considerados como afectados por nubes, quedándonos con 624 datos comparables. Análogamente a lo que ocurría con la técnica GNSS, el radiómetro MFRSR tiende a medir aproximadamente un 50\% más de agua precipitable que lo que se obtiene con el FTIR.

En la figura 3.5.1 representamos los parámetros del ajuste y la gráfica de la comparación. 
En este caso, vemos que el ajuste entre MFRSR y FTIR presenta poca dispersión y una buena correlación, mejor que con el GNSS. Creemos que esto es debido al hecho de que, al comparar con FTIR, aseguramos que los datos corresponden a días completamente despejados con lo que los eventuales posibles fallos del filtro de nubes del MFRSR son nulos o despreciables. Los datos alejados del ajuste, serán debidos, exclusivamente, a efectos de la calibración o a la mala calidad de algunos de ellos.

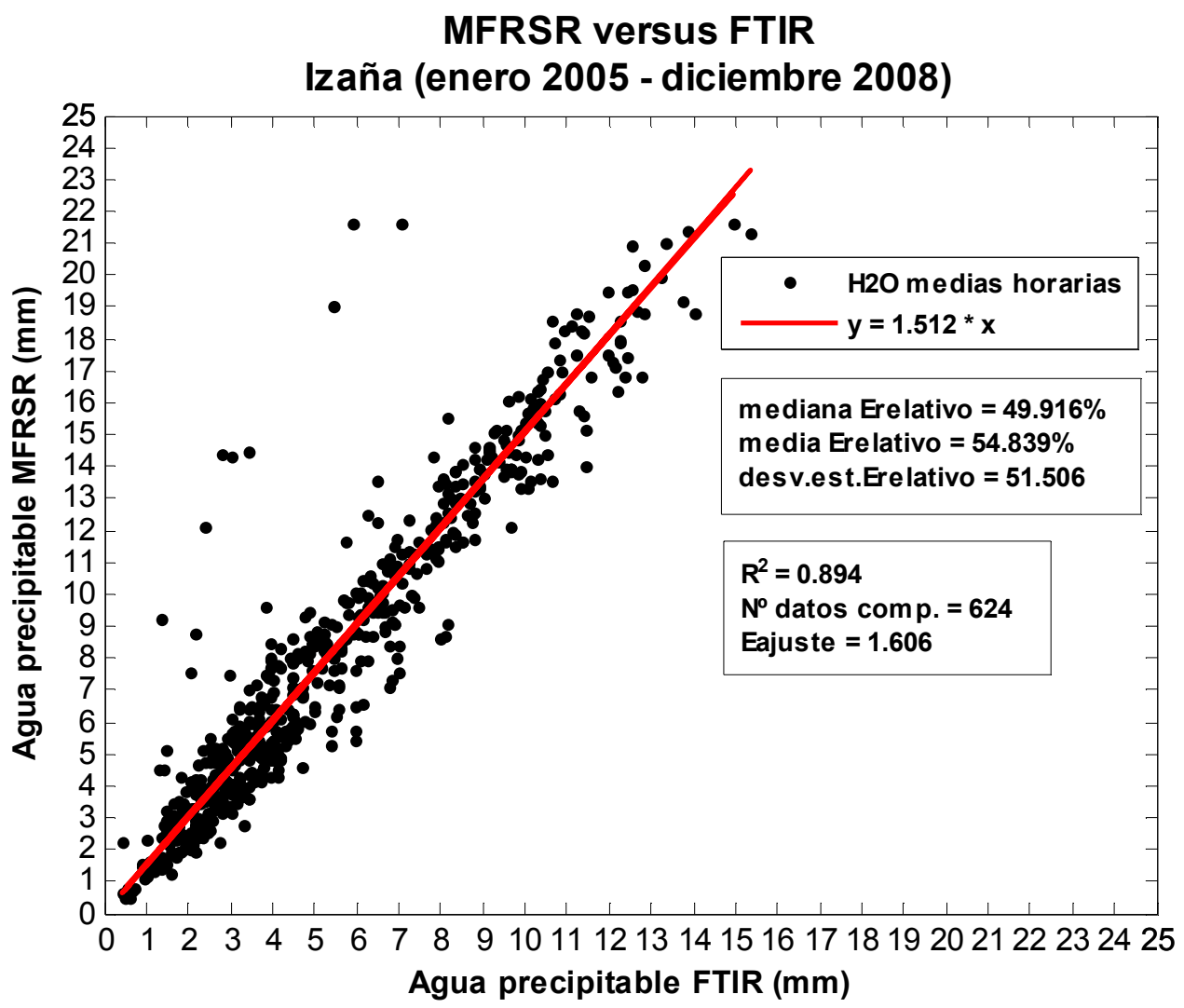

Figura 3.5.1. Comparación MFRSR-FTIR.

\subsection{SONDEOS frente a FTIR}

Aunque el período de comparación entre estas dos técnicas es similar al anterior, sólo 97 parejas de valores son comparables (el 100\% de los datos cruzados) debido, sobre todo y como ya se comentó, a la poca disponibilidad de sondeos diarios y al hecho de que el FTIR sólo mide en días completamente despejados. En la figura 3.6.1 podemos ver cómo el error en el ajuste es del orden del $0.6 \%$, lo que indica gran coherencia y estabilidad entre ambas medidas; sin embargo, en lo que a la magnitud se refiere, la mediana del error relativo porcentual entre las mismas es, aproximadamente del orden de $-14 \%$. Como se aprecia en la gráfica de relación del error con la cantidad de agua, es precisamente por debajo de los $3 \mathrm{~mm}$, cuando se dispersa y aumenta este error haciéndolo negativamente, lo que indica que, en este caso, es el sondeo el que está infravalorando la medida. En cambio, en la comparación SONDEO con GNSS y en la comparación FTIR con GNSS, el error se dispersa y aumenta positivamente por debajo de $3 \mathrm{~mm}$, lo que nos indica que, la técnica GNSS, infravalora con respecto al sondeo y con respecto al FTIR, mientras que el sondeo, lo hace con respecto al FTIR. 


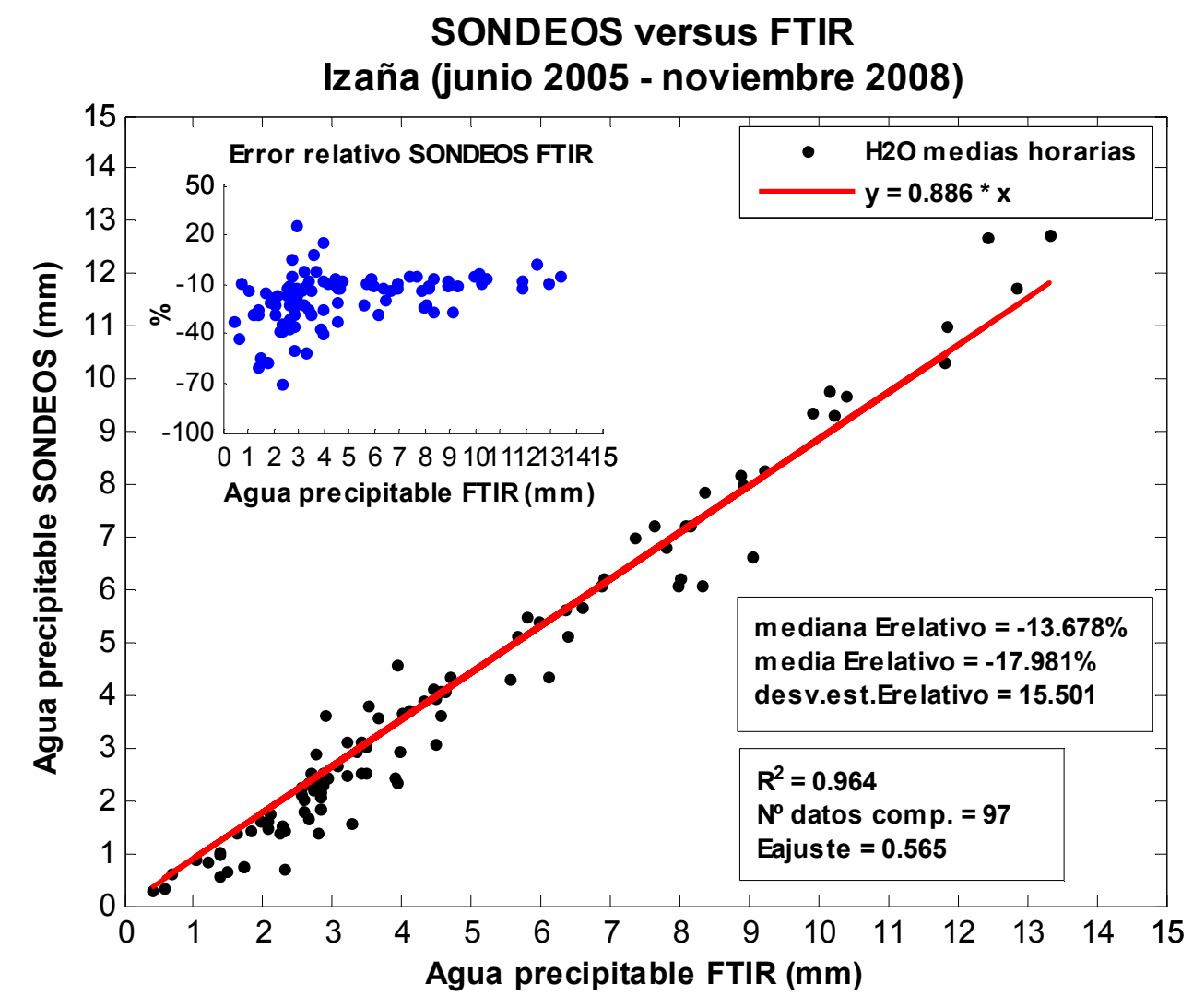

Figura 3.6.1. Comparación SONDEOS-FTIR.

\subsection{CIMEL frente a FTIR}

CIMEL versus FTIR

Izaña (enero 2005 - julio 2007)

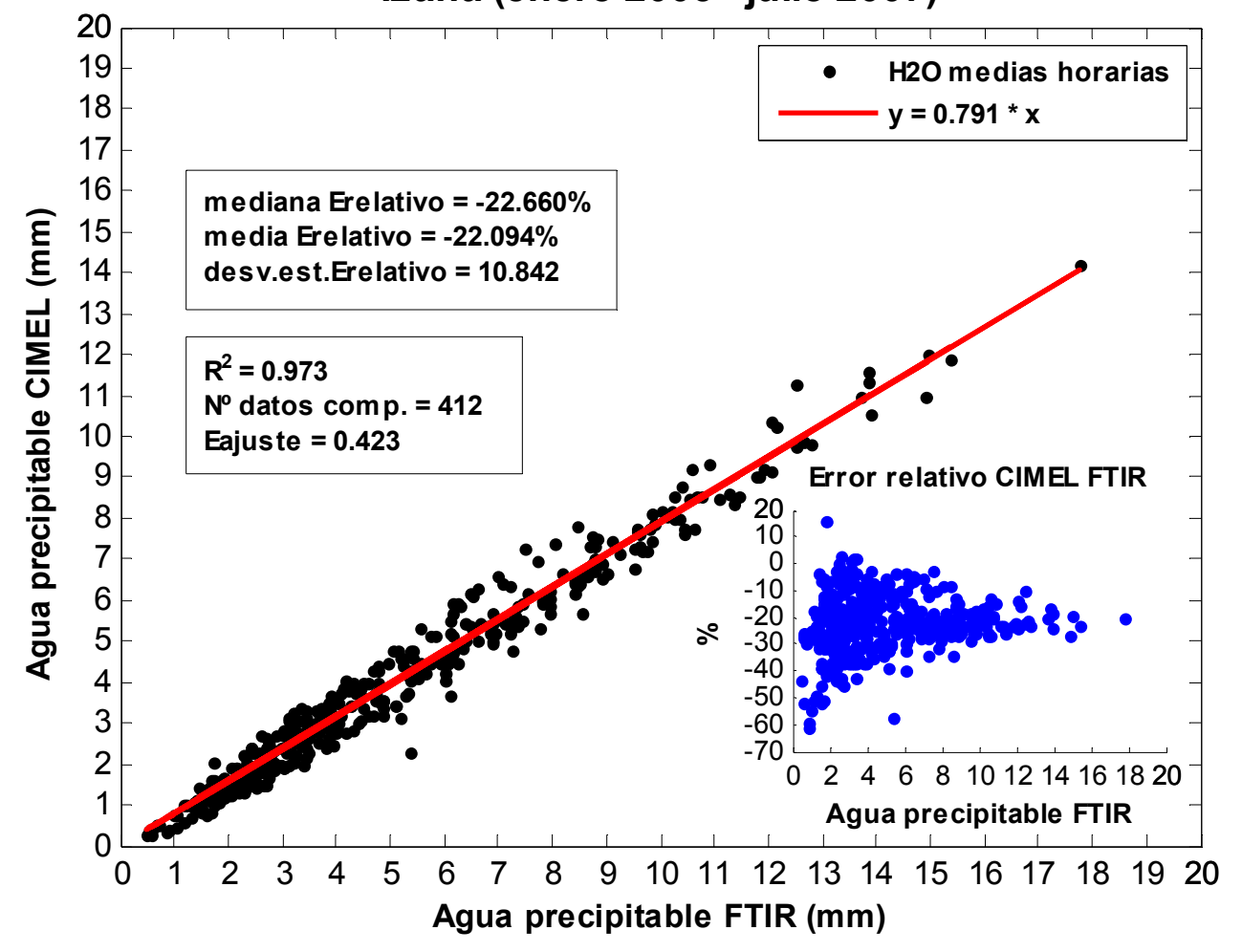

Figura 3.7.1. Comparación CIMEL-FTIR. 
Los excelentes resultados que pueden observarse de la figura anterior en la comparación del fotómetro solar CIMEL con respecto al FTIR, nos permiten concluir dos cosas: la primera, que el filtro AERONET usado para depurar automáticamente nubes, combinado con la inspección y depuración visual de los ficheros, produce mejores resultados que la simple aplicación automática del filtro de depuración de nubes usado para el MFRSR. La segunda, es que la técnica radiométrica aplicada al CIMEL, que es un equipo que mide directamente la radiación solar directa, produce mejores resultados que los que se producen cuando la radiación directa es obtenida de forma indirecta como ocurre con el radiómetro MFRSR. En efecto, recordemos que este equipo mide directamente la radiación solar global, luego mide directamente la difusa interponiendo la banda entre el Sol y el sensor, corrige esta última medida debido al exceso de zona sombreada por la banda, y luego, obtiene la radiación solar directa restando analíticamente la global y la difusa corregida. Es evidente que la obtención de la radiación solar directa por este procedimiento no puede ser tan exacta como la que medimos directamente a través de un fotómetro de gran precisión como el CIMEL.

Observando los parámetros del ajuste y los valores de los errores expresados en la comparación de la figura 3.7.1 entre CIMEL y FTIR deducimos que la estabilidad y coherencia entre ambas medidas es realmente buena (por debajo del $0.5 \%$ ) y que el CIMEL mide del orden de un 23\% menos cantidad de agua precipitable que el FTIR. También el CIMEL tiende a medir menos agua de lo esperado en atmósferas secas, ya que, el error, aumenta negativamente y bruscamente por debajo de los $3 \mathrm{~mm}$. de agua precipitable. Para la comparación se han usado el $100 \%$ de los datos cruzados.

\subsection{MFRSR frente a CIMEL}

\section{MFRSR versus CIMEL}

Izaña (septiembre 2004 - julio 2007)

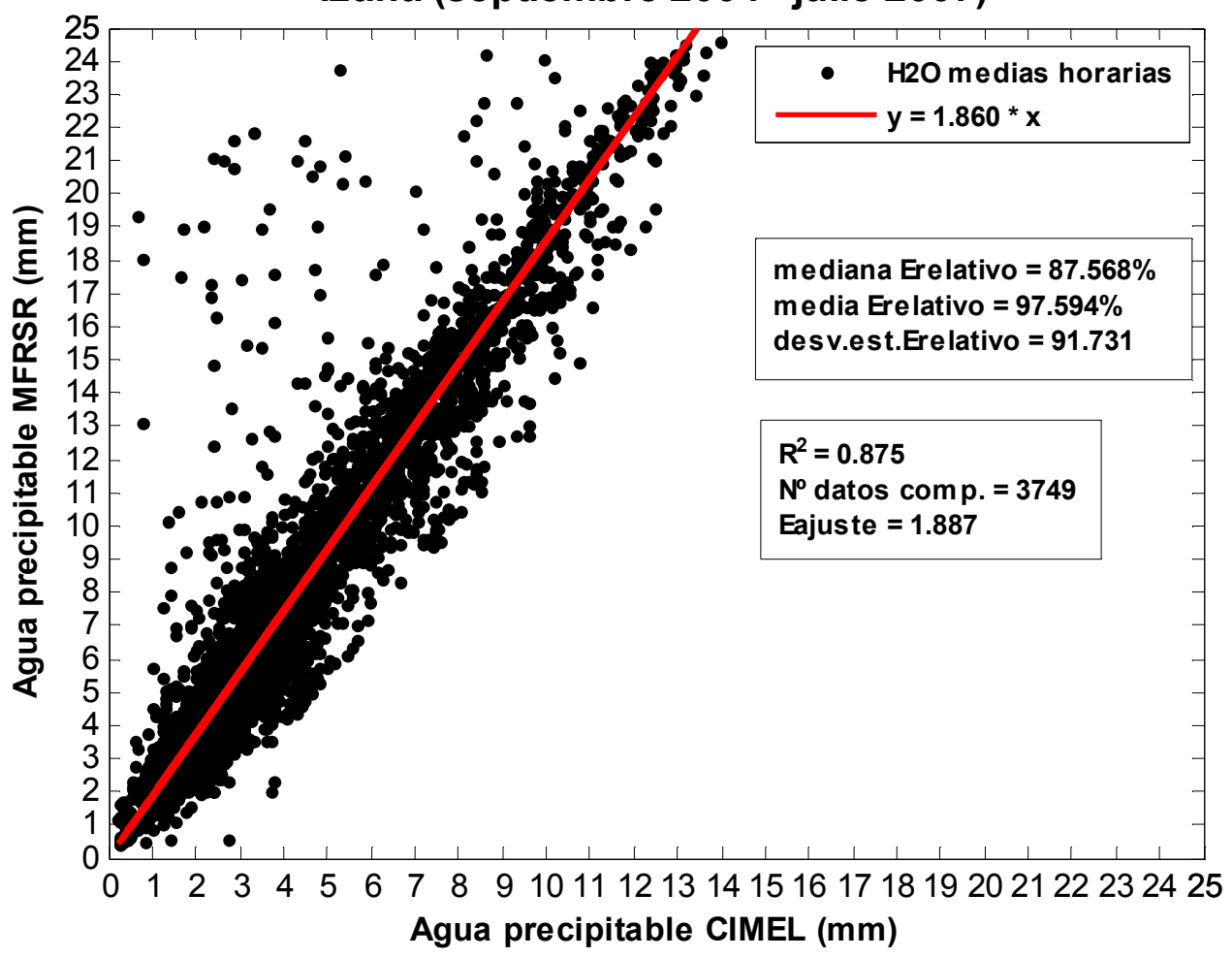

Figura 3.8.1. Comparación MFRSR-CIMEL. 
En este caso, tenemos un total de 5038 datos cruzados, pero hubo que rechazar 1161 porque eran considerados nubosos por alguno de los dos equipos más 128 del MFRSR por estar fuera de rango; quedaron 3749 parejas de datos para comparar. Aún así, es un elevado número de datos comparables y ello es debido, por un lado, a que el período de comparación es de casi tres años y por otro, a que, del MFRSR, tenemos medidas cada minuto, y del CIMEL, cada 15 minutos. Como puede apreciarse de la figura 3.8.1, el radiómetro MFRSR mide casi el doble de agua precipitable que el CIMEL.

\subsection{SONDEOS frente a CIMEL}

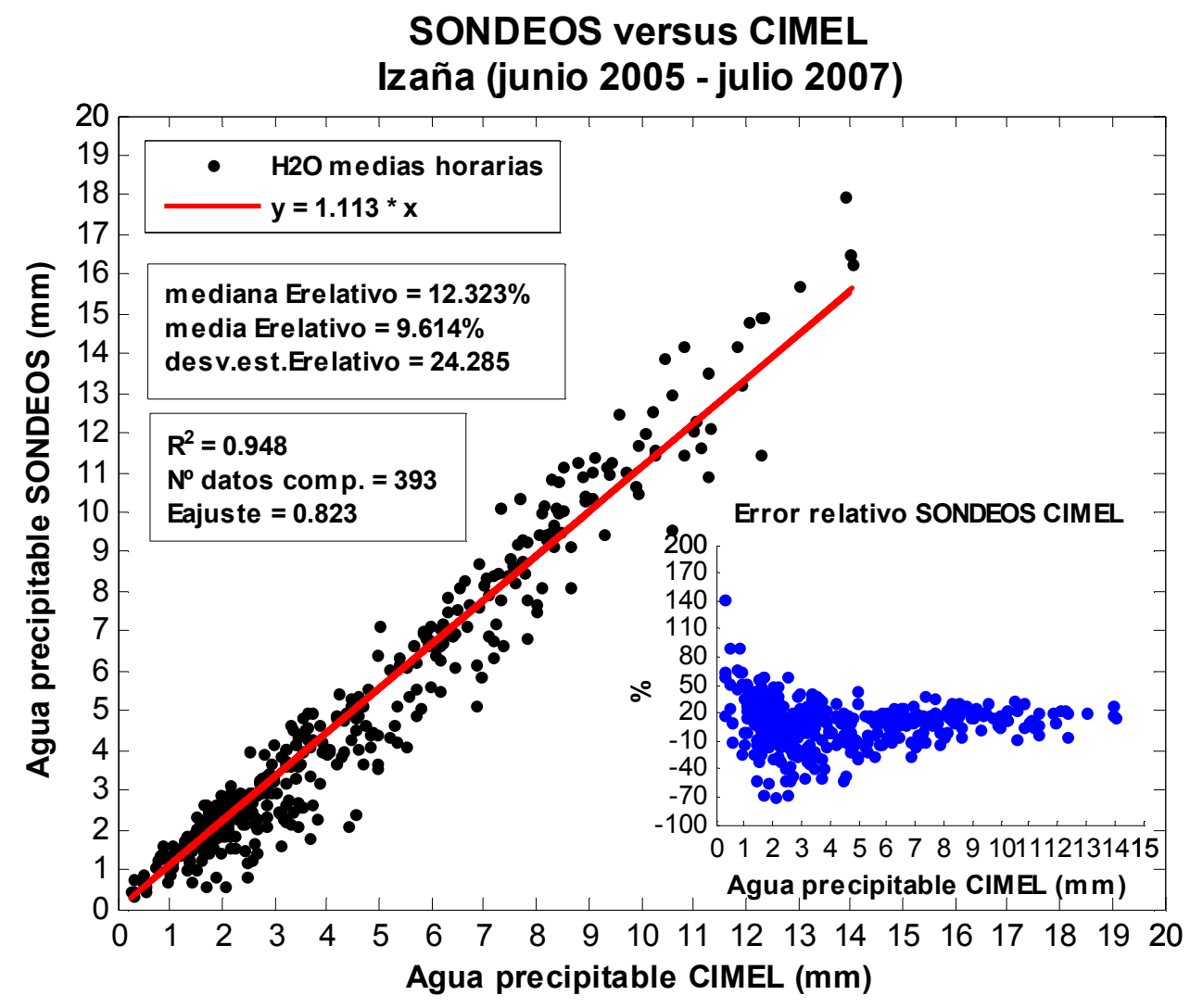

Figura 3.9.1. Comparación SONDEOS-CIMEL.

En este análisis, hemos podido comparar el $100 \%$ de los datos cruzados. Gran coherencia puede verse con una dispersión en torno al ajuste inferior al 1\%. Por otro lado, el sondeo mide un $12 \%$ más agua precipitable que lo que mide el CIMEL.

\subsection{MFRSR frente a SONDEOS}

Aquí tenemos un período de comparación de unos tres años y medio, aproximadamente, con 1102 parejas de datos cruzados. En esta ocasión, son 2 los datos de los sondeos que ha habido que descartar por dar valores nulos de agua precipitable y 42 del MFRSR por dar valores excesivamente altos a los que hay que añadir 169 más que el MFRSR considera afectados por nubes, con lo que el número de datos comparables es de 889 (un 81\%) de los datos cruzados. Como se ve de la figura 3.10.1 el radiómetro mide casi un $65 \%$ más agua precipitable que el sondeo, de forma que se confirma la tendencia de este equipo a medir por exceso el agua precipitable. 


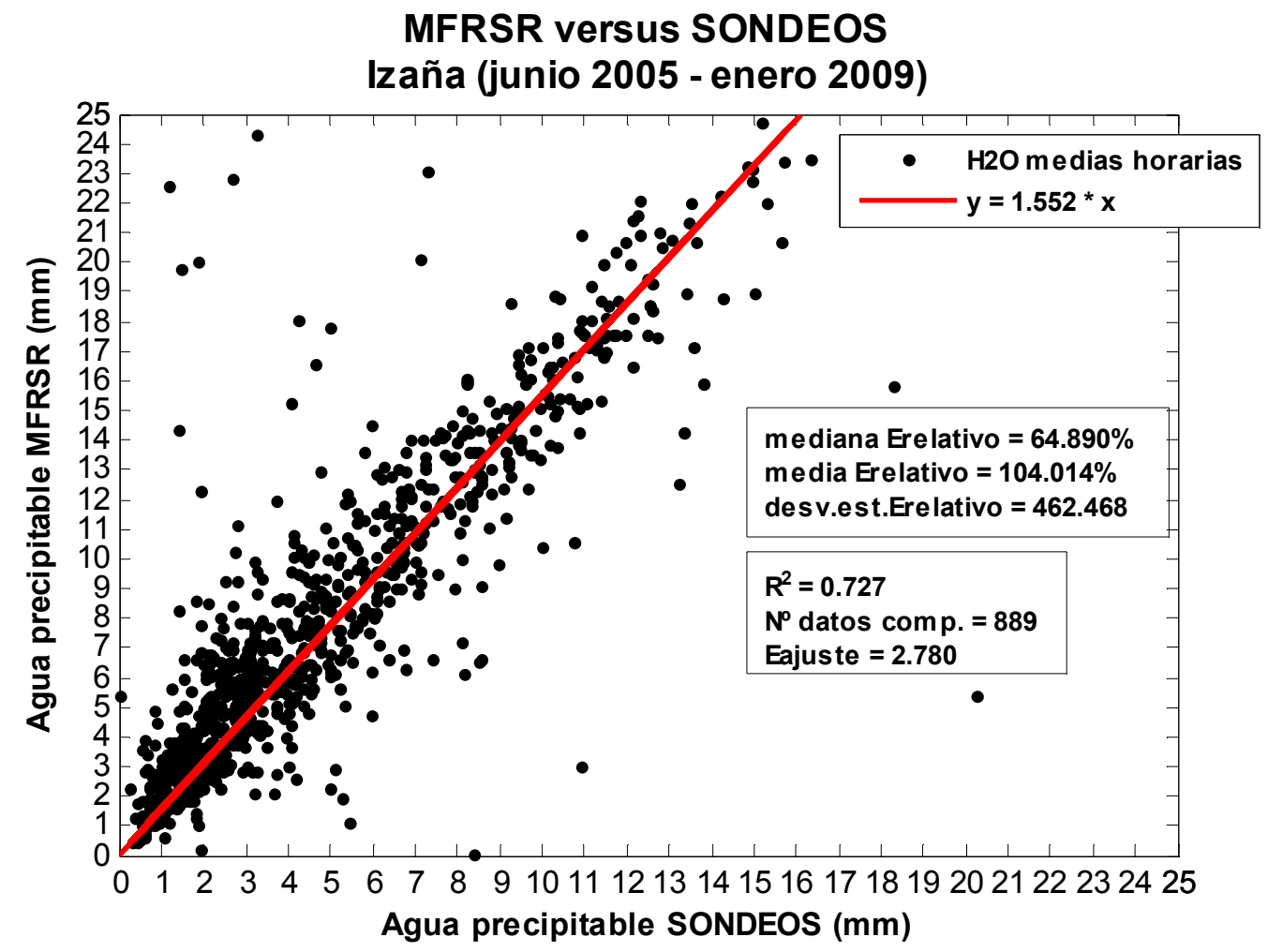

Figura 3.10.1. Comparación MFRSR-SONDEOS.

\subsection{Resumen}

Todos estos resultados pueden resumirse en la siguiente tabla que nos ayudará a valorar esta comparación. En ella, $\mathrm{R}^{2}$ es el coeficiente de correlación al cuadrado del ajuste entre las correspondientes técnicas, $\mathrm{N}$ es el número de valores usados en la comparación y $\mathrm{E}$ es la mediana del error relativo entre cada pareja de equipos o técnicas. Este error relativo ha de entenderse de la variable que se representa en el eje $\mathrm{Y}$ respecto de la variable que se representa en el eje X (fórmula 3.2).

\begin{tabular}{|c|l|l|l|l|}
\hline & \multicolumn{1}{|c|}{ GNSS } & \multicolumn{1}{c|}{ CIMEL } & \multicolumn{1}{c|}{ SONDEOS } & \multicolumn{1}{c|}{ MFRSR } \\
\hline FTIR & $\mathrm{R}^{2}=0.927$ & $\mathrm{R}^{2}=0.973$ & $\mathrm{R}^{2}=0.964$ & $\mathrm{R}^{2}=0.894$ \\
& $\mathrm{~N}=57$ & $\mathrm{~N}=412$ & $\mathrm{~N}=97$ & $\mathrm{~N}=624$ \\
& $\mathrm{E}=1.754 \%$ & $\mathrm{E}=-22.660 \%$ & $\mathrm{E}=-13.678 \%$ & $\mathrm{E}=49.916 \%$ \\
\hline GNSS & & $\mathrm{R}^{2}=0.786$ & $\mathrm{R}^{2}=0.932$ & $\mathrm{R}^{2}=0.678$ \\
& & $\mathrm{~N}=489$ & $\mathrm{~N}=318$ & $\mathrm{~N}=1377$ \\
& & $\mathrm{E}=-13.656 \%$ & $\mathrm{E}=-3.046 \%$ & $\mathrm{E}=40.354 \%$ \\
\hline CIMEL & & & $\mathrm{R}^{2}=0.948$ & $\mathrm{R}^{2}=0.875$ \\
& & & $\mathrm{~N}=393$ & $\mathrm{~N}=3749$ \\
& & & $\mathrm{E}=12.323 \%$ & $\mathrm{E}=87.568 \%$ \\
\hline SONDEOS & & & & $\mathrm{R}=0.727$ \\
& & & & $\mathrm{~N}=889$ \\
& & & & \\
\hline
\end{tabular}

Tabla 3.1. Datos de la comparación entre las diferentes técnicas

Se observa que, las correlaciones más altas, se dan para cada técnica, cuando se las compara frente al FTIR, ya que es entonces cuando presentan los coeficientes más 
altos de correlación al cuadrado (si bien, el GNSS, presenta un coeficiente ligeramente superior cuando se la compara con los SONDEOS). Esto coloca al FTIR como una referencia de medida de agua en columna frente a todas las demás técnicas aplicadas y demuestra que existe, en general, buena coherencia entre las mismas. Al mismo tiempo, podemos apreciar que los errores relativos entre la técnica MFRSR y todas las demás son los más elevados. Como, además, dichos errores resultan ser positivos, esto significa que la técnica MFRSR tiende a medir el agua precipitable en exceso frente a las otras técnicas. La razón de esto probablemente esté en el error acumulado en el cálculo del espesor óptico del aerosol en $941 \mathrm{~nm}$ a partir de los espesores ópticos en otras longitudes de onda, así como en la calibración de la constante extraterrestre para el vapor de agua y el uso de un filtro de nubes no siempre eficiente.

Existe una aparente contradicción entre los resultados de la comparación SONDEOS-GNSS que se ha hecho en esta sección con los resultados de la comparación reflejada en la figura 2.2.1.1.6 de la sección 2. Allí se indicaba que la técnica GNSS, en promedio, tendía a medir menos agua precipitable que el sondeo: $\left(P W V_{G P S}-P W V_{\text {SONDEOS }}=-0.54 \mathrm{~mm} \pm 1.16 \mathrm{~mm}\right)$, mientras que aquí ocurre al contrario, es el sondeo el que tiende a medir menos agua que la técnica GNSS (-3.046\%). A tal efecto, es preciso aclarar que la comparación de la figura 2.2.1.1.6 se realizó para un período de tiempo ligeramente menor (desde el 13 de julio de 2008 al 12 de noviembre de 2008). En esta sección, el período de comparación se amplía hasta el 31 de enero de 2009 y utilizamos un criterio de cruce de datos medios horarios ligeramente distinto al de la sección 2. En cualquier caso, si aquí calculamos el error medio absoluto, tal y como se hizo en aquella, tenemos que $P W V_{G P S}-P W V_{\text {SONDEOS }}=0.21 \mathrm{~mm} \pm 1.11 \mathrm{~mm}$. Podemos comprobar cómo existe un solapamiento entre las medidas y los intervalos de error de ambas comparaciones donde son equivalentes.

Señalar también que, en las gráficas insertadas en las que se representa en azul el error relativo frente a cantidad de agua precipitable en columna, se ve cómo la dispersión del error entre los equipos va aumentando con la disminución del agua precipitable, de tal manera que, existe un umbral situado sobre los $3 \mathrm{~mm}$, aproximadamente, por debajo del cual la dispersión del error se dispara, indicando que las medidas de los equipos se vuelven imprecisas y poco fiables.

Por otro lado, y teniendo en cuenta que la comparación entre GNSS y FTIR es excelente, con una mediana del error relativo por debajo del $2 \%$, podemos concluir que la técnica GNSS produce resultados próximos a la técnica FTIR, siempre que el agua precipitable sea superior a $3 \mathrm{~mm}$. Como resulta que también observamos que cualquiera de las técnicas empleadas presenta un bajo error relativo cuando se la compara con GNSS, incluyendo la técnica FTIR que es la más sofisticada y teóricamente la más precisa, pensamos que la técnica GNSS es la mejor opción para el estudio en tiempo real y con alta resolución temporal del contenido de agua precipitable en columna y se convierte en el mejor substituto del FTIR para días nublados y períodos nocturnos.

Las diferencias, a veces notables, entre los resultados producidos por todas estas técnicas no impiden establecer ecuaciones de conversión, a modo de funciones de transferencia (rectas de ajuste) entre cada pareja de instrumentos y técnicas, de manera que, a partir de las medidas de uno de ellos, podamos simular a los otros. Estas equivalencias nos permitirán disponer de una herramienta para estimar el valor del agua precipitable en series temporales donde haya intervalos en los que las incidencias en un determinado equipo no hayan hecho posible la medida con él, o bien, no nos hayan permitido hacerlo de forma correcta. Si disponemos de medidas efectuadas con otro de los equipos o técnicas de las que aquí se han comparado, entonces podremos completar los huecos en los que hay ausencia de datos en la serie y darle una solución conveniente. 


\section{Líneas futuras para reducir la incertidumbre en el agua precipitable GPS}

En la sección 2.2.1.1 se probó cómo usando el retraso cenital total (ZTD) calculado por el software Bernese 5.0 a partir de las observaciones GNSS, podíamos variar los resultados de agua precipitable y el error obtenidos empleando diversas aproximaciones consistentes en considerar diferentes tipos de atmósferas: en primer lugar, se probó con una atmósfera estándar de la OACI, en segundo lugar, se utilizó una atmósfera real sobre Izaña, y en tercer lugar, una atmósfera climatológica propia de Izaña. Vimos cómo esta última opción era óptima, no sólo por ser la que menos diferencia presentaba con respecto a los resultados obtenidos de los sondeos, sino por ser la más idónea para el cálculo y representación en tiempo real del agua precipitable.

Lo que se propone en esta sección, es intentar mejorar los resultados en la obtención del propio ZTD a través del software Bernese 5.0. Este software calcula los ZTDs mediante un algoritmo en el que utiliza unas ecuaciones aproximadas para la presión, temperatura y humedad relativas basadas en un determinado perfil teórico de variación de estas magnitudes en una atmósfera estándar. Pero en la atmósfera real, sobre una estación particular, las variaciones de dichas magnitudes en la vertical pueden diferir bastante de las expresadas en las ecuaciones mencionadas. Es por ello por lo que pretendemos que el software Bernese 5.0 realice el cálculo de los ZTDs usando, no las ecuaciones teóricas por defecto, sino las empíricas que nosotros le propongamos basadas en una climatología.

A estos efectos, se ha elaborado, para las tres variables esenciales de presión, temperatura y humedad relativa, una climatología del perfil sobre Izaña basada en los valores obtenidos de dichas variables en la serie de sondeos sobre Izaña.

Se han escogido los sondeos meteorológicos diarios desde 1995 hasta noviembre de 2008 y se ha procedido de la siguiente manera:

1) Se han extraído, de cada sondeo, las variables altitud, temperatura, presión y humedad relativa a partir del nivel de Izaña.

2) Se calcula, para cada sondeo y por cada $100 \mathrm{~m}$. de elevación, comenzando desde el nivel de Izaña hasta los $12 \mathrm{~km}$ (tropopausa), la mediana de los valores de cada una de las variables anteriores.

3) Gráficamente representamos un perfil global de cada variable usando todos los valores de las medianas en cada tramo de altura para todos los sondeos del período de interés.

4) Ajustamos por mínimos cuadrados cada perfil global teniendo en cuenta los valores normales de la climatología en Izaña para las variables temperatura, presión y humedad relativa en el período 1971-2000, intentando conservar la forma de las ecuaciones suministradas en el manual del software Bernese, pero particularizando y tomando como referencia los valores específicos de la climatología de nuestra estación.

El valor normal medio anual para la temperatura en Izaña es de $9.8^{\circ} \mathrm{C}$, para la humedad relativa es de $48 \%$ y para la presión atmosférica está en torno a los $770 \mathrm{hPa}$. Los resultados se representan más abajo. En ellos podemos ver que, mientras para la presión y la temperatura el ajuste matemático es bastante razonable y parece reproducir con bastante aproximación el perfil medio de la atmósfera sobre Izaña, en el caso de la humedad relativa, los resultados experimentales difieren bastante de cualquier ajuste matemático que podamos realizar debido a la gran variabilidad que presenta. En 
cualquier caso, el ajuste aquí calculado es más parecido a la realidad que la aproximación dada por las ecuaciones teóricas del software Bernese.

Perfil medio de presión sobre Izaña sondeos (1995-2008)

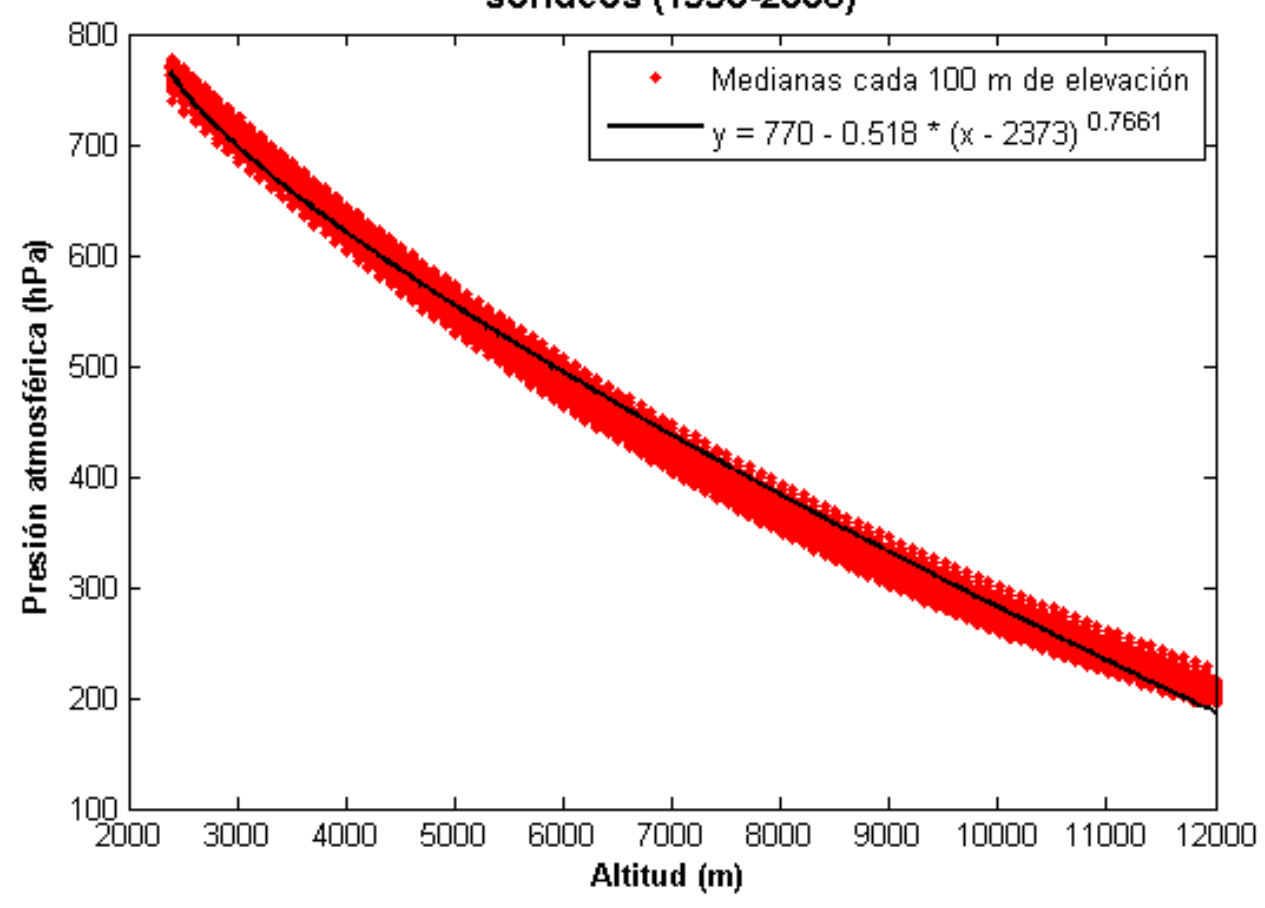

Figura 4.1. Perfil medio de presión sobre Izaña. Datos extraídos de los sondeos.

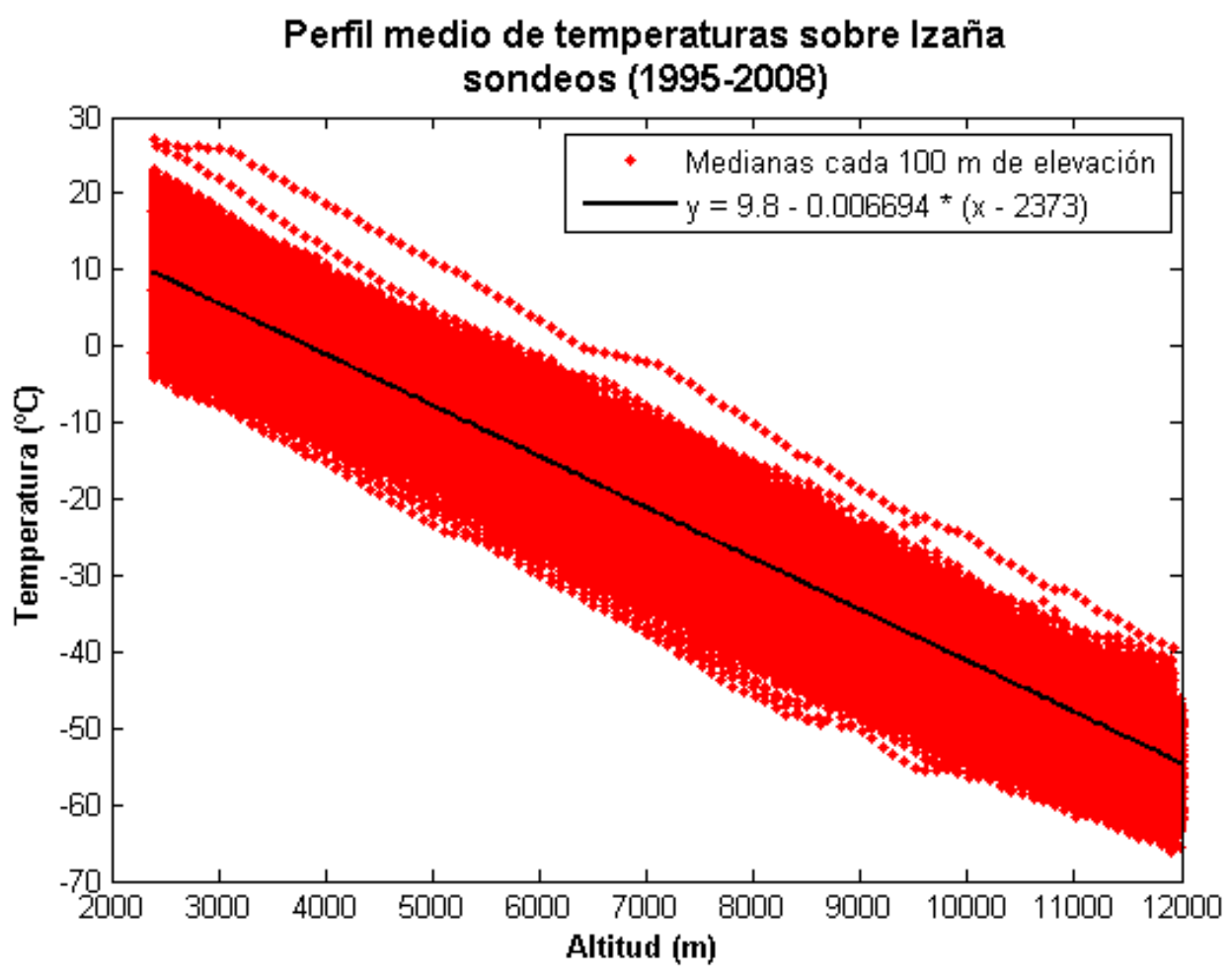

Figura 4.2. Perfil medio de temperatura sobre Izaña. Datos extraídos de los sondeos. 


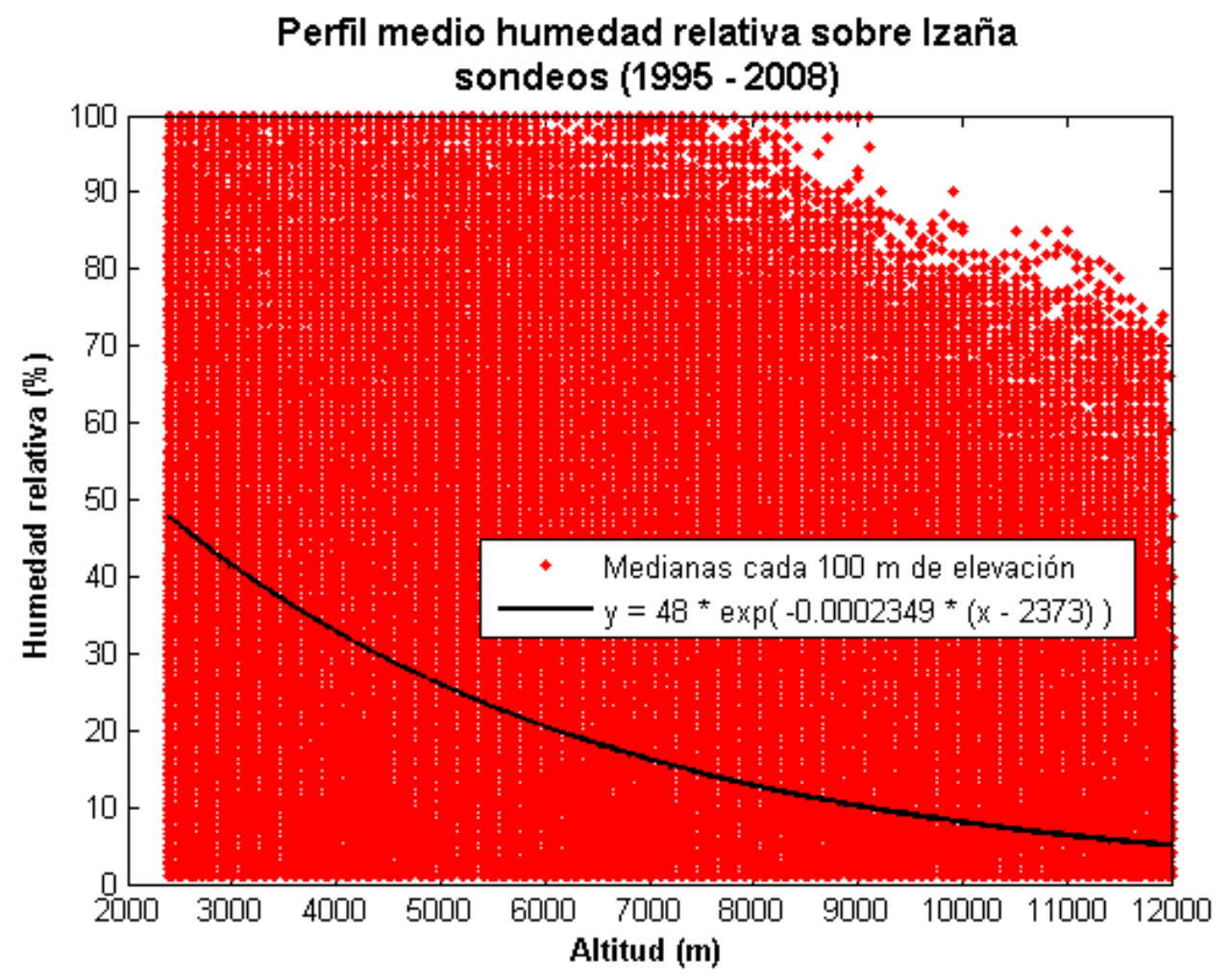

Figura 4.3. Perfil medio de humedad sobre Izaña. Datos extraídos de los sondeos.

Una vez comprobada si estas aproximaciones son realmente útiles y mejoran los resultados en el cálculo de los ZTDs, proponemos abordar también, como línea de investigación complementaria o alternativa, las siguientes acciones:

5) Repetir el estudio pero obteniendo perfiles mensuales globales y así poder comprobar si el ajuste por meses para cada una de las variables difiere mucho de su ajuste respectivo para todo el período.

6) Es posible también que existan perfiles estacionales medios y se puedan ajustar dando buenos resultados.

7) También podría calcularse, para cada variable, un perfil diario climatológico en un año estándar de 366 días, por un procedimiento similar al que se usó en el cálculo de la temperatura media en la columna atmosférica.

Las ecuaciones del software Bernese 5.0 se basan en una atmósfera estándar válida sólo hasta la tropopausa. Realmente, es hasta esa altura, donde se ubica el 99\% del vapor de agua. Por lo tanto, la influencia del resto de la columna atmosférica no parece que sea decisiva ni significativa en el cálculo del ZTD. Por esta razón, el ajuste que nosotros hemos realizado también se ha hecho hasta los $12 \mathrm{~km}$ que es, aproximadamente, la altura de la tropopausa sobre Izaña. 


\section{Conclusiones}

De forma muy resumida se pueden establecer las siguientes reflexiones y conclusiones:

A. La espectrometría infrarroja por transformadas de Fourier es la técnica, a día de hoy, más sofisticada y precisa usada para determinar la concentración de cualquier componente atmosférico que absorba en el infrarrojo. Aplicándola a la obtención de agua precipitable, y tomándola como referencia, se ha procedido a compararla con otras técnicas de medida actuales como la GNSS.

B. Existe un límite situado sobre $\operatorname{los} 3 \mathrm{~mm}$ de agua precipitable en columna, por debajo del cual, cualquiera de las otras técnicas usadas (sondeos, técnicas radiométricas, y GNSS) tienden a infravalorar la cantidad de agua precipitable. Este hecho es especialmente importante en las regiones subtropicales en las que la troposfera libre (por encima de la capa de mezcla marina), es extremadamente seca (con frecuencia, menos de $1 \mathrm{~mm}$. de agua en columna).

C. El acuerdo entre el CIMEL y la sonda RS-92 es muy bueno. Esto hace de la técnica radiométrica una buena herramienta para completar valores diurnos en series de agua precipitable. Se ha comprobado que las diferencias en los resultados al utilizar las versiones 1.5 y 2.0 de AERONET son despreciables. Esto significa que el número de estaciones AERONET y la cantidad de datos disponibles de agua precipitable es muy alto, ya que prácticamente todas las estaciones operativas alcanzan la depuración de la versión 1.5. El número de datos disponibles en la versión 2.0, al que se llega tras aplicar las calibraciones de irradiancia y radiancia, es muchísimo menor. De este modo, la red mundial AERONET de fotómetros solares CIMEL puede constituir un excelente complemento a la red mundial de estaciones de radiosondeos RS-92 para la vigilancia de la evolución del agua precipitable en todo el mundo.

D. La técnica radiométrica aplicada del radiómetro MFRSR puede servir para estimaciones no muy precisas de la cantidad de agua precipitable. Es necesario mejorar el filtro de depuración de nubes propuesto en esta técnica y aplicar las ecuaciones de conversión deducidas de las comparaciones aquí efectuadas para obtener resultados que empiecen a aproximarse en calidad a los obtenidos por otras técnicas.

E. La técnica GNSS se configura como una técnica que proporciona medidas de calidad del agua precipitable que puede complementar a las del FTIR y a la RS-92. Esta técnica tiene varias ventajas: proporciona datos en tiempo cuasi-real, mide con nubes y en período nocturno, por lo que se puede obtener información mucho más completa de la evolución temporal del agua precipitable, en general, y dar cuenta en particular, de su evolución diurna. Asimismo, permite estudiar esta evolución en diferentes situaciones meteorológicas. Sin embargo, es necesario mejorar con ecuaciones propias de la atmósfera de cada lugar concreto la medida del retraso cenital total así como de la obtención del agua precipitable a partir de ella a fin de no infravalorar la medida por debajo de los $3 \mathrm{~mm}$. El establecimiento de una red nacional GNSS para medida de agua precipitable no solo será muy útil para asimilación de datos en modelos de predicción meteorológica, contribuyendo a la Red Meteorológica Europea (EUMETNET) con GNSS, sino que sería un importante elemento para el seguimiento de esta variable climática esencial que cada vez cobra mayor importancia en la vigilancia del cambio climático. 


\section{Agradecimientos}

Los autores agradecen a Jorge Pereda, del Centro Geofísico de Canarias (Instituto Geográfico Nacional), su eficaz trabajo en la instalación y comunicación del GPS-GLONASS del IGN en Izaña, así como sus labores de mantenimiento. De igual forma, los autores agradecen al gran equipo del CIAI que ha participado o participa en la operación, mantenimiento, chequeo y calibración de los equipos que han sido utilizados en esta Nota Técnica, su gran trabajo y profesionalidad: Virgilio Carreño, Carlos Torres, Cándida Hernández, Julián Pérez, Carmen Guirado, Sergio Afonso Rodríguez y César López (SIELTEC Canarias). 


\section{Bibliografía}

1. Alastuey, A., X. Querol, S. Castillo, M. Escudero, A. Avila, E. Cuevas, C. Torres, P.M. Romero, F. Exposito, O. Garcia, J.P. Diaz, R.V. Dingenen, J.P. Putaud, Characterisation of TSP and PM2.5 at Izana and Sta. Cruz de Tenerife (Canary Islands, Spain) during a Saharan Dust Episode (July 2002), Atmos. Environ., 39, 26,4715-4728, 2005.

2. Alexandrov, M. D., B. Schmid, D. D. Turner, B. Cairns, V. Oinas, A. A. Lacis, S. I. Gutman, E. R. Westwater, A. Smirnov, and J Eilers, Columnar water vapor retrievals from multifilter rotating shadowband radiometer data, J. Geophys. Res., 114, D02306, doi: 10.1029/2008JD010543. 2009.

3. Alonso-Pérez S., Cuevas E., Querol X., Viana M., Guerra J.C., Impact of the Saharan intrusions on the total suspended particles (TSP) background levels in the Marine Boundary Layer (MBL) of the Subtropical Eastern North Atlantic Ocean. Atmospheric Environment, 41, 9468-9480, 2007

4. Bevis, M., Businger, S., Chiswell, S., Herring, T.A., Anthes, R.A., Rocken, C., Ware, R.H. GPS Meteorology: Mapping Zenith Wet Delays onto Precipitable Water. American Meteorological Society. March 1994.

5. Bevis, M., Businger, S., Herring, T.A., Rocken, C., Anthes, R.A., Ware, R.H. GPS Meteorology: Remote Sensing of Atmospheric Water Vapor Using the Global Positioning System. Journal of Geophysical Research, Vol. 97, NO. D14, pages 15,787-15,801, October 20, 1992.

6. Boccolari, M., Fazlagic, S., Frontero, P., Lombroso, L., Pugnaghi, S., Santangelo, R., Corradini, S., Teggi, S. GPS Zenith Total Delays and Precipitable Water in Comparison with Special Meteorological Observations in Verona (Italy) during MAP-SOP. Annals of Geophysics, Vol. 45, N. 5, October 2002.

7. Boccolari, M., Fazlagic, S., Lombroso, L., Frontero, P., Pugnaghi, S., Santangelo, R., Corradini, S., Teggi, S. Precipitable Water Estimation in Comparison between Zenith Total Delays (ZTD) by Radiosounding Data and by GPS Data. Geophysical Observatory (OGMO), DSI, University of Modena and Reggio Emilia (Italy). Environmental Department of Verona Province (ARPAV), Verona (Italy).

8. Brown, S., S. Desai, S. Keihm, W. Lu, Ch. S. Ruf. Ocean Water Vapor and Cloud Burden Trends Derived from the Topex Microwave Radiometer, IEEE International Geoscience and Remote Sensing Symposium, 23-27 July 2007. Barcelona, Spain.

9. Cess, R. D., et al. Intercomparison and interpretation of climate feedback processes in 19 atmospheric general circulation models. J. Geophys. Res., 95(D10), 16,601-16,615. 1990.

10. Cubasch, U., G.A. Meehl, G.J. Boer, R.J. Stouffer, and M. Dix: Projections of future climate change. Climate Change 2001: The Scientific Basis, J. T. Houghton et al., Eds., Cambridge University Press, 525-582. 2001.

11. Davis, S. P., Abrahams, M. C., and Brautt, J. W.: Fourier Transform Spectrometry. Academic Press. ISBN: 0-12-042510-6. 2001.

12. Flores, A., Escudero, A., Sedó, M. J. and Rius, A. A Near Real Time System for Tropospheric Monitoring Using IGS Hourly Data. Earth Planets Space, 52,681684, 2000.

13. Haan de, S. (KNMI, Netherlands). World Meteorological Organization. Instruments and Observing Methods. Report $\mathrm{N}^{\mathrm{o}}$ 92. National/Regional 
Operational Procedures of GPS Water Vapour Networks and Agreed International Procedures. WMO / TD-No. 1340. 2006.

14. Hu, Y., and Q. Fu. Observed poleward expansion of the Hadley circulation since 1979, Atmos. Chem. Phys., 7, 5229-5236. 2007.

15. Hugentobler, U., Dach, R., Fridez, P., Meindl, M. Bernese GPS software Version 5.0. Astronomical Institute University of Bern. Enero 2007.

16. Iqbal, M. An Introduction to Solar Radiation. Academic Press 1983.

17. Li, P.W., Wang, X.Y., Chen, Y.Q., Lai, S.T. Use of GPS Signal Delay for Realtime Atmospheric Water Vapour Estimation and Rainfall Nowcast in Hong Kong. The First International Symposium on Cloud-prone \& Rainy Areas Remote Sensing, Chinese University of Hong Kong, 6-8 October 2005. Hong Kong Observatory. Reprint 606.

18. Prata, A.J. Precipitable Water Retrieval from Multi-Filter Rotating Shadowband Radiometer Measurements. CSIRO Atmospheric Research Technical Paper $\mathrm{N}^{\mathrm{o}}$ 47. 2000.

19. Prospero, J.M., R. Schmitt, E. Cuevas, D. Savoie, W.Graustein, K.Turekian, A.Volz-Thomas, A. Diaz, S. Oltmans, H. Levy-II, Temporal Variability of Summer-time Ozone and Aerosols in the Free Troposphere over the Eastern North Atlantic, Geophys. Res. Lett., 22, 21, 2925-2928, 1995.

20. Rodgers, C. D. Inverse Methods for Atmospheric Sounding. Theory and Practice. Series on Atmospheric, Oceanic and Planetary Physics. Vol.2. World Scientific. ISBN: 981-02-2740-X. 2000.

21. Ruffini, G., Kruse, L.P., Rius, A., Bürki, B., Cucurrull, L., Flores, A. Estimation of Tropospheric Zenith Delay and Gradients over the Madrid Area Using GPS and WVR Data. Geophysical Research Letters, Vol. 26, NO. 4, pages 447-450, February 15, 1999.

22. Schneider, M. and Hase, F.: Reviewing the development of a ground-based FTIR water vapour inversion algorithm,, submitted to Atmos. Meas. Tech., April 2009.

23. Sridevi, J., Vijayan, M.S.M. GPS-Based Atmospheric Precipitable Water Vapor Estimation Using Meteorological parameters interpoled from NCEP Global Reanalysis Data. Journal of Geophysical Research, Vol. 113, D03106, doi:10.1029/2007JD008758, 2008.

24. Tregoning, P., Boers, R., O'Brien, D., Hendy, M. Accuracy of Absolute Precipitable Water Vapor Estimates from GPS Observations. Journal of Geophysical Research, Vol. 103, NO. D22, pages 28,701-28,710, November 27, 1998.

25. Tregoning, P., Herring, T.A. Impact of a Priori Zenith Hydrostatic Delay Errors on GPS Estimates of Station Heights and Zenith Total Delays. Geophysical Research Letters, Vol. 33, L23303, doi:10.1029/2006GL027706, 2006.

26. Trenberth, K.E., J. Fasullo, L. Smith. Trends and variability in columnintegrated atmospheric water vapor, Climate Dynamics (2005) 24: 741-758 DOI 10.1007/s00382-005-0017-4. 2005.

27. Yankee Environmental Systems, Inc. MFR-7 Rotating Shadowband Radiometer. Installation and User Guide. Version 2.0. (Chapter 3: Interpreting the Data). 


\section{Anexo}

A continuación se listan algunos de los programas en código MATLAB usados para la evaluación y obtención de los datos de agua precipitable. Estos programas aparecen debidamente comentados en el propio código listado. Los comentarios aparecen en verde y precedidos del signo \%. En el editor de MATLAB, tres puntos azules seguidos significan que la línea continúa abajo.

\section{Programa "precgps.m"}

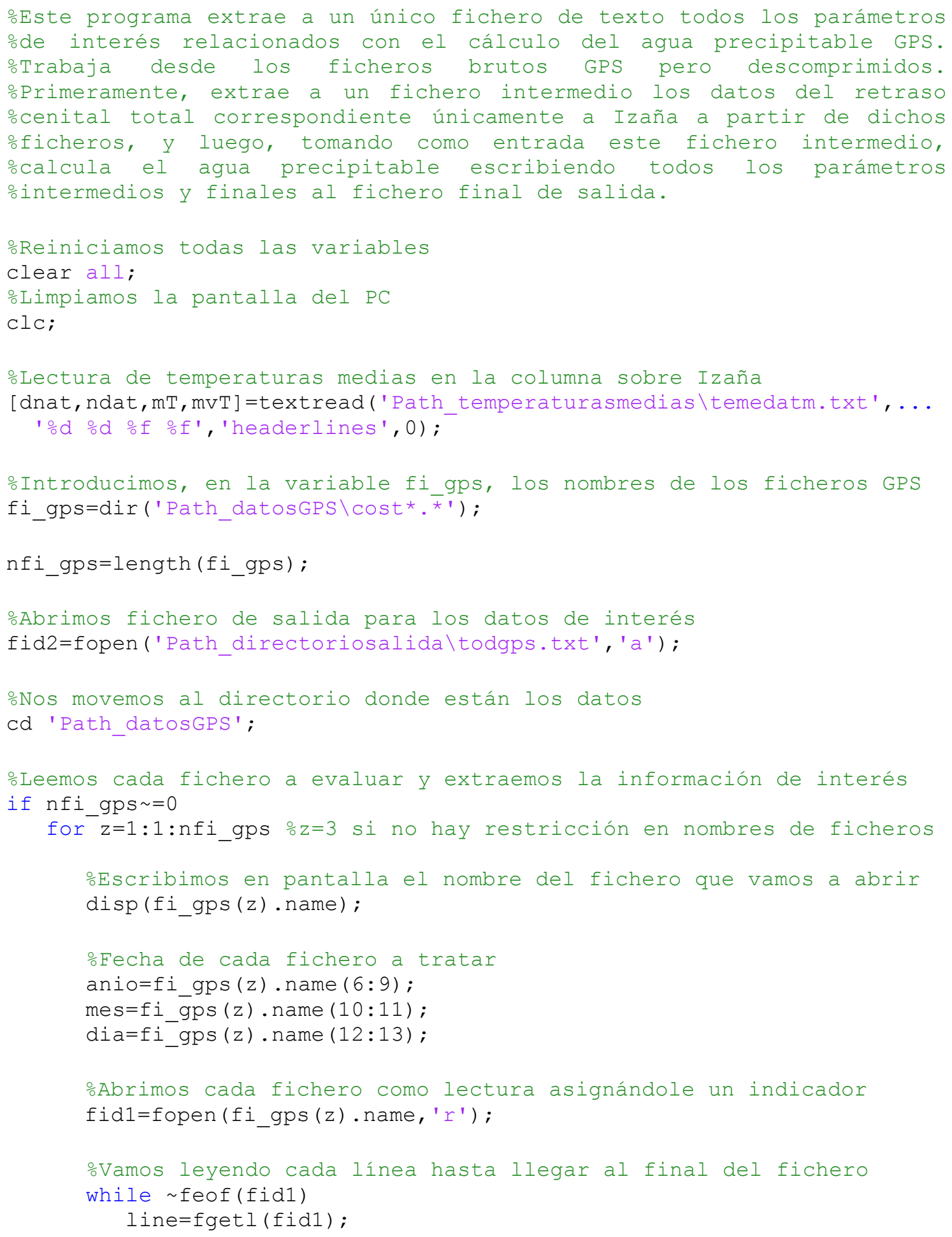




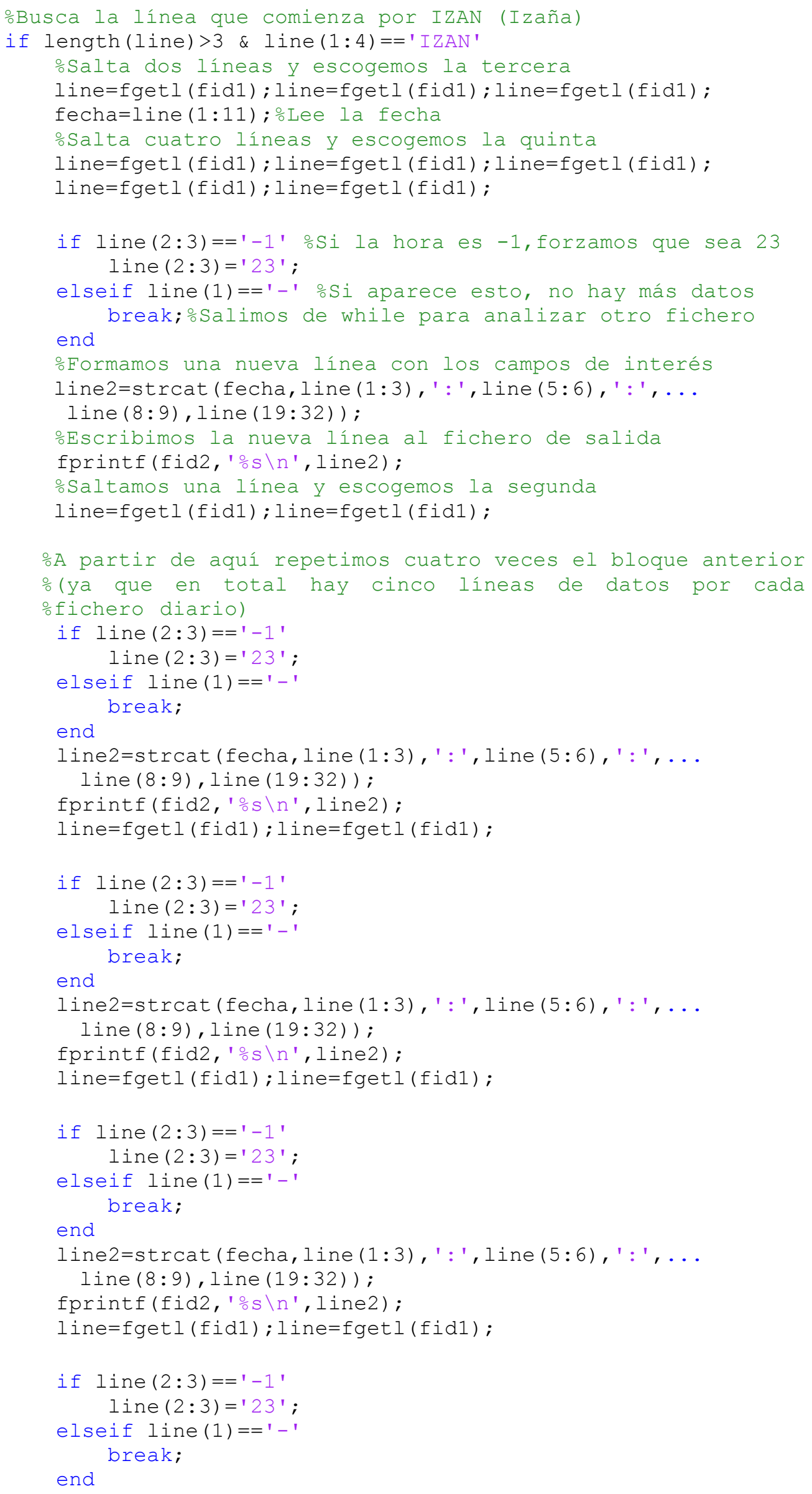




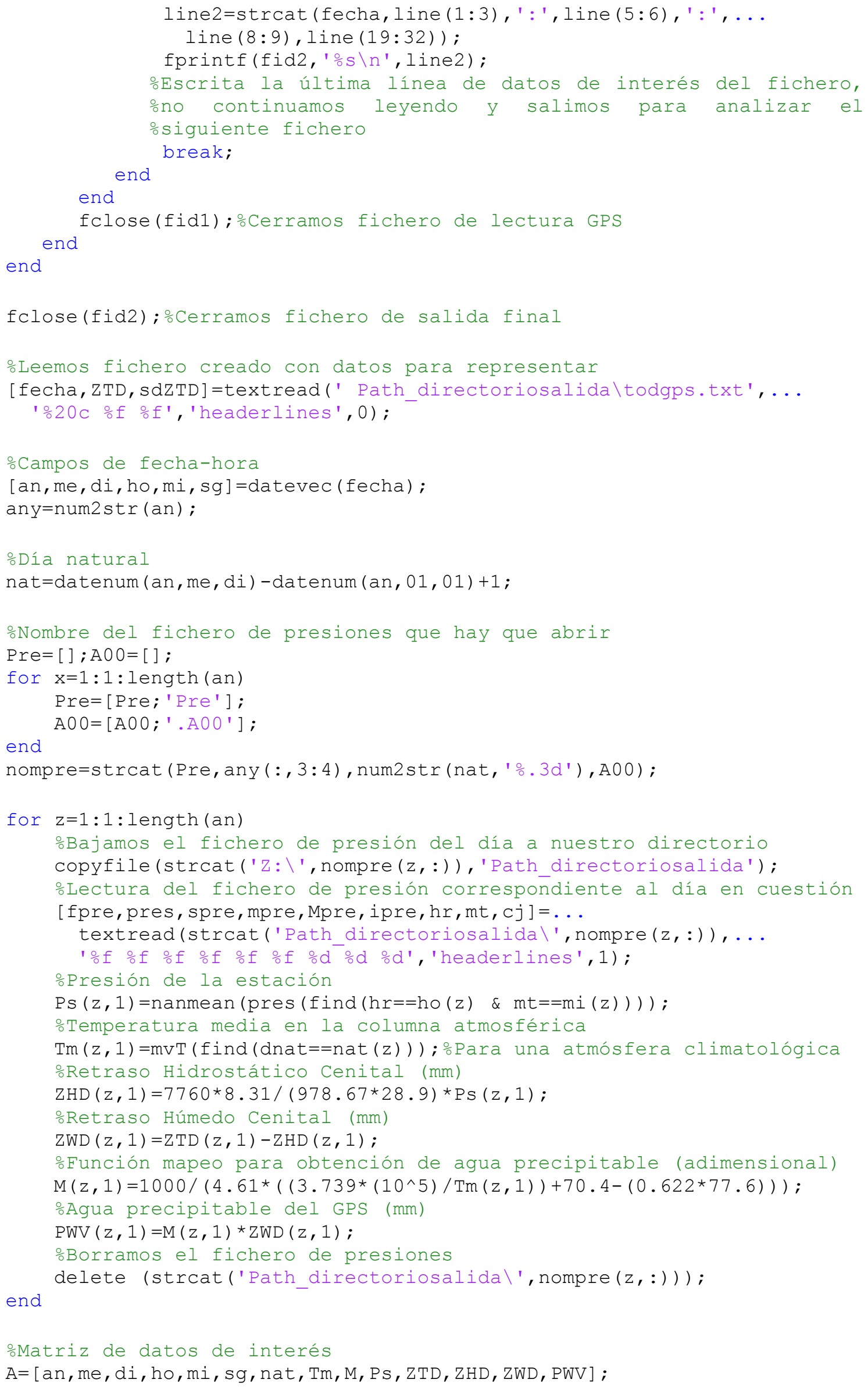


oAbrimos fichero de salida para los datos de interés fid3=fopen ('Path directoriosalida \precgps.txt', 'a' ) ; oEscribimos los datos de interés

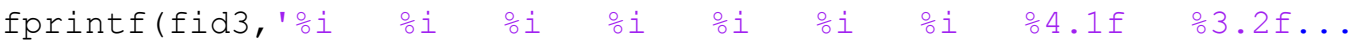
$\left.\circ 4.1 f \quad \circ 6.1 f \quad \frac{6}{6} .1 f \quad \% 6.1 f \quad \circ 3.1 f \backslash n^{\prime}, A^{\prime}\right)$;

oCerramos fichero de salida final

fclose (fid3);

cd 'C: \Archivos de programa \MATLAB71 \work\gps';

\title{
Programa "gpstiemreal.m"
}

\author{
function gpstiemreal()
}

\begin{abstract}
oEste programa se baja de la red los ficheros GPS y extrae de ellos el ㄱTD para posteriormente calcular el agua precipitable y representar olos datos en tiempo real. Usa la climatología sobre Izaña para la otemperatura media en la columna atmosférica y como presión usa los ovalores de la torre y no de la SOS. Está pensado para ejecutarse odesde cualquier directorio con la única condición de que el fichero ode la climatología (temedatm.txt) se encuentre en el mismo directorio oque este programa ejecutable.
\end{abstract}

clear all;

clc;

oLectura de de temperaturas medias en la columna sobre Izaña $[$ dnat, $\mathrm{ndat}, \mathrm{mT}, \mathrm{mvT}]=\ldots$

textread ('temedatm.txt', 'd od of $\frac{\circ}{\circ}$ ', 'headerlines', 0 ) ;

obtenemos datos de fecha y hora en tiempo real

[anio, mes, dia, hora, minu, segu]=datevec (now);

anio=num2str (anio);

mes=num2str (mes, ' $\left.\% .2 d^{\prime}\right)$;

dia=num2str (dia, ' $\%$. 2d');

oConstruimos un fichero para la descarga ftp

nombre=strcat ('cost_', anio,mes, dia, '*_ige_.gz') ;

fid=fopen ('comftp gps', 'w');

fprintf (fid, 'os $\backslash n$ ', 'usuario');

fprintf (fid, '⿳s $\backslash n$ ', 'contraseña') ;

fprintf(fid, 'os $\backslash n$ ', 'cd /directorio datos de red');

fprintf (fid, '⿳s $\backslash \mathrm{n}^{\prime}$, ' $^{\mathrm{b}} \mathrm{in}$ ') ;

fprintf (fid, 'ㅇs', 'mget ') ;

fprintf(fid, '은 ', nombre); $\frac{\circ}{\circ}$ Nombres de los ficheros a descargar

fprintf (fid, 'os $\backslash n$ ', 'quit') ;

fclose (fid);

Descargamos los ficheros GPS del servidor

!ftp -i -s:comftp_gps dirección_IP_del_servidor_remoto

oDescompresión de ficheros descargados

gunzip ('*.gz');

delete '*.gz'; delete '*.A00'; ㅇorramos los que ya no usaremos

oIntroducimos, en la variable fi gps, los nombres de los ficheros GPS fi_gps=dir ('cost*.*'); 


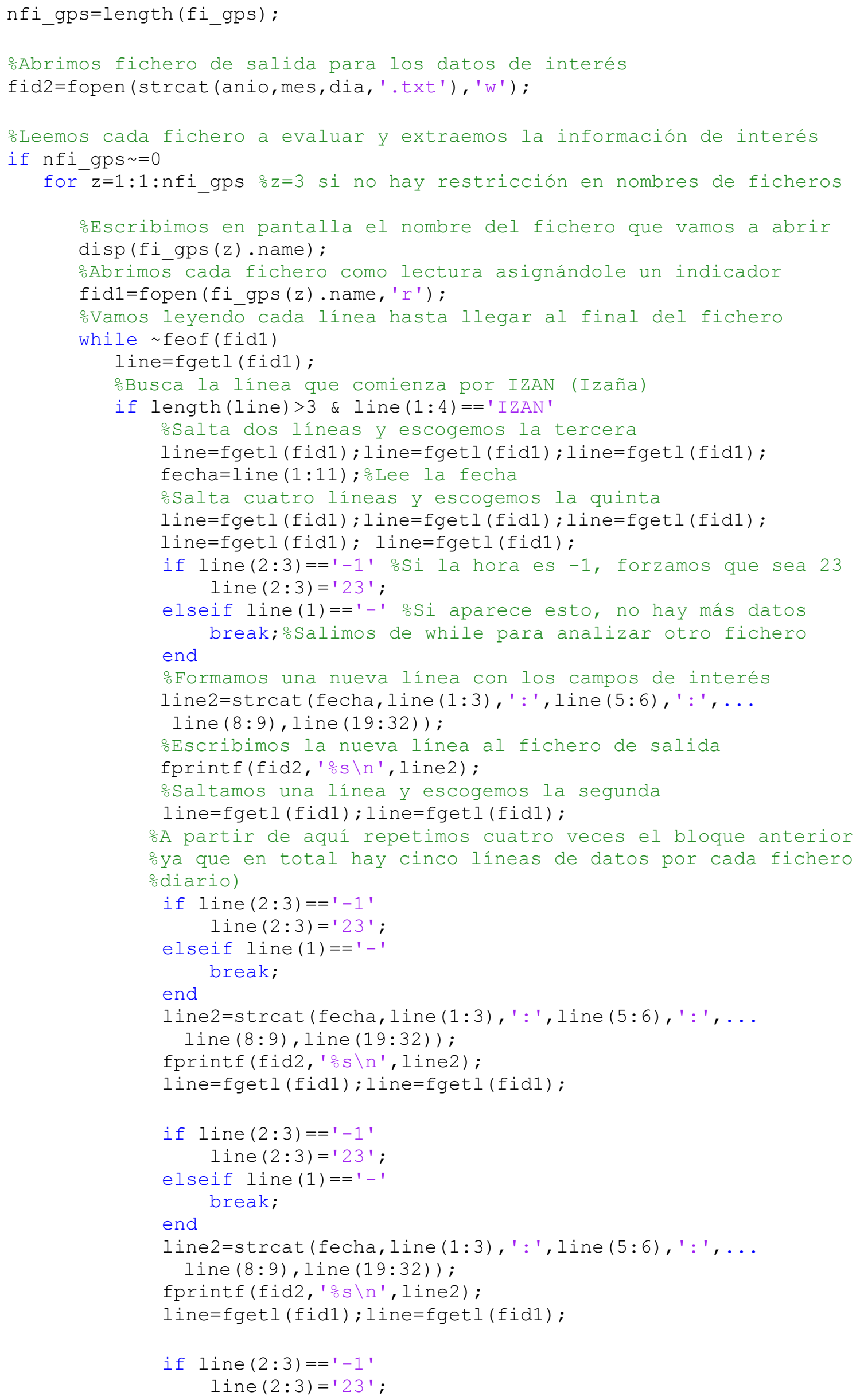




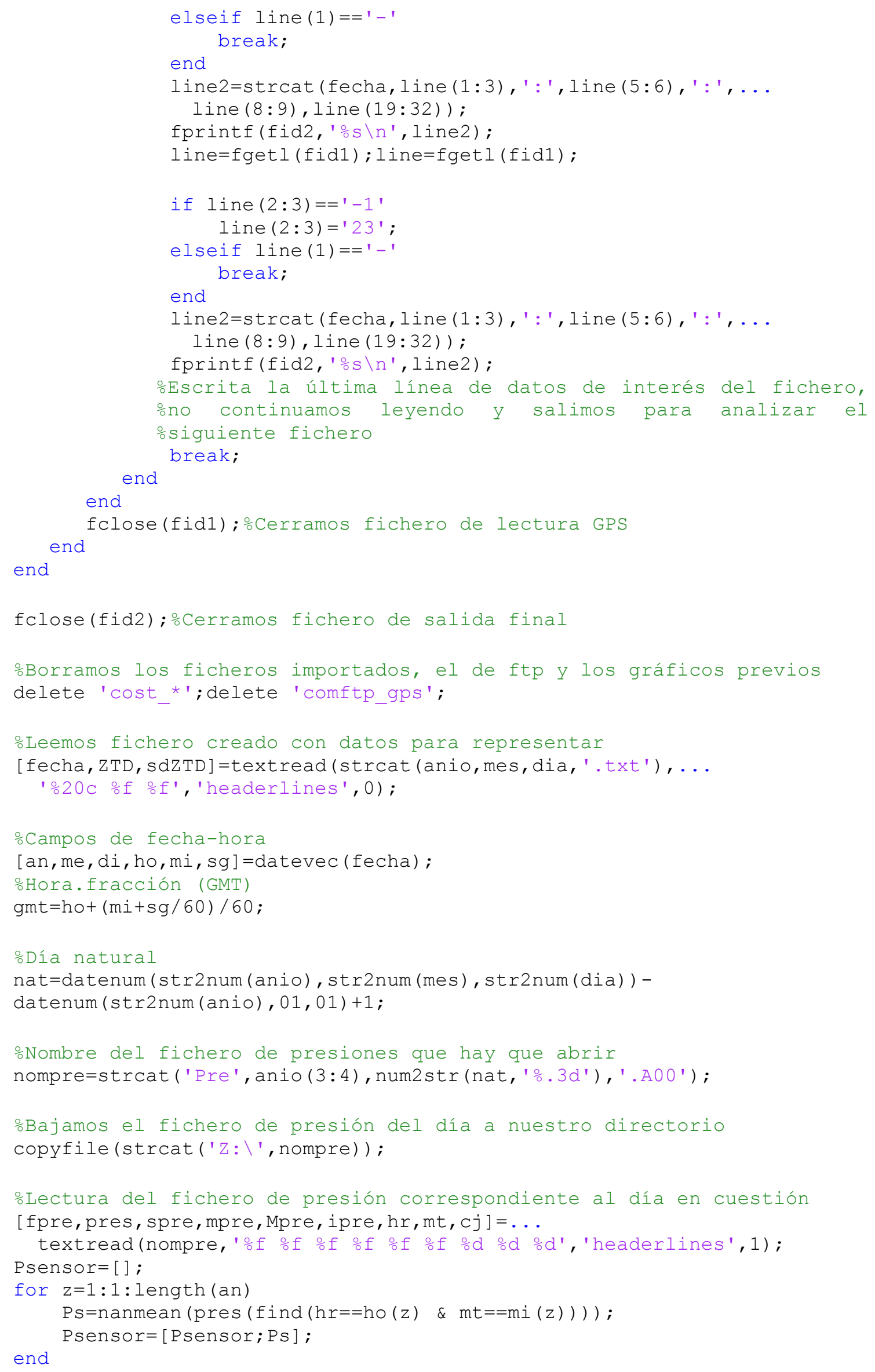




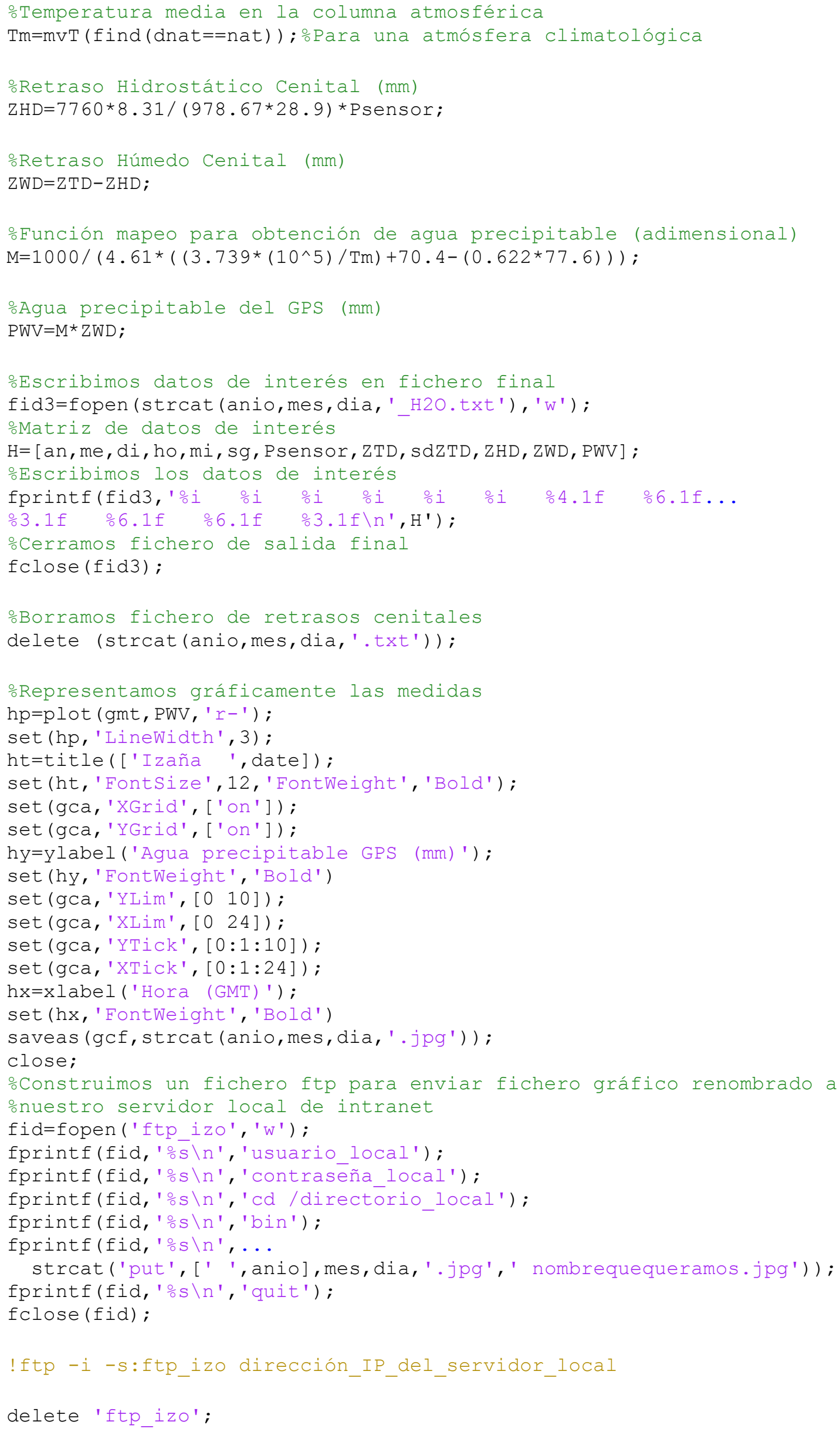




\section{Programa "Temeatm.m"}

Este programa calcula la temperatura media de la atmósfera (Tm) que ohay por encima del nivel de Izaña (elei=2360 m.s.n.m.) a partir de olos sondeos. Esta temperatura media parece serlo sólo de la parte de oatmósfera en donde hay medida apreciable de vapor de agua. Está odefinida como un cociente. El numerador es la integral sobre la oaltitud del sondeo del cociente entre tensión del vapor de agua y la otemperatura absoluta. El denominador es la integral sobre la altitud odel sondeo del cociente entre tensión del vapor de agua y el cuadrado ode la temperatura absoluta. En el fichero de salida se añaden como oúltimas columnas la temperatura en el momento en el que se rebasa el onivel de Izaña y el número de datos usados en los cálculos.

clear all;

clc;

oAltitud de la estación (m.s.n.m.)

elei=2360;

oIntroducimos, en fi son, los nombres de los ficheros de los sondeos fi son=dir('Path_directorio_sondeos $\backslash *$ txt') ;

nfí_son=length (fíi_son);

oNos cambiamos al directorio de los ficheros de los sondeos cd 'Path_directorio_sondeos' ;

-Abrimos fichero de salida para escribir los resultados de interés fids=fopen ('Temeatm', 'a');

if nfi_son $\sim=0$

for $k=1: 1: n f i \_s o n$

oPonemos en pantalla el nombre del fichero de sondeo a tratar disp (fi_son (k).name);

Datos de fecha del fichero

anio=str2num (fi son (k). name (1:2));

if anio<50

anio=anio 2000 ;

else

anio=anio+1900;

end

mes=str2num ( fi son (k). name $(3: 4))$;

dia=str2num (fi son (k). name $(5: 6))$;

jul=datenum $($ an $\bar{i} \circ$, mes, dia $)$-datenum $(1899,12,31)+1$;

oAbrimos fichero de sondeo para ver qué formato tiene

fid=fopen ( $f i$ son (k). name, 'r') ;

num $=0$;

while 1

num=num +1 ; 
ind01=length (findstr(line, 'File: ')) ;

if ind $01==1$

hoco=str 2 num (line $(33: 34))$; ․Hora comienzo del sondeo mico=str2num(line $(36: 37))$; Minuto comienzo del sondeo end

ind02=length (findstr (line, 'Location' ) );

if ind02 $==1$

elesta=str2num(line (41:43)); ㅌlevación estación sondeo end

indl=length (findstr (line, 'Veloc.' )) ;

ind2=length (findstr (line, 'DPD')) ;

ind3=length (findstr (line, 'Ozone')) ;

if ind $1==1$ | ind $2==1$ | ind $3==1$

break;

end

end

fclose (fid);

num $=$ num +3 ;

oMatriz con las filas y columnas del sondeo a analizar

if ind $1==1$

$[\mathrm{mnt}, \mathrm{sgu}, \mathrm{prs}, \mathrm{atu}, \mathrm{tmp}, \mathrm{hre}, \mathrm{skn}, \mathrm{drc}]=\ldots$.

textread (fi_son (k). name, ...

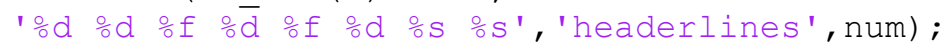

elseif ind $2==1$ \& ind $3==0$

[mnt, sgu, prs, atu, tmp, hre, vrt, dpd, lra, asr $]=\ldots$.

textread(fi_son(k).name,...

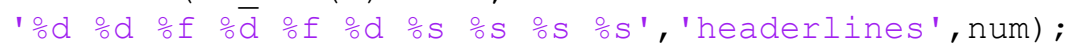

elseif ind $2==1$ \& ind $3==1$

[mnt, sgu, prs, atu, tmp, hre, vrt, dpd, lra, asr, ono ] =.. . textread (fi son (k). name, ...

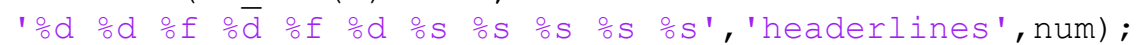

end

o $N^{\circ}$ datos de interés cuando el sondeo rebasa la altitud elei nudat $=$...

length (find (atu>=elei \& prs>0 \& tmp<999\& hre>0 \& hre<999)); if nudat $>0$

oFecha y hora en que sondeo rebasa el nivel de la estación sreb=sgu (find (atu==min (atu (find (atu>=elei))) )) ;

mreb $=\operatorname{mnt}($ find $($ atu $==\min (\operatorname{atu}($ find $($ atu $>=e l e i))))$ );

hreb=hoco+( (mico+mreb+ $($ sreb/60) $) / 60)$; oHora.Fracción (GMT)

hora $=\mathrm{fix}($ hreb) ; minu=fix ( hreb-hora)*60);

segu $=((($ hreb-hora $) * 60)-$ minu $) * 60$;

$[$ ano, mez, dya, ora, nuto, gundo $]=\ldots$

datevec (datenum (anio, mes, dia, hora, minu, segu)) ;

jla=datenum (ano, mez, dya, ora, nuto, gundo)-693960;

oVariables de interés por encima del nivel de la estación alti $=\ldots$ atu(find (atu>=elei \& prs>0 \& tmp<999 \& hre>0 \& hre<999)); temi $=\ldots$ tmp (find (atu>=elei \& prs>0 \& tmp<999 \& hre>0 \& hre<999)); huri=... hre (find (atu>=elei \& prs>0 \& tmp<999 \& hre>0 \& hre<999)); 


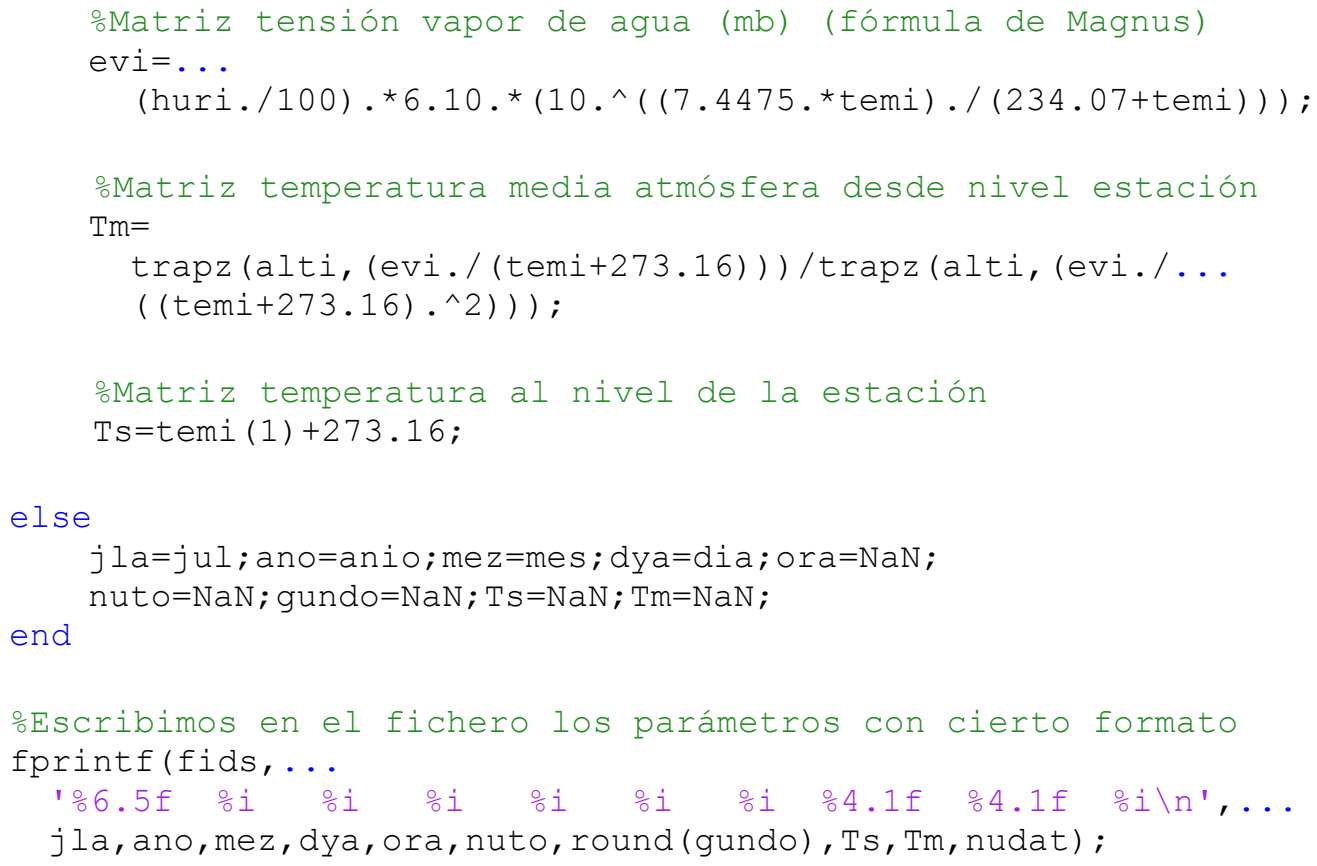

end

end

fclose (fids);

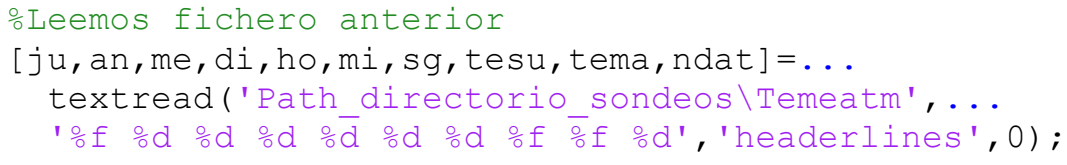




\section{Programa “atmoestandar.m"}

oEste programa calcula la temperatura media en una atmósfera estándar osobre Izaña usando las ecuaciones P, T, H, de la página 231 del omanual del software Bernese 5.0 del GPS.

elei=2360; Nivel de la estación de Izaña (m.s.n.m.)

oEcuaciones de la atmósfera estándar del software Bernese (GPS)

atu $=[0: 20: 12000]^{\prime} ;$ ㅇlturas sólo hasta la troposfera, pongamos $12000 \mathrm{~m}$

tmp $=18-0.0065 *$ (atu) ;

pre $=1013.25 *(1-0.0000226 *(\mathrm{atu})) \cdot \wedge 5.225$;

hum $=50 * \exp (-0.0006396 *(\mathrm{atu}))$;

oMatriz tensión saturante del vapor de agua (mb) (fórmula de Magnus) evi=6.10.* $\left(10 .^{\wedge}((7.4475 . * t m p) . /(234.07+t m p))\right)$;

oMatriz tensión del vapor de agua (mb)

ev=hum. *evi/100;

oMatriz temperatura media de la atmósfera desde nivel de estación

$\mathrm{Tm}=\operatorname{trapz}($ atu $($ find $($ atu $>=$ elei) $),($ ev (find (atu $>=e l e i)) . / \ldots$

$(\operatorname{tmp}($ find $($ atu $>=$ elei) $)+273.16))) / \ldots$

trapz (atu (find (atu>=elei)), (ev(find (atu>=elei))./..

$\left((\operatorname{tmp}(\right.$ find $($ atu $\left.\left.\left.>=e l e i))+273.16) \cdot{ }^{\wedge} 2\right)\right)\right)$;

cd 'C: \Archivos de programa \MATLAB71\work\gps';

\section{Programa "VAPGPSSOND.m"}

oEste programa calcula el agua precipitable a partir del Retraso oCenital Total suministrado por el GPS. Usando los datos de presión y otemperatura al nivel de la estación se calcula el Retraso oHidrostático Cenital, el Retraso Húmedo Cenital, la función de mapeo oy finalmente el agua precipitable en mm. Se diferencia de VAP.m en oque aquí se escoge como entrada el fichero de correlación entre datos odel GPS y los sondeos. Para realizar el cruce correspondiente con los odatos de temperatura y presión al nivel de la estación promediamos olos valores de estos últimos previamente.

oNOTA: Podemos aplicar el programa para distintos tipos de atmósferas. oHabrá que habilitar o deshabilitar las variables M (función de mapeo) oy Tm (temperatura media en la columna atmosférica sobre Izaña) oadecuadas, según corresponda.

clear all;

clc;

\%Lectura del fichero ZTD del GPS

[anigps, mesgps, diagps, horgps, ZTD, stZTD, H2O] =...

textread('Path_directorio_ZTD \gPssondeo.txt', ...

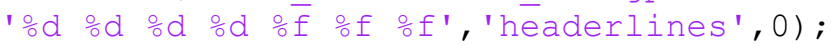

oLectura del fichero temperatura del sensor en Izaña

$[j \mathrm{tem}, \mathrm{t} 1, \mathrm{t} 2, \mathrm{tem}]=.$.

textread('Path_directorio_temperatura \Temperatura.txt',...

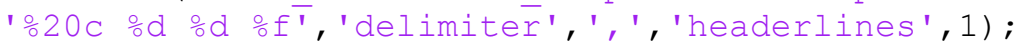

oLectura del fichero presión del sensor en Izaña 


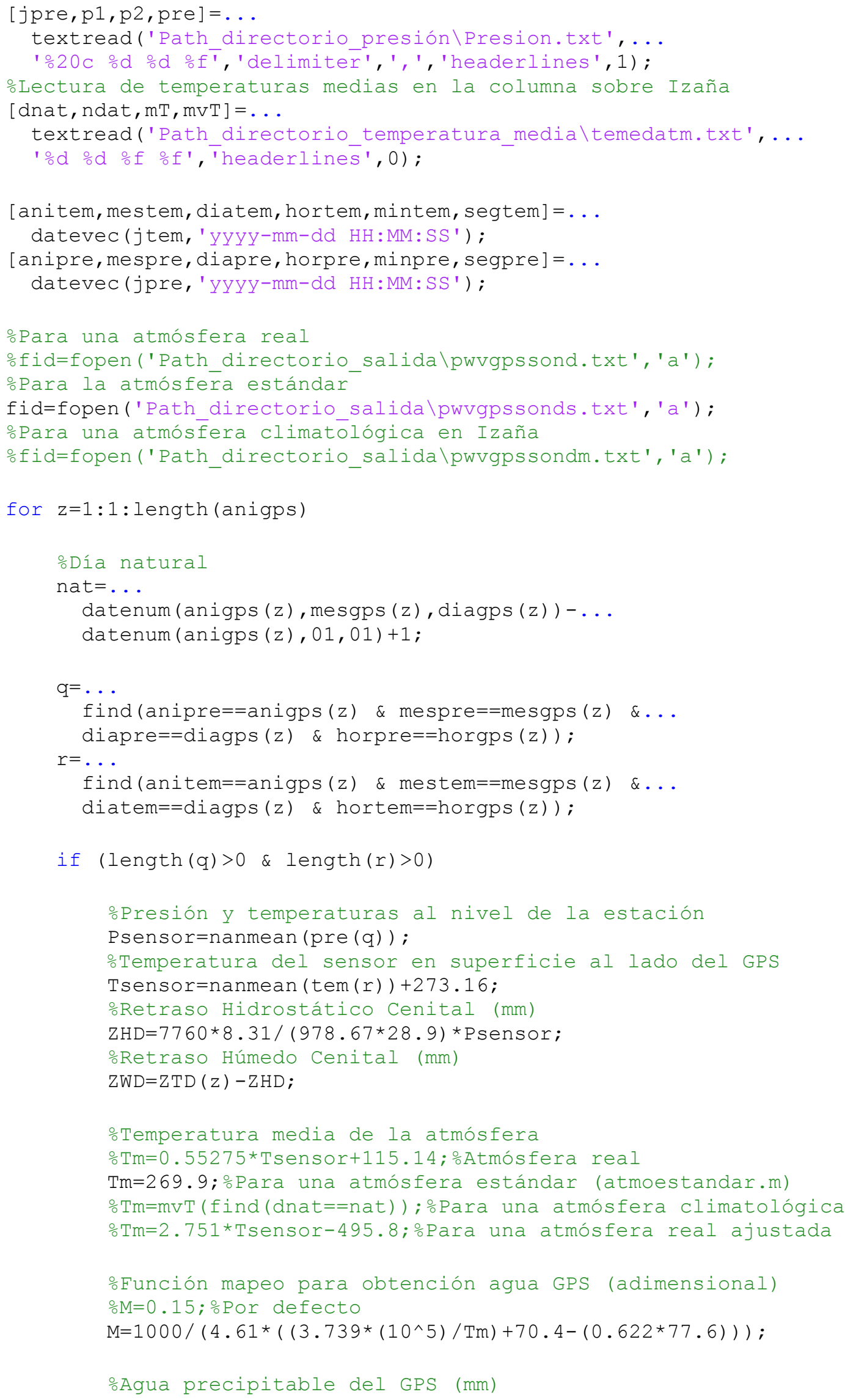




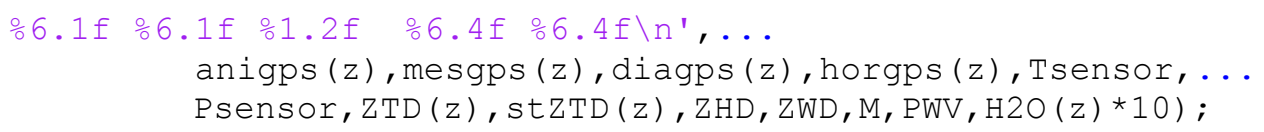

end

end

fclose (fid);

cd 'C: \Archivos de programa \MATLAB71\work\gps';

\section{Programa “cruza.m"}

oEste programa cruza los datos de temperatura al nivel de Izaña y otemperatura media en la atmósfera, obtenidos de los sondeos con los de otemperatura al nivel de Izaña obtenidos del sensor que está cerca del $\div$ GPS.

clear all;

clc;

[jul, anio, mes, dia, hor, minu, seg, Ts, Tm, ndat] $=. .$.

textread('Path directorio temperatura media \Temeatm.txt', ...

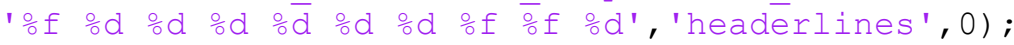

$[j t e m, t 1, t 2, t e m]=\ldots$

textread('Path directorio temperatura \Temperatura.txt',...

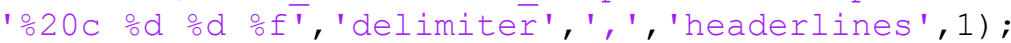

[aniotem, mestem, diatem, hortem, mintem, segtem] =. .

datevec (jtem, 'yyyy-mm-dd HH:MM:SS') ;

fid=fopen('Path_directorio salida\TsTm.txt', 'a' );

for $z=1: 1:$ length $(j u l)$

$\mathrm{p}=\ldots$

min (find (aniotem==anio(z) \& mestem==mes $(z) \& \ldots$

diatem==dia $(z)$ \& hortem==hor (z) \& mintem==minu(z)));

if $\operatorname{length}(\mathrm{p})>0$

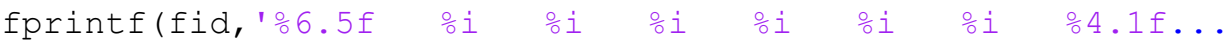

$\div 4.1 \mathrm{f}$

$\div i \quad \% 4.1 f \backslash n^{\prime}, \ldots$

jul (z), anio(z), mes(z), dia (z), hor (z), minu(z), seg(z), ..

$\operatorname{Ts}(z), \operatorname{Tm}(z), \operatorname{ndat}(z), \operatorname{tem}(\mathrm{p}))$;

end

end

fclose (fid); 